\title{
REVISTA
}

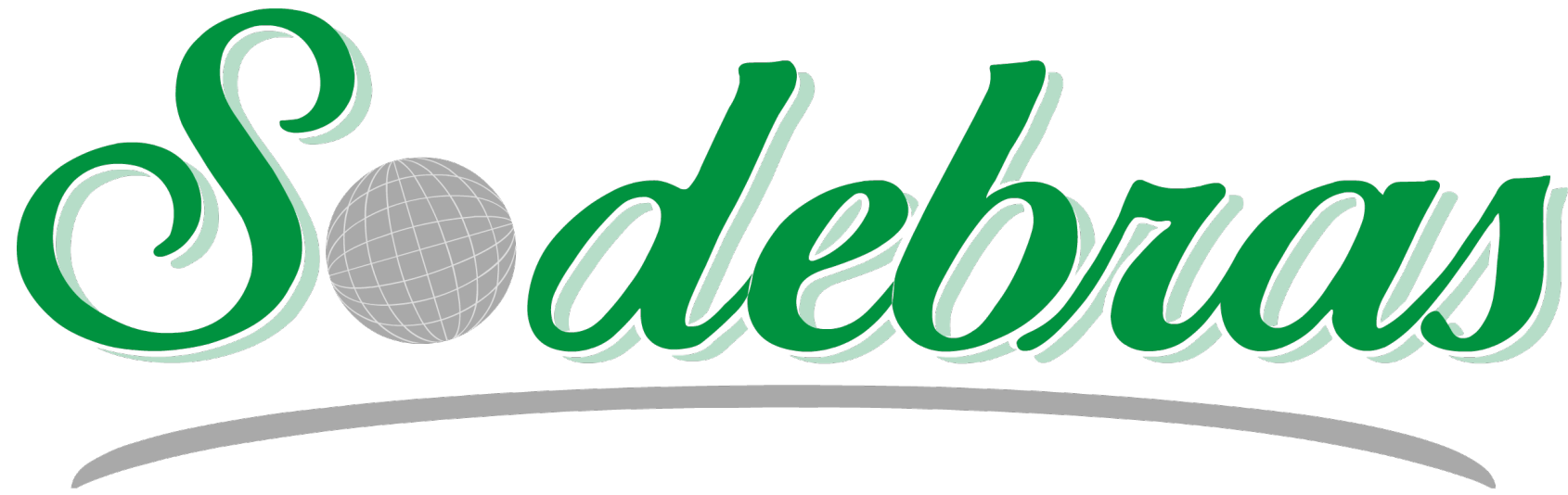

SOLUÇÕES PARA O DESENVOLVIMENTO DO PAÍS 


\title{
ARTIGOS PUBLICADOS
}

PUBLICAÇÃO MENSAL

Nesta edição

\begin{abstract}
SEGURANÇA E ERGONOMIA PARA FORÇA LABORAL FEMININA NA INTERAÇÃO COM MÁQUINAS COLABORATIVAS
\end{abstract}

SAFETY AND ERGONOMICS FOR FEMALE WORKFORCE IN INTERACTION WITH COLLABORATIVE MACHINES - Isabela Oliveira Jacinto Cunha; Iranildo Alves Coutinho Junior; Giovani Galvão De Moura;

Roque Antônio De Moura; Messias Borges Silva

DIDÁTICA DA MATEMÁTICA: UM ESTUDO DAS METODOLOGIAS DE ENSINO E AS DIFICULDADES DA APRENDIZAGEM DOS ALUNOS DE ENSINO MÉDIO

DIDACTICS OF MATHEMATICS: A STUDY REGARDING THE TEACHING METHODOLOGIES AND THE LEARNING DIFFICULTIES OF HIGH SCHOOL - Jesuino Jésus Lisbôa De Oliveira Silva; Raquel Martins Fernandes; Rodrigo Ribeiro De Oliveira

PROPOSTA DE APLICAÇÃO DA METODOLOGIA 5S EM LABORATÓRIO DE PROCESSAMENTO DE MATERIAIS COMPÓSITOS

PROPOSAL OF THE APPLICATION OF THE 5S METHODOLOGY IN A COMPOSITE MATERIAL PROCESSING LABORATORY - Natasha Martins Rodrigues De Jesus; Rafael Soares Souza; Rita De Cassia Mendonça Sales Contini; Teófilo Miguel De Souza; Thais Santos Castro

ESTIMATIVA NUMÉRICA DA GERAÇÃO DE ENERGIA SOLARFOTOVOLTAICA NA COBERTURA DO ESTACIONAMENTO DA BIBLIOTECA DA FZEA - USP

NUMERICAL ESTIMATE OF SOIL-PHOTOVOLTAIC ENERGY GENERATION IN THE PARKING COVERAGE OF FZEA - USP LIBRARY - Fernando De Lima Caneppele; Emmanuel Zullo Godinho; Luis Fernando Soares Zuin; Jair Antonio Cruz Siqueira

MODELOS DE OTIMIZAÇÃO PARA DETERMINAR AS LOCALIZAÇÕES DOS PONTOS DE ACESSO SEM $\mathrm{FIO}$

MODELS OF OPTIMIZATION TO DETERMINE LOCATIONS OF THE WIRELESS ACCESS POINTS - Lucas Barcelos Mendes; Mário Mestria

INFLUÊNCIA DO RAIO DE PONTA NO DESGASTE DA FERRAMENTA DE CORTE E NA CORRENTE ELÉTRICA CONSUMIDA NO TORNEAMENTO DO AÇO ABNT 1045

INFLUENCE OF TOOL NOSE RADIUS ON THE TOOL WEAR AND ELECTRIC CURRENT CONSUMED DURING TURNING OF THE ABNT STEEL 1045 - André Luís Pedroza De Oliveira; Marcos Guilherme Carvalho Braulio Barbosa; Lívio Bruno Nery Da Silva Viana; Patrick Abreu De Oliveira; Lívia Fernanda Nery Da Silva 


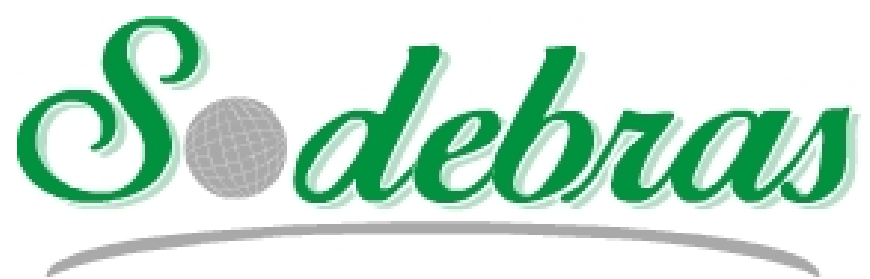

Edição 187 de julho de 2021

http://www.sodebras.com.br/

ISSN - 1809-3957

DOI: https://doi.org/10.29367/issn.1809-3957

\section{CONSELHO EDITORIAL}

Prof. Dr. Teófilo Miguel de Souza, UNESP-FEG (Editor Geral).

Prof. Dr. Paulo Jonas dos Santos Júnior, UNESP-FEG (Editor Adjunto).

Prof. Dr. Osiris Canciglieri Júnior, Lough. Univ-UK, PUC-PR.

Prof. Dr. Maria Claudia Botan, UNIVESP.

Prof. Dr. Thais Santos Castro, UNESP.

Prof. Dr. Agustín Valverde Granja, Universidad de Ibagué- Colômbia.

Prof. Dr. Joacy de Lima Freitas Junior, Agência Nacional de Aviação Civil.

Prof. Dr. José Leandro Casa Nova Almeida, Instituto Federal-RJ.

Prof. Dr. Marcio Zamboti Fortes, UFF.

Prof. Dr. Jair Urbanetz Junior, UTFPR.

Prof. Dr. José Rui Camargo, UNITAU.

Prof. Dr. José Renato de Oliveira Lima, Universidade Federal do Maranhão.

\section{COMITÊ CIENTÍFICO}

Valdir Agustinho de Melo, COPPE/UFRJ

Juliana Corrêa Crepalde, CTIT/ UFMG

Lila Teixeira de Araújo Janahú, ESAMAZ

Volmer Avelino Silvio Paula da Silveira, Estácio

Durval Corrêa Meirelles, Estácio

Ana D'Arc Martins de Azevedo, FAAM/UEPA

Maria Lígia Carrijo Monteiro, FACEG

Marcus Antonius Costa Nunes, Fac. Vale do Cricaré - PE

Zélia Maria De Melo De Lima Santos, FALUB.

Sérgio Roberto Montoro, FATEC - Pindamonhangaba

Claudio Antonio Frederico, IEAV / CTA

Maria Manuela Camino Feltes, IFC

Felipe José da Silva, IFRJ

Givanildo Alves dos Santos, IFSP

Paulo Marcos de Aguiar, IFSP

Airton Viriato de Freitas, INSTITUTO DE

INFECTOLOGIA EMÍLIO RIBAS

Claudio Edilberto Höfler, Instituto Federal Farroupilha

Leila Ribeiro dos Santos, ITA / CTA

Letícia Peret Antunes Hardt, PUC -PARANÁ

Eduardo Concepción Batiz, SOCIESC

Marcelo Macedo, SOCIESC

Ariovaldo de Oliveira Santos, UEL

André Luiz Martinez de Oliveira, UEL

Leonardo Sturion, UEL

Jean-Marc Stephane Lafay, UEL

Emília Kiyomi Kuroda, UEL

Henrique de Santana, UEL

Marli Terezinha Oliveira Vannuch, UEL
Paulo Bassani, UEL

Marlene Marchiori, UEL

Carlos Humberto Martins, UEM

Paulo Fernando Soares, UEM

Deisy Cristina Corrêa Igarashi, UEM

Moisés Meza Pariona, UEPG

Jarem Raul Garcia, UEPG

Elizabete Campos de Lima, UFABC

Carlos Suetoshi Miyazawa, UFABC

Marcio Zamboti Fortes, UFF

Pablo Silva Machado Bispo dos Santos, UFF

Paulo Henrique Furtado de Araujo, UFF

Paulo Sérgio Scalize, UFG

Juliana da Cunha, UFG

Hilton Pereira da Silva, UFPA

Anderson Gonçalves da Silva, UFRA

Antonio Carlos Baptista Antunes, UFRJ

Claudinei de Souza Guimarães, UFRJ

Antônio Assis Vieira, UFRRJ

Joel Dias da Silva, UFSC

Leandro Belinaso Guimarães, UFSC

Silvio Serafim da Luz Filho, UFSC

Antonio Pedro Novaes de Oliveira, UFSC

Rozângela Curi Pedrosa, UFSC

Débora de Oliveira, UFSC

Fabiano Rodrigues de Souza, UFT -TO

Cláudio Homero Ferreira da Silva, UFU

Márcia Susana Nunes Silva, ULBRA

Maria Eloisa Farias, ULBRA 
Maria Lúcia Castagna Wortmann, ULBRA

Hélio Raymundo Ferreira Filho, UNAMA/UEPA

Maria Claudia Botan, UNESP

Ana Maria Pires Soubhia, UNESP - Araçatuba

Eduardo Maffud Cilli, UNESP - Araraquara

Helena Carvalho de Lorenzo, UNESP - Araraquara

Heitor Miranda Bottura, UNESP - Bauru

Helio Grassifilho, UNESP - BOTUCATU

Leonice Domingos dos Santos Cintra Lima, UNESP.

Augusto Eduardo Baptista Antunes, UNESP.

Durval Luiz Silva Ricciulli, UNESP - Guaratinguetá

Francisco Antônio Lotufo, UNESP - Guaratinguetá

Inácio Bianchi, UNESP - Guaratinguetá

João Zangrandi Filho, UNESP - Guaratinguetá

José Feliciano Adami, UNESP - Guaratinguetá

Leonardo Mesquita, UNESP - Guaratinguetá

Marcio Abud Marcelino, UNESP - Guaratinguetá

Messias Borges Silva, UNESP - Guaratinguetá

Rubens Alves Dias, UNESP - Guaratinguetá

Silvia Maria A. Lima Costa, UNESP - Ilha Solteira

Gláucia Aparecida Prates, UNESP - Itapeva

Áureo Evangelista Santana, UNESP - Jaboticabal

Teresa Cristina Tarlé Pissarra, UNESP - Jaboticabal

Gilda Carneiro Ferreira, UNESP - Rio Claro

Fernando Luis Fertonani, UNESP - São José do Rio Preto

Azor Lopes da Silva Júnior, UNESP - São José do Rio

Preto

Andréa Rossi Scalco, UNESP - Tupã

José Renato Oliveira de Lima, UNESP-IQ, Araraquara

Luiz Antonio Rossi, UNICAMP

Nelson Nunes Tenório Júnior, UNICESUMAR

Luis Henrique de Carvalho Ferreira, UNIFEI - Itajubá

Paulo Cesar Crepaldi, UNIFEI - Itajubá

Robson Luiz Moreno, UNIFEI - Itajubá

Tales Cleber Pimenta, UNIFEI - Itajubá

Fernando das Graças Braga da Silva, UNIFEI - Itajubá

Leonardo Breseghello Zoccal, UNIFEI-Itajubá

Larissa Morimoto Doi, UNIFESP

Fernando Kenji Nampo, UNIFIL

Adriano Vargas Freitas, UNIGRANRIO

Angelo Santos Siqueira, UNIGRANRIO

Eline das Flores Victer, UNIGRANRIO

Luiz Eduardo Silva Souza, UNIGRANRIO

Michel Jean Marie Thiollent, UNIGRANRIO

Abel Rodolfo Garcia Lozano, UNIGRANRIO / UERJ

Lileane Praia Portela de Aguiar, UNINORTE.

Eliane Cardoso Brenneisen, UNIOESTE

Luiz Ernani Henkes, UNIPAMPA

Maria Conceição de Oliveira, UNIPLAC

Wilson Engelmann, UNISINOS

Giorgio Eugenio Oscare Giacaglia, UNITAU

Pedro Paulo Leite do Prado, UNITAU

Luiz Eduardo Nicolini do Patrocínio Nunes, UNITAU

Adriana Araujo Diniz, UNIV. ESTADUAL DO

MARANHÃO
Danilo Émmerson Nascimento Silva, UNIV. FEDERAL DE PERNAMBUCO

Adelar João Pizetta, UNIV. FEDERAL DO ESPÍRITO

SANTO

Adriana Fiorotti Campos, UNIV. FEDERAL DO

ESPÍRITO SANTO

Adriana Demite Stephani Carvalho, UNIV. FEDERAL DO TOCANTINS

Ademir Gomes Ferraz, UNIV. FEDERAL RURAL DE PERNAMBUCO

Rudimar Luís Scaranto Dazzi, UNIVALI

Carlos Nabil Ghobril, Universidade de São Paulo - USP

Filomena Maria Cordeiro Moita, Universidade Estadual da Paraíba

Márcia Maria Melo Araújo, Universidade Estadual de Goiás

Élsio José Corá, Universidade Federal da Fronteira do Sul - UFFS

Edemar Rotta, Universidade Federal da Fronteira do Sul UFFS

Walter Roberto Hernãndez Vergara, Universidade Federal de Grande Dourados - FAEN-UFGD

Édison Martinho da Silva Difante, Universidade Federal de Passo Fundo - RS

Antonio Amaral Barbosa, Universidade Federal de Pelotas João Carlos Gomes, Universidade Federal de Rondônia

ANA EUCARES VON LAER, Universidade Federal de

Santa Maria - UFSM

André Riani Costa Perinotto, Universidade Federal Do

Piauí, Campus De Parnaíba

Diogo da Silva Cardoso, UFRJ.

Cláudia Moura de Melo, Universidade Tiradentes.

Osvaldo Yoshimi Tanaka, USP

Ana Cristina D'andretta Tanaka, USP

Heloiza Helena Gomes de Matos, USP

Rodrigo Pinto de Siqueira, USP - Lorena

José Leandro Casa Nova Almeida, USS

Adalberto Matoski, UTFPR

Guataçara dos Santos Junior, UTFPR

Rita de Cassia da Luz Stadler, UTFPR

Juares da Silva Thiesen, UTFPR

Maria de Lourdes Bernartt, UTFPR

Alessandro Jaquil Waclawovsky, UTFPR

Pedro Ramos da Costa Neto, UTFPR

Frieda Saicla Barros, UTFPR

Rogério Marcos da Silva, UTFPR

Gerson Máximo Tiepolo, UTFPR

Jair Urbanetz Junior, UTFPR

Ariel Orlei Michaloski, UTFPR

Fabiana de Fátima Giacomini, UTFPR

Ieda Viana, UTP

Camila Nunes de Morais Ribeiro, UTP

Angela Ribas, UTP

Sandro Germano, UTP

Maria Rose Jane Ribeiro Albuquerque, UVA- Acaraú 


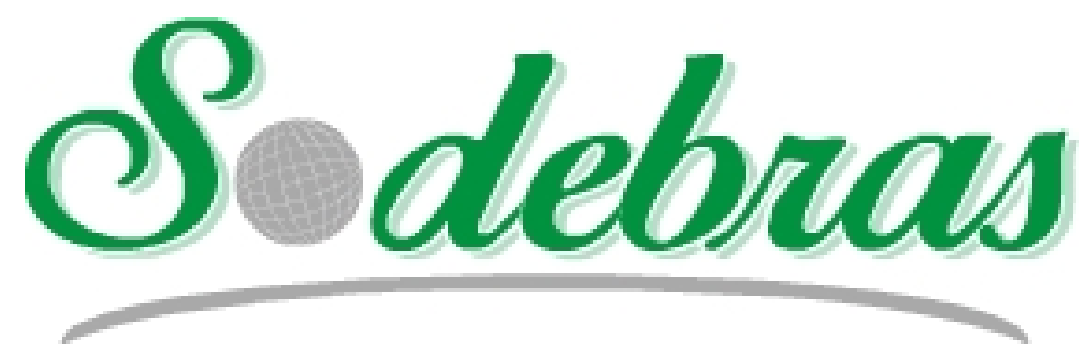

Vol. $16-\mathrm{N}^{\circ} 187-\mathrm{JULHO} / 2021$

\section{EDITORIAL}

O conhecimento é libertador; e desde a antiguidade a busca pelo saber e pela compreensão sóbria da vida e do universo tem guiado o ser humano na jornada da ciência. Tales de Mileto, foi um matemático, astrônomo, engenheiro, físico, e um dos primeiros pensadores da Filosofia, marcou sua época ao defender uma ciência livre e metodológica. Hoje, cabe ao cientista explorar as possibilidades da tecnologia de modo a contribuir para que a humanidade tenha mais qualidade de vida.

Nesta perspectiva, a SODEBRAS - Soluções Para o Desenvolvimento do País publica artigos científicos das mais diferentes áreas do conhecimento. Devido seu caráter interdisciplinar e a qualidade de seu corpo editorial a Revista tem sido utilizada por pesquisadores do Brasil e do mundo, para publicar estudos de alta relevância para o desenvolvimento técnico-científico da sociedade humana. Além disso, a SODEBRAS conta com o apoio da UNALAR, editora que está no mercado há mais de duas décadas; e também do ITANACIONAL, instituto de ensino e pesquisa localizado em Cisneiros distrito de Palma-MG.

Neste mês, a edição 187, de julho de 2021, traz seis artigos com temáticas multidisciplinares e perspectivas acadêmicas de diferenciados pontos das ciências. Para contribuir com uma dinâmica ainda maior, no que diz respeito à circulação e a produção do conhecimento, a SODEBRAS adota uma periodização mensal. Sabe-se que em um mundo de rápidas mudanças e de constantes transformações a ciência precisa estar na vanguarda da propagação de informações. Além disso, as edições possuem formato eletrônico de acesso livre e gratuito, assim como indexação internacional.

Isabela Oliveira Jacinto Cunha, Iranildo Alves Coutinho Junior, Giovani Galvão de Moura, Roque Antônio de Moura e Messias Borges Silva apresentam o estudo intitulado "SEGURANÇA E ERGONOMIA PARA FORÇA LABORAL FEMININA NA INTERAÇÃO COM MÁQUINAS COLABORATIVAS".

O segundo estudo, "DIDÁTICA DA MATEMÁTICA: UM ESTUDO DAS METODOLOGIAS DE ENSINO E AS DIFICULDADES DA APRENDIZAGEM DOS ALUNOS DE ENSINO MÉDIO", é de autoria de Jesuino Jésus Lisbôa de Oliveira Silva, Raquel Martins Fernandes e Rodrigo Ribeiro de Oliveira. 


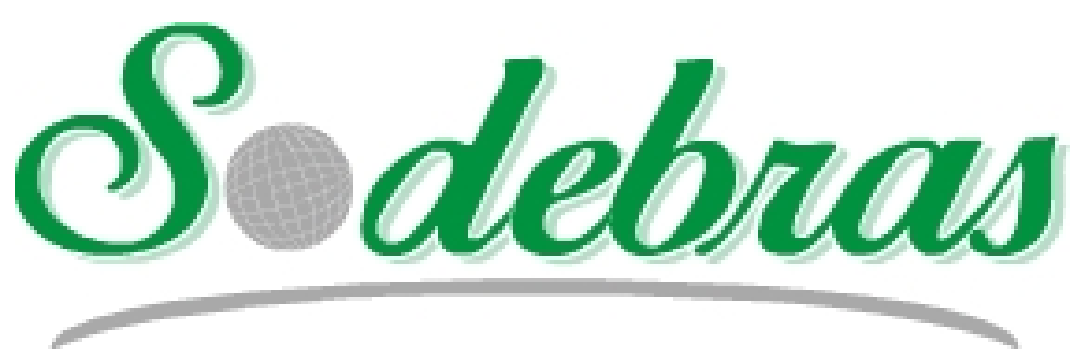

Vol. $16-\mathrm{N}^{\circ} 187-\mathrm{JULHO} / 2021$

Natasha Martins Rodrigues de Jesus, Rafael Soares Souza, Rita de Cassia Mendonça Sales Contini, Teófilo Miguel de Souza e Thais Santos Castro, contribuíram com a pesquisa "PROPOSTA DE APLICAÇÃO DA METODOLOGIA 5S EM LABORATÓRIO DE PROCESSAMENTO DE MATERIAIS COMPÓSITOS”.

O quarto artigo desta edição, "ESTIMATIVA NUMÉRICA DA GERAÇÃO DE ENERGIA SOLAR-FOTOVOLTAICA NA COBERTURA DO ESTACIONAMENTO DA BIBLIOTECA DA FZEA - USP" é de autoria de Fernando de Lima Caneppele, Emmanuel Zullo Godinho, Luis Fernando Soares Zuin e Jair Antonio Cruz Siqueira.

"MODELOS DE OTIMIZAÇÃO PARA DETERMINAR AS LOCALIZAÇÕES DOS PONTOS DE ACESSO SEM FIO” de autoria de Lucas Barcelos Mendes, Mário Mestria.

E por fim, o estudo "INFLUÊNCIA DO RAIO DE PONTA NO DESGASTE DA FERRAMENTA DE CORTE E NA CORRENTE ELÉTRICA CONSUMIDA NO TORNEAMENTO DO AÇO ABNT 1045", de autoria de André Luís Pedroza de Oliveira, Marcos Guilherme Carvalho Braulio Barbosa, Lívio Bruno Nery da Silva Viana, Patrick Abreu De Oliveira e Lívia Fernanda Nery da Silva.

Boa leitura

Prof. Dr. Paulo Jonas dos Santos Júnior

Editor Adjunto - Revista SODEBRAS 


\section{Área: Interdisciplinar}

\begin{tabular}{|c|l}
\hline $9-8$ & $\begin{array}{l}\text { SEGURANÇA E ERGONOMIA PARA FORÇA LABORAL FEMININA NA } \\
\text { INTERAÇÃO COM MÁQUINAS COLABORATIVAS }\end{array}$ \\
& $\begin{array}{l}\text { SAFETY AND ERGONOMICS FOR FEMALE WORKFORCE IN } \\
\text { INTERACTION WITH COLLABORATIVE MACHINES } \\
\text { Isabela Oliveira Jacinto Cunha; Iranildo Alves Coutinho Junior; Giovani Galvão } \\
\text { De Moura; Roque Antônio De Moura; Messias Borges Silva }\end{array}$ \\
\hline
\end{tabular}




\title{
Revista SODEBRAS - Volume 16 $\mathrm{N}^{\circ} 187-\mathrm{JULHO} / 2021$ \\ SEGURANÇA E ERGONOMIA PARA FORÇA LABORAL FEMININA NA INTERAÇÃO COM MÁQUINAS COLABORATIVAS
}

\author{
SAFETY AND ERGONOMICS FOR FEMALE WORKFORCE IN \\ INTERACTION WITH COLLABORATIVE MACHINES
}

\author{
ISABELA OLIVEIRA JACINTO CUNHA ${ }^{1}$; IRANILDO ALVES COUTINHO JUNIOR ${ }^{1}$; \\ GIOVANI GALVÃO DE MOURA ${ }^{2}$; ROQUE ANTÔNIO DE MOURA ${ }^{1,2,3}$; MESSIAS BORGES SILVA ${ }^{3,4}$ \\ 1-FACULDADE DE TECNOLOGIA SÃO JOSÉ DOS CAMPOS; 2-UNIVERSIDADE DE TAUBATÉ - \\ UNITAU; 3-UNIVERSIDADE ESTADUAL PAULISTA - UNESP; 4-EEL - USP LORENA \\ isabella.cunha01@fatec.sp.gov.br; iranildo.coutinho@fatec.sp.gov.br; giovanigalvao97@gmail.com; \\ roque.moura@fatec.sp.gov.br; messias.silva@unesp.br
}

\begin{abstract}
Resumo - A quarta revolução industrial e suas tecnologias inteligentes, preveem humanos e robôs trabalhando lado a lado. Assim, desenvolver métodos de garantir a segurança humana ao prevenir acidentes e eliminar riscos de colisão, é essencial. Neste sentido, o artigo objetiva, com o aumento da força laboral feminina, revisar a percepção da falta do equipamento protetivo para elas. A metodologia incluiu pesquisa bibliográfica $e$ entrevistas com 139 voluntárias, $(95 \%,+5 \%)$, que trabalham em diversos ramos $e$ atividades. $O$ resultado demonstra que os fabricantes fornecem equipamentos baseados em formas $e$ formatos masculinos, que são ajustados por elas antes do uso. Conclui-se ser preciso revisar parâmetros antropométricos femininos e conceber projetos, moldes e formas específicas para elas ao invés de apenas e grosseiramente desmontar e ajustar os masculinos.
\end{abstract}

Palavras-chave: EPI Feminino. Força Laboral Feminina. Indústria.

\begin{abstract}
The fourth industrial revolution 4.0 and its smart technologies predict humans and robots working side by side. Thus, developing methods to ensure human safety by preventing accidents and eliminating collision risks is essential. In this sense, this article aims, with the increase of the female workforce, to review the perception of the lack of protective equipment for them. The methodology included bibliographic research and interviews with 139 volunteers $(95 \%, \pm 5 \%)$, who work in different fields and activities. The result demonstrates that manufacturers provide equipment based on male shapes and formats, which are adjusted by them before use. It is concluded, be necessary to review female anthropometric parameters and design projects, molds, and specific shapes for them, rather than unplanned dismounting of the male ones.
\end{abstract}

Keywords: Female PPE. Female Workforce. Industry.

\section{INTRODUÇÃO}

O mundo está vivenciando a quarta revolução industrial, fruto de um projeto do governo alemão para promover a digitalização e um seleiro de oportunidades, riscos e desafios. A eficiência produtiva será obtida através de postos de trabalho colaborativos e compartilhados entre humanos e máquina que aliás afetará a percepção humana de atividade segura (SIVATHANU e PILLAI, 2018).
Outra mudança, é que a quarta revolução industrial terá impacto sobre as qualificações exigidas do mercado de trabalho, principalmente com novas habilidades e competências para a interação colaborativa entre humanos e máquinas, ou seja, um novo perfil profissional combinará know-how e criatividade para inovar com a premissa básica da segurança humana. Humanos são habilidosos e criativos na solução de problemas inesperados, contudo, máquinas colaborativas resistem a fadiga, trabalhos repetitivos e monótonos, como por exemplo, solda ponto em placas de circuitos impressos (BENEŠOVÁ e TUPA, 2017).

$\mathrm{O}$ trabalho compartilhado com máquinas colaborativas nas atividades industriais é uma tendência crescente, pois, trabalham em um espaço compartilhado com humanos e ampliam a capacidade humana em atividades desgastantes, repetitivas e perigosas. Contudo, a segurança precisa contar com equipamentos de proteção individual (EPI) na preparação, montagem e execução das atividades, haja vista que, colisões acontecem e a parte humana mais comumente atingida é a colisão de cabeça (AYOUBI et al., 2019).

\section{1 - Antropometria e equipamento de proteção individual}

Segundo Moura et al (2019), a antropometria, cuida das dimensões corporais humanas visando maior conforto e bemestar dos indivíduos. Tais medidas dizem respeito ao alcance, movimentos do corpo e posturas nas atividades laborais. Há diferença antropométrica entre os gêneros masculino e feminino. Equipamentos, dispositivos e postos de trabalho devem observar as dimensões dos indivíduos respeitando o gênero, as limitações físicas e o membro dominante. Portanto a proteção da força laboral feminina, requer um projeto feminino ou deve prever um mínimo de ajuste do EPI pela usuária, sem necessidade de cortes (roupa protetora) o que leva ao uso inadequado e alteração das características específicas e de projeto do EPI.

Atualmente a população mundial estimada do planeta é superior a sete bilhões e meio de habitantes, sendo o gênero feminino mais de $51 \%$, seja por que nascem em maior número ou por viverem mais que o gênero masculino, com histórico da expectativa de vida de 1950-2020 para os gêneros masculino (70.8 anos) e feminino (75.6 anos), o que 
por si só, já justifica desenvolver EPI específico para a mulher (UN, 2020).

Outro incentivo para se desenvolver EPI específico feminino, é demonstrado no Quadro 1, sobre os resultados de afastamentos entre gêneros na última década. $\mathrm{O}$ afastamento para o gênero masculino, foi de $0,7 \%$, enquanto no feminino, o afastamento atingiu um índice de 34\% (DIEESE, 2015).

Quadro 1 - Afastamento de trabalhadores por gênero

\begin{tabular}{|c|c|c|c|c|c|c|}
\hline $\begin{array}{c}\text { Afastametta por gêneso } \\
\text { de: } 2005 \text { gate } 2015\end{array}$ & \multicolumn{3}{|c|}{ Feminino } & \multicolumn{3}{|c|}{ Masculino } \\
\hline Acidente Tipico Rotineiro & 66.0151 & 81598 & $23 \%$ & 229.690 & 213.564 & $.7 \%$ \\
\hline Acidente Trajeto Percurso & 8.035 & 13292 & $65 \%$ & 21.282 & 29.160 & $36 \%$ \\
\hline Doenca Trab.Profissiesal & 61.553 & 86979 & $41 \%$ & 84.366 & 94.629 & 125 \\
\hline Acumulado (década) & 135.639 & 181.869 & $34 \%$ & 335.338 & 337.453 & $0.7 \%$ \\
\hline
\end{tabular}

\section{2 - EPI projetados segundo a antropometria e gênero}

Segundo Moura et al (2021), os EPIs devem atender a necessidade protetiva de ambos os gêneros, o que não é possível sem avaliação antropometria média entre ambos.

Nesse contexto, há tímidos estudos abordando a necessidade do EPI feminino. É preciso desenvolver e estabelecer projetos femininos, inclusive na construção de máquinas, dispositivos e equipamentos e não, meramente, desmontar os maquinários construídos para antropometria masculina e após reformar e pintar, dizer que foram adequados ao gênero feminino, como acontece com máquinas antigas e ultrapassadas de um parque industrial obsoleto, cuja modernização já consta em um mapa estratégico da indústria com o desafio de tornar a indústria competitiva, inovadora, global e sustentável, frente a transição demográfica acelerada (CNI, 2021).

Além da segurança e ergonomia para força laboral feminina na interação colaborativa com máquinas colaborativas, é preciso também verificar as características psicofisiológicas, responsável pelo desconforto, insegurança e baixo desempenho devido ao excesso de esforço físico e mental que levam ao stress e fadiga, seja pelo ritmo ou pelo EPI desconfortável. Um exemplo de desconforto, incômodo e que até machucam, são os calcados de segurança, especificamente na região da biqueira de aço (Figura 1), que é inflexível, pesado e fonte das reclamações femininas, por ser fabricado a partir de moldes e formas masculinos, são acabados, pintados e entregues como de uso unissex (JANSON, NEWMAN e DHOKIA, 2020).

Figura 1 - Calçado de segurança unissex

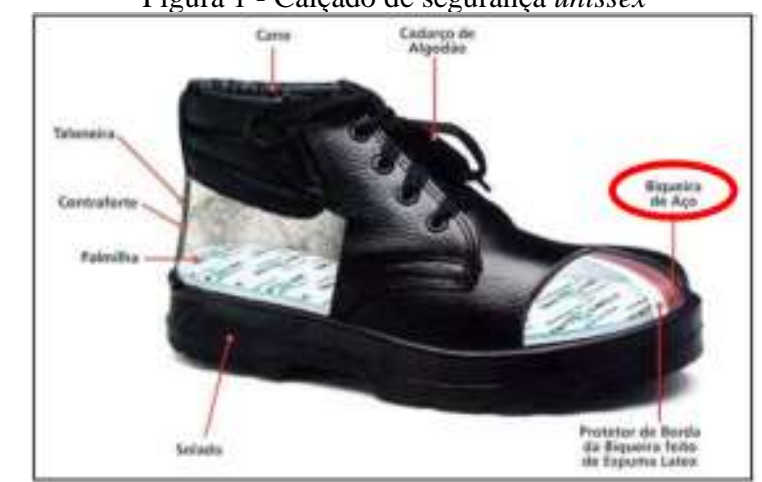

Fonte:https://vienairon.com.br/wp-content/uploads/2020/02/detalhes-bota.jpg
Uhl, Lindenmann e Matthiesen (2020) ensinam que a interação entre humano e máquina só pode ser otimizada se forem reconhecidos os riscos envolvidos, o que requer por exemplo, simulação com movimentação de cabeça e tronco, para averiguar as medidas antropométricas. Regra geral, os projetos foram desenhados e realizados para o gênero masculino e sua antropometria, e quando mulheres assumem os mesmos postos de trabalho, precisam ajustar antes do uso ou início da atividade (BALANAY et al., 2014; CHOWDHURY et al., 2021).

\section{3 - Hierarquia de controle dos riscos}

Segundo Moura et al. (2021), o EPI embora necessário, é o último recurso que deve ser utilizado na hierarquia das medidas de proteção e controle do risco, conforme ilustra a Figura 2.

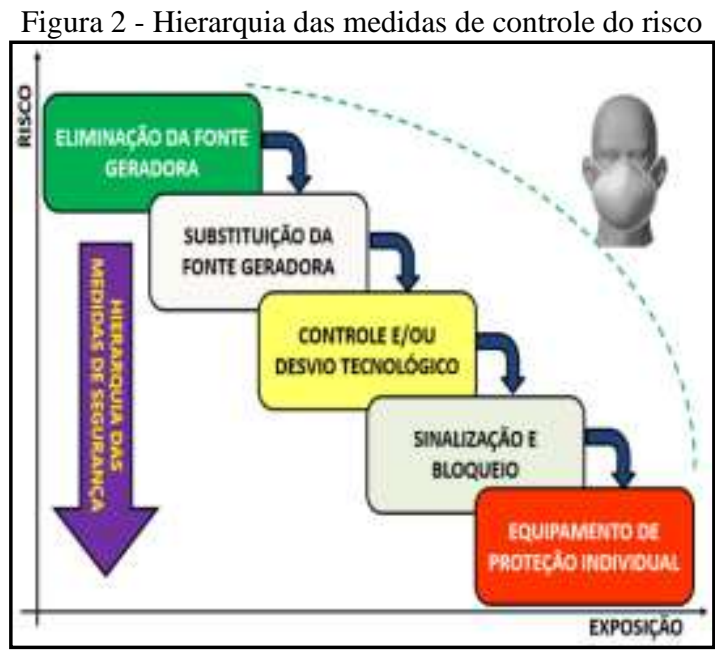

Fonte: Adaptado pelo Autores (2021).

\section{METODOLOGIA}

A pesquisa bibliográfica foi realizada na plataforma Scopus em relação ao assunto e ano de publicação inerente ao tema em tela. A Figura 3 ilustra a rede de palavras chaves correlacionadas a força laboral feminina e seu campo de atuação. As cores nas marcações das palavras-chave simbolizam o ano de publicação, podemos observar que desde o ano 2014 o assunto tem uma oportunidade de ser melhor explorado e pesquisado.

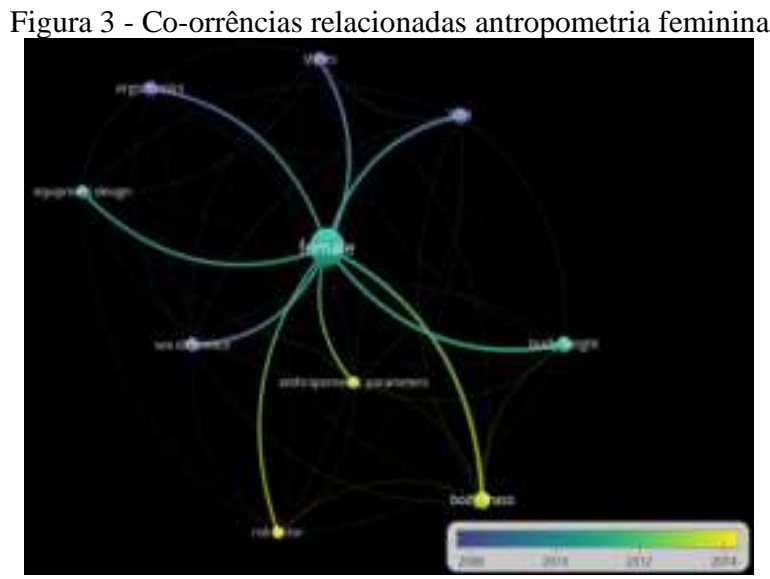

Fonte: Software desenvolvido por Eck e Waltman (2021). 


\section{1 - Entrevista com trabalhadoras}

Foram entrevistadas 139 voluntárias que trabalham e estudam e que responderam a quatro questões durante os meses de abril, maio e junho de 2021 de forma on-line pelo Microsoft forms no Teams.

As questões e suas alternativas foram:

1. Qual a sua idade?

2. Você trabalha ou trabalhou em:

o Indústria de transformação (montadoras e similares)

o Comércio varejista ou atacadista (shopping e similares)

o Prestação de serviços (Urbam e similares)

o Saúde (hospital, clínicas e similares)

o Serviço público (prefeitura, Inpe)

o Outros

3. Na sua função, ao receber gratuitamente o equipamento de Proteção Individual, para sua segurança, você:

o Ajustava de forma moderada

o Ajustava excessivamente

o Usava sem fazer ajustes

○ Não recebia, pois não havia

4. Ao usar o Equipamento de Proteção Individual, qual a sua percepção:

$\circ$ Parecia ser EPI masculino

o Parecia ser EPI feminino

o Não recebia nenhum EPI

\section{RESULTADOS E DISCUSSÃO}

Alguns equipamentos de proteção são combinados aos equipamentos de proteção coletiva (EPC), pois há vários riscos que podem ocorrer simultaneamente e nesse caso, é necessário usar mais de um tipo de EPI, como ilustra a Figura 4, que aliás, foi desenvolvida pelos autores pela dificuldade de encontrar nos sites de domínio público, um exemplar do gênero feminino disponível.

Figura 4 - Modelo feminino usando vários EPIs

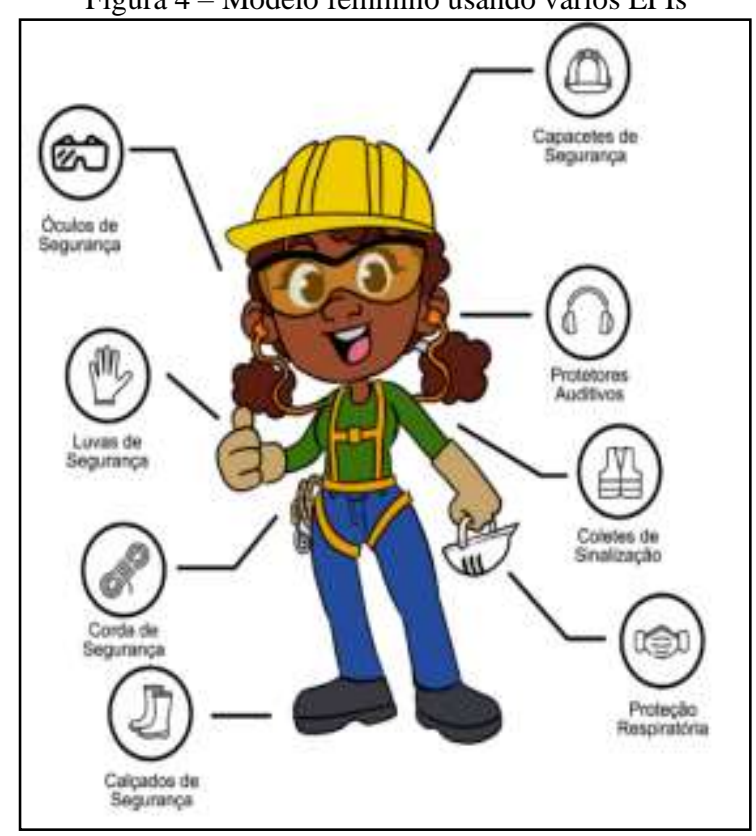

Fonte: Elaborado pelos Autores (2021).

Nexus (2020) dispõe e alerta sobre algumas das peculiaridades e diferenças antropométricas que devem ser observadas e respeitadas em um projeto e desenvolvimento do EPI feminino. O quadro 2 demonstra os mais requisitados.

\begin{tabular}{|c|c|c|}
\hline \multicolumn{3}{|c|}{ Quadro 2 - Principais EPIs } \\
\hline $\begin{array}{l}\text { Bquipamento de } \\
\text { Protesajo Individual }\end{array}$ & Quanto no uso e dimenslo & Inagen \\
\hline $\begin{array}{l}\text { Óculos } \\
\text { de segurança }\end{array}$ & $\begin{array}{l}\text { Ha difereacha entre o rosto feminino e } \\
\text { masculino. O EPI deve ateoder as } \\
\text { dimensóes corretas para maior seguranç. }\end{array}$ & \\
\hline $\begin{array}{c}\text { Capacete } \\
\text { cons cinto jugular }\end{array}$ & $\begin{array}{l}\text { Utilizar cinto de jugular no EPI preso ao } \\
\text { queixo melhori a segarança. Dimeasōes } \\
\text { das capacetes varian conforme o géaero. }\end{array}$ & \\
\hline $\begin{array}{c}\text { Protetor } \\
\text { Auricular de espema }\end{array}$ & $\begin{array}{l}\text { O género feminino tem canais de ouvidos } \\
\text { menores que o mascalies, Importante } \\
\text { usar material expansivo conforme canal. }\end{array}$ & \\
\hline $\begin{array}{l}\text { Calçado de } \\
\text { Segurança }\end{array}$ & $\begin{array}{l}\text { Ha diferença do tamanho do pé fentiaino } \\
\text { para o masculiao. O EPI deve eacaixar as } \\
\text { dimensóes e conforto do gêneto. }\end{array}$ & \\
\hline Luvas & $\begin{array}{l}\text { Protegem as mãos. O tamunho varia de } \\
\text { acordo com o guthera. Usar luvas mal } \\
\text { fimensionada acarreta acidentes. }\end{array}$ & \\
\hline
\end{tabular}

Fonte: Adaptados de Nexus (2020).

\section{1 - Resultado da entrevista com as trabalhadoras}

$\mathrm{Na}$ primeira questão, 139 respondentes assinalaram a faixa etária dos 17 aos 60 anos de idade, conforme demonstra o Gráfico 2. Portanto $94 \%$ das respondentes estão na faixa etária considerada ativa pelo mercado de trabalho.

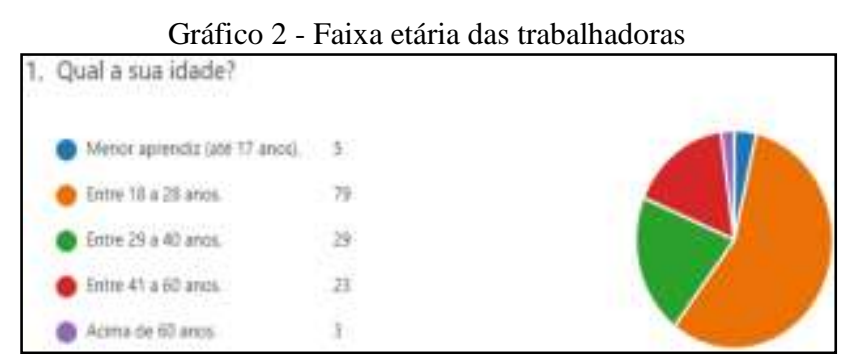

Fonte: Elaborado pelos Autores (2021).

Na segunda questão, das 139 respondentes, sobre o local que trabalham: 33\% indicaram Indústria; 21\% Outros (Jardinagem, Costura e MEI); 19\% Comércio; 11\% Área da Saúde; $11 \%$ Serviço Público e 5\% na Prestação de Serviços, conforme demonstra o Gráfico 3.

Gráfico 3 - Local e ramo da atividade laboral

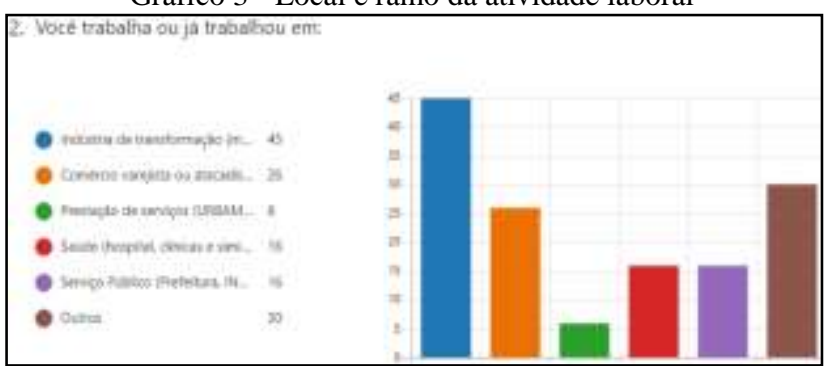

Fonte: Elaborado pelos Autores (2021).

$\mathrm{Na}$ terceira questão, das 139 respondentes, sobre se recebiam gratuitamente e ajustavam o Equipamento de Proteção Individual: $52 \%$ das mulheres disseram que recebiam e ajustavam de forma moderada; $18 \%$ usavam sem ajustar; $17 \%$ não recebiam pois não havia EPI feminino disponível e $13 \%$ ajustavam o EPI de forma exagerada antes de usarem, conforme demonstra o Gráfico 4. 
Gráfico 4 - Ajustes ao receberem o EPI

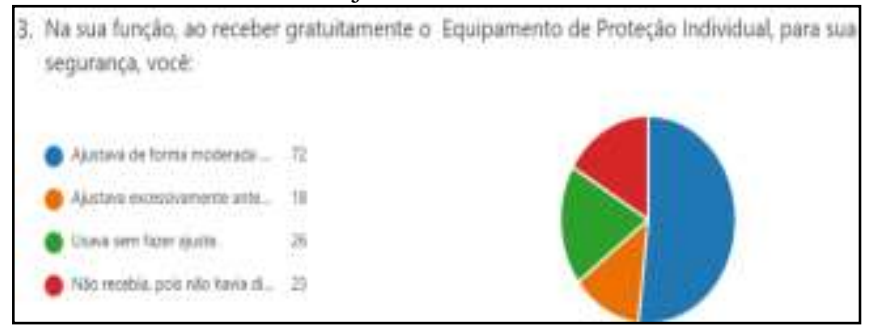

Fonte: Elaborado pelos Autores (2021).

$\mathrm{Na}$ quarta questão, das 139 respondentes, sobre a percepção ao usar o EPI: $53 \%$ das mulheres perceberam que se tratava de um EPI masculino entregue para uso feminino; $26 \%$ não recebiam pois não havia EPI feminino disponível; $21 \%$ perceberam que era um EPI feminino, conforme Gráfico 5.

Gráfico 5 - Percepção sobre o projeto do EPI ser feminino

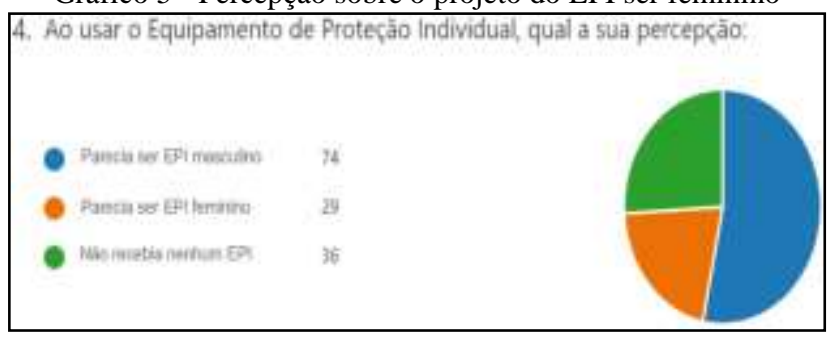

Fonte: Elaborado pelos Autores (2021).

\section{CONCLUSÃO}

A proposta deste artigo foi destacar a importância do Equipamento de Proteção Individual feminino, haja vista que, como os equipamentos, máquinas e dispositivos, na maioria das vezes, o EPI é grosseiramente readaptado do masculino, ou seja, não há um projeto que respeite a antropometria e particularidades das dimensões femininas.

$\mathrm{Na}$ pesquisa realizada, 139 respondentes, de 17 aos 60 anos de idade, trabalham na Indústria metalmecânica (33\%), Jardinagem, Costura e MEI (21\%), Comércio (19\%), na área da Saúde $(11 \%)$, no Serviço público $(11 \%)$ e $5 \%$ são prestadoras de serviços.

Contudo, ao receber o EPI, $52 \%$ das mulheres disseram que ajustavam de forma moderada e $13 \%$ ajustavam de forma exagerada antes de usar. Este fato é prejudicial, pois ao ajustar de forma exagerada, pode-se comprometer a durabilidade e funcionalidade proposta pelo EPI.

Quanto a percepção se o EPI era um projeto específico para o público feminino, $53 \%$ das mulheres disseram que se tratava de um EPI masculino ajustado para uso feminino e $26 \%$ disseram que não recebiam pois não havia EPI feminino disponível.

Conclui-se que os fabricantes, precisam rever os parâmetros antropométricos dos gêneros e iniciar a fabricação com moldes e formas específicas para o púbico alvo, ao invés de simplesmente e grosseiramente sem observar os dados antropométricos feminino, fazem a desmontagem do masculino, o que, pode ter impactado no índice de afastamento feminino, conforme Quadro 1.

Como trabalho futuro sugere-se uma amostragem maior e focar em roupas industriais e uniformes, os quais durante a entrevista, apurou-se haver casos de cortes, ajustes e reformas pré-maturas.

\section{REFERÊNCIAS}

AYOUBI, Y., LARIBI, M.A., ZEGHLOUL, S., ARSICAULT, M. V2SOM: A novel safety mechanism dedicated to a cobots rotary joints, Robotic, 2019. DOI: $\underline{10.3390 / \text { robotics } 8010018}$

BALANAY, J. A. G.; ADESINA, A.; KEARNEY, G. D.; RICHARDS, S. L. Assessment of occupational health and safety hazard exposures among working college students. Avaliação de exposições a riscos de saúde e segurança ocupacional entre estudantes universitários que trabalham, 2014. https://doi.org/10.1002/ajim.22256

BENEŠOVÁ, A., TUPA, J. Requirements for education and qualification of people in Industry 4.0. Procedia Manufacturing, 11 , pp. 2195-2202, 2017. DOI: 10.1016/j.promfg.2017.07.366.

CHOWDHURY, N. S.; LUU, W.; PALMISANO, S.; UJIKE, H.; KIM, J. Spatial presença depends on coupling between body sway and visual motion presented on head, 2021. DOI: https://doi.org/10.1016/j.apergo.2021.103355

CNI. Confederação Nacional da Indústria. Futuro da indústria. Semana da indústria: encontros virtuais com representantes da OCDE para discutir temas estratégicos, 2021. Disponível em http://www.portaldaindustria.com.br/cni/en/about/ Acesso em 13jul.2021

DIEESE. Departamento intersindical de estatística e estudos socioeconômicos. MTb. Rais. De 2005 a 2015. Disponível: https://www.dieese.org.br/anuario/2017/Livro7_Saude.pdf Acesso em 21 abr.2021.

JANSON, D.; NEWMAN, S.T.; DHOKIA, V. Safety footwear: A survey of end-users. Appl Ergon. 2021 Apr; 92: 103333. DOI: 10.1016/j.apergo.2020.103333. Epub 2020 Dec 21. PMID: 33359927.

MOURA, R. A.; DE JESUS, N. M. R.; SOUZA, R. S. Ergonomia e antropometria como ferramentas de vanguarda produtivas nas indústrias do futuro. Revista Sodebras [online]. vol. 14. $\mathrm{n}^{\circ}$ 157, pp 109-112. Janeiro/ 2019. ISSN 18093957. DOI: https://doi.org/10.29367/issn.18093957.2019.157.

MOURA, R. A.; MARQUES, D. J. R.; COSTA, J. C. L.; SILVA, M. B. A urbanidade da higiene ocupacional na era digital e o negacionismo social da antecipação e prevenção. 2021. Revista Sodebras [on-line]. vol. 16. n 184, pp 29-33. 2021. ISSN 1809-3957. https://doi.org/10.29367/issn.1809$\underline{3957.16 .2021 .184 .29}$

NEXUS. 2020. Equipamentos de proteção individual - EPI. EPI para mulheres: são os mesmos dos homens? Disponível:

https://www.nexusepi.com.br/epi-para-mulheres-sao-osmesmos-dos-homens Acesso em 13mai.2021

SIVATHANU, B., PILLAI, R. Smart HR 4.0 - how industry 4.0 is disrupting HR. Human Resource Manage International Digest, 26 (4), pp. 7-11, 2018. DOI: 10.1108/HRMID-042018-0059

UHL, M.; LINDENMANN, A.; MATTHIESEN, S. Analysis of factors influencing the productivity of hammer drilling-user forces, human fatigue, drilling direction, drill bit, 2020. https://doi.org/10.1016/j.apergo.2020.103338 
UN. United Nations (Nações Unidas). Organização das Nações Unidas. Dez países mais populosos, 2020.

Disponível em: https://www.un.org/en/globalissues/population Acesso em 21abr.2021.

\section{COPYRIGH}

Direitos autorais: Os autores são os únicos responsáveis pelo material incluído no artigo. 


\section{Área: Ciências Exatas e Engenharias}

\begin{tabular}{|c|c|}
\hline $1-1$ & $\begin{array}{l}\text { DIDÁTICA DA MATEMÁTICA: UM ESTUDO DAS METODOLOGIAS DE ENSINO } \\
\text { E AS DIFICULDADES DA APRENDIZAGEM DOS ALUNOS DE } \\
\text { ENSINO MÉDIO } \\
\text { DIDACTICS OF MATHEMATICS: A STUDY REGARDING THE TEACHING } \\
\text { METHODOLOGIES AND THE LEARNING DIFFICULTIES OF HIGH SCHOOL } \\
\text { Jesuino Jésus Lisbôa De Oliveira Silva; Raquel Martins Fernandes; Rodrigo Ribeiro } \\
\text { De Oliveira }\end{array}$ \\
\hline 3-1 & $\begin{array}{l}\text { PROPOSTA DE APLICAÇÃO DA METODOLOGIA 5S EM LABORATÓRIO DE } \\
\text { PROCESSAMENTO DE MATERIAIS COMPÓSITOS } \\
\text { PROPOSAL OF THE APPLICATION OF THE 5S METHODOLOGY IN A } \\
\text { COMPOSITE MATERIAL PROCESSING LABORATORY } \\
\text { Natasha Martins Rodrigues De Jesus; Rafael Soares Souza; Rita De Cassia } \\
\text { Mendonça Sales Contini; Teófilo Miguel De Souza; Thais Santos Castro }\end{array}$ \\
\hline $3-4$ & $\begin{array}{l}\text { ESTIMATIVA NUMÉRICA DA GERAÇÃO DE ENERGIA SOLARFOTOVOLTAICA } \\
\text { NA COBERTURA DO ESTACIONAMENTO DA BIBLIOTECA DA FZEA - USP } \\
\text { NUMERICAL ESTIMATE OF SOIL-PHOTOVOLTAIC ENERGY GENERATION IN } \\
\text { THE PARKING COVERAGE OF FZEA - USP LIBRARY } \\
\text { Fernando De Lima Caneppele; Emmanuel Zullo Godinho; Luis Fernando Soares } \\
\text { Zuin; Jair Antonio Cruz Siqueira }\end{array}$ \\
\hline $3-4$ & $\begin{array}{l}\text { MODELOS DE OTIMIZAÇÃO PARA DETERMINAR AS LOCALIZAÇÕES DOS } \\
\text { PONTOS DE ACESSO SEM FIO } \\
\text { MODELS OF OPTIMIZATION TO DETERMINE LOCATIONS OF THE WIRELESS } \\
\text { ACCESS POINTS } \\
\text { Lucas Barcelos Mendes; Mário Mestria }\end{array}$ \\
\hline $3-5$ & $\begin{array}{l}\text { INFLUÊNCIA DO RAIO DE PONTA NO DESGASTE DA FERRAMENTA DE } \\
\text { CORTE E NA CORRENTE ELÉTRICA CONSUMIDA NO TORNEAMENTO DO } \\
\text { AÇO ABNT } 1045 \\
\text { INFLUENCE OF TOOL NOSE RADIUS ON THE TOOL WEAR AND ELECTRIC } \\
\text { CURRENT CONSUMED DURING TURNING OF THE ABNT STEEL 1045 } \\
\text { André Luís Pedroza De Oliveira; Marcos Guilherme Carvalho Braulio Barbosa; Lívio } \\
\text { Bruno Nery Da Silva Viana; Patrick Abreu De Oliveira; Lívia Fernanda Nery Da Silva }\end{array}$ \\
\hline
\end{tabular}




\author{
Revista SODEBRAS - Volume 16 \\ $\mathrm{N}^{\circ} 187-\mathrm{JULHO} / 2021$
}

\title{
DIDÁTICA DA MATEMÁTICA: UM ESTUDO DAS METODOLOGIAS DE ENSINO E AS DIFICULDADES DA APRENDIZAGEM DOS ALUNOS DE ENSINO MÉDIO
}

\author{
DIDACTICS OF MATHEMATICS: A STUDY REGARDING THE TEACHING \\ METHODOLOGIES AND THE LEARNING DIFFICULTIES OF HIGH SCHOOL
}

\author{
JESUINO JÉSUS LISBÔA DE OLIVEIRA SILVA ${ }^{1}$; RAQUEL MARTINS FERNANDES²; \\ RODRIGO RIBEIRO DE OLIVEIRA ${ }^{3}$ \\ 1 - UDS UNIVERSIDAD; 2 - INSTITUTO FEDERAL DE MATO GROSSO; 3 - INSTITUTO FEDERAL \\ DE SÃO PAULO \\ jesuinolisboa@hotmail.com; raquel.fernandes@blv.ifmt.edu.br; rodrigo.oliveir@ifsp.edu.br
}

\begin{abstract}
Resumo - Em todo o lugar, no Brasil ou até no Mundo, raras não são as vezes que os alunos relatam suas dificuldades em relação a Matemática. Também são diversas as razões que levam a tais fatores: complexidade dos conteúdos, falta de qualificação do profissional, deficiência de aprendizagem na base alfabetização, falta de conhecimento da real importância da Matemática em seu cotidiano e muitos outros. O presente trabalho teve como objetivo identificar as metodologias de ensino e as dificuldades da aprendizagem dos alunos de Ensino Médio. A pesquisa foi realizada no mês de outubro de 2019, com duração de cinco dias, junto a 73 alunos, do segundo ano, do turno matutino, distribuídos em cinco classes. Estes alunos foram convidados a participarem, voluntariamente, respondendo dois questionários, um sobre a Matemática e um sobre o conteúdo de Trigonometria, ministrado no início do ano letivo de 2019. Após o levantamento dos dados, esses foram tabulados e foi realizada uma análise dos resultados. Logo, foi possível entender as questões referentes às dificuldades em aprender Matemática e encontrar possiveis caminhos para soluções. Os alunos expõem como causa de suas dificuldades ou facilidades a metodologia aplicada pelo professor, apoio familiar e falta de recursos das escolas e afinidade com o próprio componente curricular Matemática. Com base nas pesquisas levantadas, no presente trabalho, algumas das recomendações implicam em que a escola oportunize à coordenação, aos professores e aos alunos refletirem sobre a prática pedagógica acerca do trabalho realizado e incentivar as famílias a participarem da vida escolar dos filhos em tarefas/atividades extraescolares diversas, para que possam manter uma relação de apoio ao trabalho que está sendo realizado na escola.
\end{abstract}

Palavras-chave: Ensino de Matemática. Ensino Médio., Dificuldades de Aprendizagem. Percepções de Estudantes.

Abstract - Everywhere in Brazil or even in the world, it is not unusual for students to report their difficulties in relation Mathematics. There are also several reasons that lead to such factors: complexity of content; lack of professional qualification; learning disability since childhood - literacy; lack of knowledge of the real importance of Mathematics in their daily lives; and many other issues. The present work aimed to identify the teaching methodologies and learning difficulties of high school students of a State. The research was conducted in October 2019, lasting five days, comprising 73 students of second year morning shift, and distributed into five classes. These students were invited to participate, voluntarily, by answering two questionnaires, one about Mathematics and other about the content of Trigonometry, which is taught at the beginning of school years in 2019. After collecting the data, these data were tabulated and an analysis of the results was carried out. Therefore, it was possible to understand the issues related to the difficulties in learning Mathematics and then, discuss a solution to print a possible path. The students revealed the methodology applied by the teacher, family support, lack of resources in schools and affinity with the components of the curriculum (Mathematics) as their difficulties or facilities in learning Mathematics. According to the research conducted in the present work, some of the recommendations imply that the school should provide for the coordination, teachers and students the opportunity to reflect on the pedagogical practice regarding the work that it is being carried out as well as encourage families to be involved in the school life of their children in many different types of extracurricular tasks/activities, for maintaining a supportive relationship to the work being done at school.

Keywords: Mathematics Teaching. High School. Learning Difficulties. Student Perceptions.

\section{INTRODUÇÃO}

As questões relativas à educação que envolvem o Objetivo de Desenvolvimento Sustentável número 4 (quatro) "Educação de qualidade - Assegurar a educação inclusiva, e equitativa e de qualidade, e promover oportunidades de aprendizagem ao longo da vida para todos" são incontornáveis, porque mais da metade das crianças e dos adolescentes de todo o mundo não atingiram os padrões básicos de proficiência em leitura e matemática, segundo (UN, 2015; UNESCO, 2017). Nesse sentido, é essencial promover esforços para melhorar a qualidade da educação. As disparidades na educação ainda são acentuadas, sendo necessário investir mais em infraestrutura educacional, sobretudo entre os países não desenvolvidos (IPEA, 2020).

Em todo o lugar, no Brasil ou até no Mundo, raras não são as vezes em que os alunos relatam as dificuldades em relação à aprendizagem da Matemática. Também são diversas as razões que levam a tais fatores: complexidade dos conteúdos, falta de qualificação dos profissionais da educação e professores, deficiência de aprendizagem na 
base - alfabetização, falta de conhecimento da real importância da Matemática em seu cotidiano e muitos outros.

Os alunos precisam aprender a ler matemática e ler matemática para aprender, pois para interpretar um texto matemático, é necessário familiarizar-se com a linguagem e com os símbolos próprios desse comportamento curricular e encontrar sentido naquilo que lê, compreendendo o significado das formas escritas (NACARATO; MENGALI; PASSOS, 2019, p. 44).

Um dos maiores problemas e desafios, em aprender Matemática, é o gostar do próprio componente curricular, enfrentando a complexidade de ler e interpretar seus símbolos.

Quando o aluno fala, lê, escreve ou desenha, ele não só mostra quais habilidades e atitudes estão sendo desenvolvidas no processo de ensino, como também indica os conceitos que domina e as dificuldades que apresenta. Com isso, é possível verificar mais um aspecto importante na utilização de recursos de comunicação para interferir nas dificuldades e provocar cada vez mais o avanço dos alunos (NACARATO; MENGALI; PASSOS, 2019, p. 45).

O estudo da Matemática nas escolas deverá partir de um ensino prazeroso, dinâmico e abordando sempre uma realidade possível. O discurso do Governo do Estado de Mato Grosso frente a esta temática enfatiza a análise acima:

(...) o trabalho com Educação Matemática deverá necessariamente envolver as seguintes dimensões:

A matemática é uma atividade humana, portanto de caráter histórico-social;

A matemática é uma ciência de caráter interdisciplinar;

A matemática nos proporciona a construção de categorias de pensamento indispensável à compreensão, crítica e construção da realidade;

A matemática deve ser considerada em suas dimensões lúdicas e de aplicação no cotidiano;

As relações entre a matemática do cotidiano e a matemática formal, o que implica em considerar as experiências e os conhecimentos prévios dos alunos; Envolvimento emocional, fundamental para aprendizagem da matemática (MATO GROSSO, 2000, p. 155).

Não é raro perceber que um dos grandes e principais entraves e desafios no ensino no Brasil todo, especialmente no Mato Grosso - MT, em egressos do Ensino Fundamental, é a dificuldade que os alunos têm em aprender Matemática, em seus diversos ângulos. E é sabido que essa dificuldade se estende por todo o percurso desses alunos. Faz-se mister identificar as causas que dificultam a aprendizagem da Matemática e, só assim, propor formas de intervenção à resolução de tal problema nas escolas de todo o país. Logo, é indispensável questionar:

Quais as metodologias de ensino e as dificuldades da aprendizagem dos alunos de Ensino Médio da Escola Estadual "Prof." Adalgisa de Barros" no Município de Várzea Grande/MT? Quais os fundamentos das orientações curriculares sobre o ensino da Matemática? Quais os planejamentos de aulas em relação ao ensino da Matemática? Quais as práticas pedagógicas e as metodologias de ensino? Quais as dificuldades dos alunos na aprendizagem da Matemática? Quais as tensões e conflitos na aprendizagem da Matemática?

Analisar as metodologias de ensino e as dificuldades da aprendizagem dos alunos do segundo ano do Ensino Médio, é o principal objetivo deste trabalho, entre outros: conhecer os fundamentos das orientações curriculares sobre o ensino da Matemática; descrever os planejamentos de aulas em relação ao ensino da Matemática; caracterizar as práticas pedagógicas e as metodologias de ensino; identificar as dificuldades dos alunos na aprendizagem da Matemática e determinar tensões e conflitos na aprendizagem da Matemática.

Justificam tais objetivos a existência de alunos com graves déficits de dificuldades de aprendizagem ou de ensino, principalmente em Matemática, o que faz com que todos os profissionais da educação, inclusive o professor, se tornem abismados e impotentes e com um amargo sabor de que eles são incapazes de resolver, ou pelo menos, diminuir tal problema, já que o sistema educacional, segundo eles, não oferece um mínimo suporte curricular, condições e autonomia de trabalho para tal situação que, eventualmente, compromete o futuro educacional de seus alunos no âmbito dos números, isto é, da Matemática.

Está mais que sabido e provado que a Escola sofre grandes reflexos do ambiente social, cultural etc., logo, a dificuldade dos alunos em aprenderem Matemática é assunto em debate, constantemente, por professores de Matemática e estudiosos nacionais e internacionais. Os questionamentos são diversos: por que a falta de empatia e, consequentemente, dificuldade em relação à Matemática? Quais são as possíveis soluções para sanar ou, pelo menos, diminuir este problema?

Para isso, o que não faltam são as mais diversas explicações: ambiente inadequado (falta de estrutura), excesso de alunos em sala de aula, falta de conhecimento sobre o projeto implementado pelo sistema de ensino público, falta de conhecimento do Projeto Político Pedagógico (PPP) da Unidade Escolar, metodologias arcaicas e ultrapassadas que não contemplam a realidade da comunidade escolar atual (aluno), professores com precária formação, um déficit estrutural familiar, falta de acompanhamento de pais/responsáveis dos alunos em sua vida escolar, entre outras.

Raras não são as vezes que são presenciadas as contínuas reclamações de professores de Matemática quanto às vultosas e inúmeras dificuldades manifestadas pelos seus alunos com foco na aprendizagem dessa disciplina tão polêmica. Também não são raras as vezes que são ouvidas, não só de alunos, como de qualquer pessoal, que é grande seu problema com a Matemática, nunca estão satisfeitos e que acham a matéria difícil e pouco interessante e, consequentemente, os professores se frustram com os resultados avaliativos de seus alunos. Sabe-se que se vive em um Mundo, cada vez mais Matemático, mas seu ensino está falho, parado, necessitando ser impulsionado, modernizado para atender a realidade cotidiana do aluno e da sociedade.

Ainda neste sentido Eber (2010) afirma que:

"Todo e qualquer avanço neste tipo de tecnologia necessita profundos conhecimentos técnicos e científicos a fim de trazer os conhecimentos para o dia a dia da população (EBER, p.45, 2010).” 


\section{METODOLOGIA}

$\mathrm{O}$ enfoque desta pesquisa foi do tipo descritivo e explicativo. Elege-se esta modalidade porque se apresenta como resposta aos objetivos e que trabalhará uma realidade que se está estudando. Nesse sentido, a pesquisa descritiva explicativa, segundo Aranda (2018, p.156), para além de possibilitar que se possam trazer dados sociais relevantes, contribuindo e dando luz aos outros dados, também identifica:

Formas de comportamento, conhecendo percepções, determinando o grau de concordância ou discordância, estabelecendo preferências, etc.; descobrir e verificar possíveis associações entre variáveis e identificar características da população em estudo (ARANDA, 2018, p. 156).

Nesse sentido, a metodologia eleita nesta investigação é qualitativa-quantitativa. Em relação à pesquisa qualitativa, Minayo (2011) mostra como esta tipologia de pesquisa colabora na análise da construção da realidade, permitindo que emerjam desta realidade as crenças, os valores que não podem ser quantificados. Daí a importância do enfoque misto, porque agrega esta técnica à quantitativa e possibilita um outro olhar, que juntos se completam.

Os instrumentos de validade desta investigação foram os questionários e as entrevistas estruturadas para os alunos. Trabalha-se com uma pesquisa piloto, com dez alunos, no intuito de perceber se os questionários estavam sendo compreendidos. Nessa forma, a pesquisa alcançou o enfoque ético que deu uma clareza acerca das respostas e confiança quanto aos dados colhidos. Utilizou-se também um Termo de Consentimento para Direção Escolar, alunos e pais.

Após a coleta de dados, a partir dos instrumentos eleitos para a recolha dos dados, previamente estruturados e aplicados em relação aos sujeitos de pesquisa, partiu-se para a etapa relevante do procedimento de análise da realidade eleita para a pesquisa: a análise e discussão destes dados coletados.

A pesquisa foi realizada entre os dias 14 e 18 de outubro de 2019. Para esta investigação foram eleitos 73 alunos, matriculados no Ensino Médio, em 2019, no segundo ano, do turno matutino, da Escola Estadual, situada no município de Várzea Grande/MT, distribuídos em cinco classes. A idade ficou entre 14 e 18 anos. O critério de inclusão consistia no fato de estarem em sala de aula, ou seja, serem alunos regulares do segundo ano matutino do Ensino Médio, no ano de 2019, da escola pesquisada.

Primeira Fase: Procedimentos Preliminares - em um primeiro momento foi realizada uma pesquisa bibliográfica acerca da temática em estudo (LAKATOS; MARCONI, 2021; CERVO; BERVIAN, 2002; CHIZZOTTI, 2017) em seguida foi realizado o levantamento da literatura pertinente para a construção do aporte teórico, sustentado pelos autores que trabalham os conceitos elencados nas categorias eleitas para esta investigação.

Segunda Fase: Análise da Informação e Resultados por fim se procedeu a análise dos dados, através da compilação dos mesmos e discussão. Apresentação de sugestões e possibilidades de novas investigações, que possam verticalizar os estudos nesta temática.

\section{RESULTADOS}

Em um primeiro instante se realizou uma pesquisa no sentido de averiguar e levantar as causas da dificuldade que o aluno apresenta em aprender Matemática, assim como averiguar a problemática levantada. Nesse sentido, ficou ratificado que a dificuldade de aprendizagem da Matemática é um dos maiores problemas e desafios do sistema educacional Matemático. Foi detectado, também, que esta é uma realidade que vai desde a base do ensino até o final do Ensino Médio e que pode progredir pelo resto da vida estudantil do indivíduo.

A pesquisa buscou identificar se os alunos têm problemas ou dificuldades de aprendizagem da Matemática e que tipo de dificuldades/problemas apresentam; constatouse que, na realidade, os alunos apresentam dificuldades natas de aprender, de compreender e de gostar da Matemática. E os motivos foram diversos, tais como: o aluno não gostar da disciplina ou de quem a ministra (professor); dificuldades de entrosamento com os colegas; método ou estratégia ineficiente usado pelo professor, que não auxilia o aluno em motivação da compreensão e aprendizagem da Matemática, gerando, assim, falta de interesse em aprender; falta ou pouco acompanhamento e apoio da família nas atividades escolares extraclasse; deficiência do ensino da Matemática na base educacional de ensino; falta de interesse pessoal do aluno e outros. Assim, acredita-se que o objetivo foi alcançado.

Com base nos resultados dos questionários aplicados para aqueles alunos se pode afirmar que uma pequena maioria manifestou a culpabilidade de uma não compreensão satisfatória de aprendizagem da Matemática, um tanto a desejar em relação às práticas pedagógicas dos professores. Isso pode ser ilustrado no baixo rendimento do questionário sobre o conteúdo de Trigonometria, em que apenas $45,7 \%$ dos alunos ficaram acima da média da nota de $60 \%$. Diante desse ponto, em específico, também houve menção de pontos positivos relevantes nas afirmações sobre as diversas metodologias e no uso de recursos didáticos pedagógicos utilizados pelo professor nos anos anteriores de estudo. Assim, acredita-se que o objetivo foi alcançado.

As causas ou fatores, que impedem ou facilitam a aprendizagem da Matemática, se apresentam como um dos objetivos traçados neste estudo, o que também foi alcançado. Embora considerado unânime, pelos alunos investigados, de que a Matemática seja um componente curricular importante, ainda foram constatados que os principais motivos para sua aprendizagem envolvem: o desinteresse do aluno; falta de apoio do meio social familiar; as inadequadas práticas didáticas utilizadas pelos professores, em sala de aula, inclusive, nos anos iniciais; dificuldade de relacionar a Matemática com o cotidiano, em função de sua complexidade de compreensão; não considerar que a Matemática é sempre útil e a falta de sua empatia.

Para a execução deste trabalho foram eleitos como sujeitos 73 alunos, integrantes do segundo ano do Ensino Médio do turno matutino, da Escola Estadual, situada no município de Várzea Grande/MT, distribuídos em cinco classes, e que foram convidados a participar, voluntariamente, respondendo um questionário impresso sobre a Matemática, contendo 10 (dez) perguntas, objetivando a recolha de informação referente às opiniões/visões do tema exposto, os alunos levaram, em média, três horas para responderem ao questionário. Os dados são apresentados compilados na Tabela 1. 
Tabela 1 - Opiniões e visões dos alunos sobre a Matemática

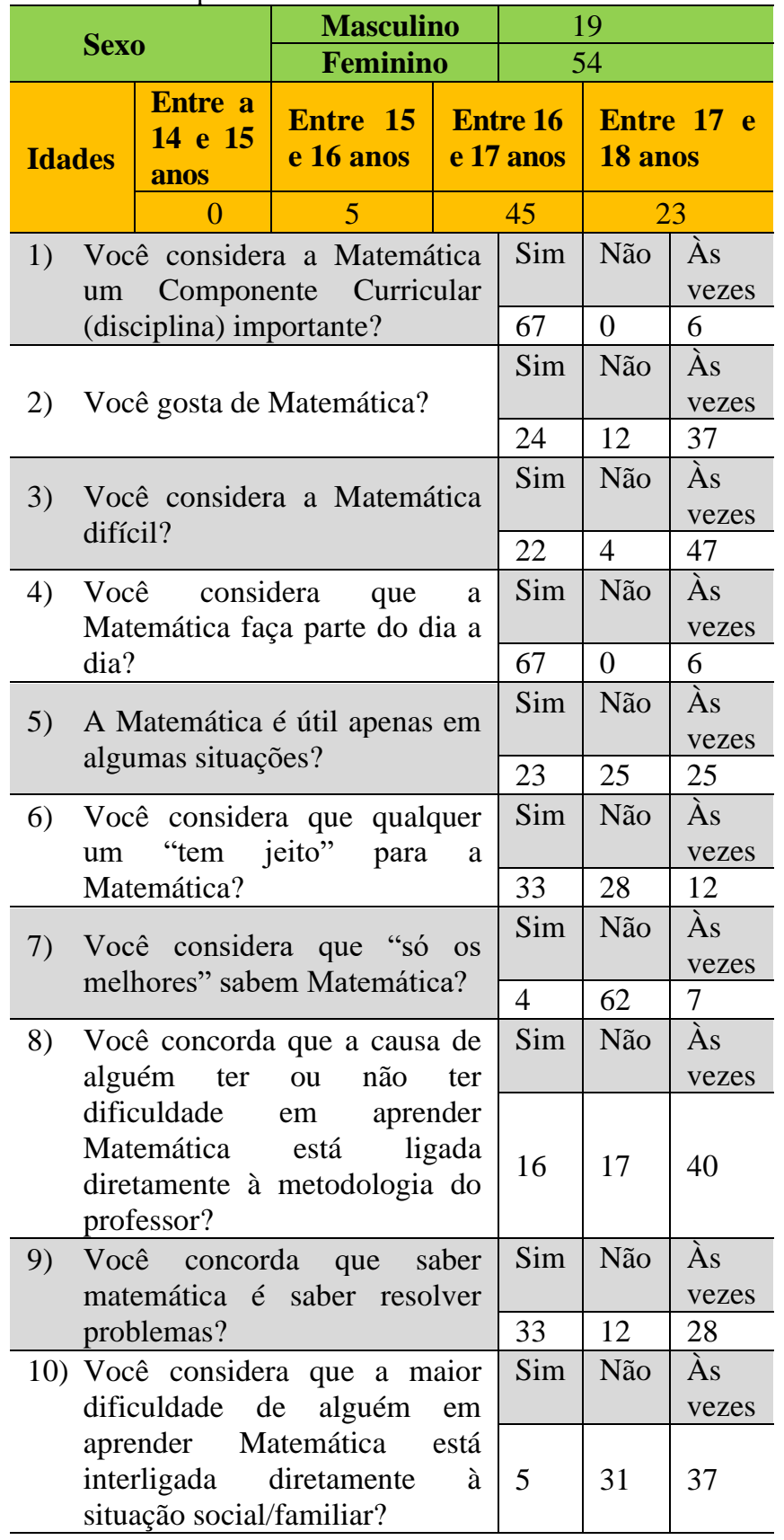
Fonte: Dados da pesquisa, 2019.

Dos sujeitos participantes da pesquisa, 67 (92\%) consideram que a Matemática seja um importante componente curricular, assim como o gostar e a sua importância em seu dia a dia, embora a considerem difícil. Observa-se aqui um dado imprescindível para compreender a dificuldade de aprendizagem da Matemática. Outro dado relevante é que 47 (64\%) dos alunos pesquisados consideram que, às vezes, enfrentam dificuldades, e essa está ligada diretamente às práticas pedagógicas dos professores e $42(57 \%)$ consideram que tal dificuldade está ligada à situação social e familiar (sim e às vezes). A dificuldade de aprendizagem em Matemática pode se manifestar em relação ao desenvolvimento cognitivo e a construção da experiência Matemática; do entendimento de noções básicas e princípios numéricos; do entendimento da numeração à prática das operações básicas, quanto à mecânica e/ou à compreensão do significado das operações (SANCHEZ, 2004).
Por se tratar de alunos do Ensino Médio se percebe um número bem mais elevado de alunos com idade de 16 anos, ficando o mediano as idades $>17$ anos e em que a minoria ficou em 15 anos.

$77 \%$ dos alunos (sim e às vezes \%) atribuem que a metodologia do professor está diretamente ligada à causa de terem ou não dificuldades em aprender Matemática.

Com o elevado percentual de $92 \%$, que consideram a Matemática importante como componente curricular, 33\% dos alunos afirmaram ( $\operatorname{sim}$ ) que gostam da Matemática, um paradoxo. Se quase a totalidade dos alunos pesquisados considera importante a Matemática, como componente curricular, e enquanto bem mais da metade não são simpáticos com a Matemática, percebe-se uma certa contradição, a qual pode ser explicada pela grande maioria (94\%) desses alunos não achar difícil a Matemática e, também, pela grande maioria $(92 \%)$ considerar que essa faz parte do dia a dia.

Ao se verificar que 45 (62\%) alunos (sim e às vezes) consideram que qualquer um "tem jeito" para a Matemática e apenas quatro $(5 \%)$ alunos afirmaram que consideram que "só os melhores" sabem Matemática, é perceptível uma relevância nos dados levantados. Se uma pessoa "tem jeito" para a Matemática, ela não é considerada "o melhor".

Em seguida, conclui-se que a causa de ter ou não dificuldade em aprender Matemática está diretamente ligada à metodologia do professor. Para 56 (77\% - sim e às vezes) alunos pesquisados, a dificuldade de o aluno aprender Matemática é causada pela metodologia aplicada pelo professor. É imprescindível ressaltar que muito se fala em "culpa". O Estado não culpa os professores pelas falhas na aprendizagem desses alunos, mas ressalta que eles também têm responsabilidade. Cabe, então, perceber qual é o tamanho dessa responsabilidade e como essa está fracionada. Quanto ao professor, ele tem que estar ciente de que a culpa do aluno não aprender não é única e exclusiva sua, mas que tem uma considerável parcela, por ser o protagonista dessa aprendizagem.

Finaliza-se com a última pergunta e fazendo uma correlação com a anterior, em que se percebe que 42 (58\% sim e às vezes) alunos consideram que a maior dificuldade de alguém aprender Matemática está interligada diretamente à situação social/familiar. Dessa forma, respondendo às questões anteriores se pode concluir que uma fração da culpabilidade acerca da aprendizagem do aluno fica para a família. Possivelmente, a outra fração de $42 \%$ fica aos profissionais da educação. Esta responsabilidade profissional não vem do nada, vem de um processo maciço de formação que não se encontra, ainda, nas Instituições Educacionais Superiores, e nem nos processos de formação continuada, que é oferecida pelas esferas Municipal, Estadual e Federal.

A metodologia do professor ao transmitir o conteúdo faz toda a diferença na contribuição das dificuldades ou facilidades de o aluno compreender a Matemática. Mais da metade dos alunos atribuiu a responsabilidade da prática usada pelo professor para as dificuldades ou facilidades em aprender Matemática. Ratificado pelas respostas dos alunos, a falta de interesse aparece também em destaque. Como aprender se falta interesse? As políticas educacionais praticadas pelo Ministério da Educação e Cultura nem sempre vêm contribuindo para o desejo de aprender.

Ficou nítido, mais uma vez aqui, que a Matemática, possivelmente, seja uma das disciplinas mais temidas pelos 
alunos, seja pelos seus complexos cálculos, ou seja, pela forma ou metodologia que o professor usa em sala. Percebese, também, uma certa divisão na percepção dos alunos pesquisados sobre a dificuldade ou facilidade em aprender Matemática. Não foi difícil visualizar, nas respostas de tais alunos, que a massificação do ensino e a formação continuada precária dos professores levaram o matemático a triplicar suas falhas em seus métodos de ensino e, porque não sair do controle na verbalização de suas aulas, tratamento individualizado do seu aluno e, principalmente, o despreparo e a irritabilidade com toda essa situação, transmitindo, involuntariamente, aos seus alunos.

A Matemática se torna um obstáculo para o aluno, quando no momento em que ele mais necessita não lhe é satisfatório, como nos concursos, nos vestibulares, no Enem e em muitos outros momentos de sua vida escolar ou pessoal/profissional cotidiana.

A deficiência de aprendizagem na base, a falta de conhecimento da real importância da Matemática em seu cotidiano, métodos variados e inovadores de ensino usados pelo professor, linguagem condizente com a realidade, desinteresse e a falta de incentivo dos pais/família são algumas possíveis causas, que levam o aluno a ter uma maior dificuldade ou interesse em aprender e compreender a Matemática.

Para Lopes e Ferreira (2013), a busca da qualidade não é algo novo, como muitos podem pensar, alegando ser "modismo". Se de repente houver mais investimento e valorização profissional na área da Educação, essa realidade pode se transformar. $O$ aluno pode ter outra visão da Matemática, do professor, da escola. Essas dificuldades podem ser sanadas ou, pelo menos, regredirem.

Quando o aluno diz que "poderia ter sido bem melhor", referindo-se à metodologia de ensino do professor e "falta de qualificação dos professores", ele está clamando uma solução para a educação, uma maior valorização profissional. Ele está dizendo que a saída está mais próxima do que se imagina, está dizendo que o Mundo mudou, que a transformação plena da educação está nas mãos do Sistema Educacional. Está dizendo que há muito o que se fazer para uma melhor e maior compreensão da Matemática e do ensino de forma geral.

\section{CONCLUSÃO}

Ao finalizar este artigo, cujo objetivo principal foi identificar as causas cruciais determinantes que dificultam a aprendizagem da Matemática, especificamente, no Ensino Médio, enfatizando as discussões sobre o fracasso escolar, no sentido de encontrar possibilidades para solucionar tal problema. Acredita-se ter concluído com êxito os propósitos previamente elencados, os quais foram pautados por referências teóricas que deram sustentação ao tema principal. Neste estudo, um objetivo pautado foi o de verificar se a prática metodológica de ensino da Matemática, utilizada pelo professor, é adequada para a aprendizagem do aluno, observadas as dificuldades na aprendizagem deste componente escolar.

Um objetivo exitoso deste estudo está no quesito de relacionar a dificuldade de alguém aprender Matemática e a ligação direta com o meio social familiar. Foi colocado pelos alunos que esta ligação é bem pequena, porém fica a cargo do próprio aluno, quando se mostra desinteressado em aprender. Logo, partindo do princípio de que a família é um dos personagens mais essenciais pela aprendizagem, de modo geral do aluno, eis um forte aliado do aluno para diminuir ou sanar as dificuldades em aprender Matemática. Considerando, ainda, que esse meio constrói uma inabalável base, que é imprescindível como apoio ao estudante.

Ao final da pesquisa foram identificadas as causas cruciais e determinantes da dificuldade de aprendizagem da Matemática, especificamente, no Ensino Médio, na confirmação das hipóteses principais: complexidade da disciplina, interesse na aprendizagem, apoio da família, práticas metodológicas inadequadas, falta de recursos didáticos específicos, estrutura precária, inexistência de formação continuada específica aos professores de Matemática, deficiência generalizada da escola pública (fracasso escolar). Há uma necessidade urgente e eficaz do trabalho conjunto entre Escola/Família, que deve ser trabalhado no âmbito escolar, em uma relação de responsabilidade e comprometimento recíprocos pela aprendizagem do aluno, rumo a um resultado de excelência.

Analisando uma outra situação, se o professor utilizar formas metodológicas ou estratégias para motivar o aluno e gerar o processo de atenção, de compreensão e de aprendizagem eficientes, averiguou-se que, apesar dos esforços, ainda precisa de inovações e de adequações nesta área, a função do professor não deve ser apenas em produzir ou reproduzir saberes, mas intervenções, práticas motivacionais e ter sensibilidade para detectar que tipo de dificuldade o aluno está tendo e solucionar, em uma metodologia abrangente, questionadora e formadora.

Assim, a ressignificação da aprendizagem do aluno passa por esses métodos e práticas educacionais, que estão se tornando, cada vez mais, tão escassas nos últimos tempos. Recomenda-se que o Coordenador Pedagógico, professor e alunos desenvolvam um plano de aula em conjunto, com base na realidade do aluno, objetivando um melhor e maior desempenho da aprendizagem. E, ao avaliá-lo, respeite-se seu contexto histórico social e suas limitações cognitivas. Conclui-se, aqui, que o aluno deve ser considerado e tratado em sua individualidade.

O professor de Matemática deve ministrar suas aulas se preocupando com os fatores individuais do aluno, como por exemplo, o tempo de aprendizagem de cada aluno, suas dificuldades ou empecilho de aprender e de compreender e resolver cálculos ou problemas matemáticos ou de raciocínio lógico. Depois de ter levantado os problemas de dificuldades em aprender Matemática se recomenda que compete ao professor dinamizar as oportunidades para que o aluno possa refletir sobre o conhecimento que possui, tomando consciência sobre o conhecimento que construiu e os processos que o levaram a esta construção. Diante desta concepção, o educador poderá identificar tais dificuldades.

\section{REFERENNCIAS}

ARANDA, T. J. C. Metodologia de la investigacion cientifica: manual para elaboracion de tesis e trabajos de investigación. Marben Editora: Assunción, Paraguay, 2018.

CERVO, A. L. BERVIAN, P. A. Metodologia científica. 5.ed. São Paulo: Prentice Hall, 2002.

CHIZZOTTI, A. Pesquisa em ciências humanas e sociais. 12. ed. São Paulo: Cortez, 2017.

CRESWELl, J. W. Projeto de pesquisa: Métodos qualitativo, quantitativo e misto. 5. ed. Artmed, 2021. 
IPEA - INSTITUTO DE PESQUISA ECONÔMICA APLICADA. Texto para discussão. Indicadores de ensino básico brasileiros relativos aos objetivos de desenvolvimento sustentável numa perspectiva internacional comparada. Milko Matijascic e Carolina Esther Kotovicz Rolon. Brasília, março de 2020.

LAKATOS, E. M.; MARCONI, M. A. Fundamentos metodologia científica. 9. ed. São Paulo: Atlas, 2021.

LOPES, L. S.; FERREIRA, A. L. A. A História da Matemática em Blog: a formação inicial do professor. In: XI ENEM - Encontro Nacional de Educação Matemática, 2013, Curitiba. Anais... XI Encontro Nacional de Educação Matemática: Educação Matemática - Retrospectivas e Perspectivas. Guarapuava: Sociedade Brasileira de Educação Matemática/Regional Paraná, 2013. p. 1-15.

MATO GROSSO. Escola Ciclada de Mato Grosso: novos tempos e espaços para ensinar. Cuiabá/MT: Seduc, 2000.

MINAYO, M. C. S. Ciência, técnica e arte: o desafio da pesquisa social. In: Pesquisa Social: teoria, método e criatividade. 1. ed. Petrópolis, Rio de Janeiro: Vozes, 2011.

NACARATO, A. M.; MENGALI, B. L. S.; PASSOS, C. L. B. A matemática nos anos iniciais do ensino fundamental: tecendo fios do ensinar e do aprender. 3. ed. Belo Horizonte: Autêntica, 2019.

SANCHEZ, J. N. G. Dificuldades de Aprendizado e Intervenção Psicopedagógico. Porto Alegre: Artmed, 2004.

UN - UNITED NATIONS. The Sustainable Development Goals, 2015.

UNESCO - ORGANIZAÇÃO DAS NAÇÕES UNIDAS PARA A EDUCAÇÃO, A CIÊNCIA E A CULTURA. Rendre des comptes en matière d'éducation: tenir nos engagements. Rapport mondial de suivi sur l'education. Paris: UNESCO, 2017.

\section{COPYRIGHT}

Direitos autorais: Os autores são os únicos responsáveis pelo material incluído no artigo. 


\author{
Revista SODEBRAS - Volume 16 \\ $\mathrm{N}^{\circ} 187-\mathrm{JULHO} / 2021$
}

\title{
PROPOSTA DE APLICAÇÃO DA METODOLOGIA 5S EM LABORATÓRIO DE PROCESSAMENTO DE MATERIAIS COMPÓSITOS
}

\author{
PROPOSAL OF THE APPLICATION OF THE 5S METHODOLOGY IN A \\ COMPOSITE MATERIAL PROCESSING LABORATORY
}

\author{
NATASHA MARTINS RODRIGUES DE JESUS ${ }^{1,3}$; RAFAEL SOARES SOUZA ${ }^{1,2}$; \\ RITA DE CASSIA MENDONÇA SALES-CONTINI ${ }^{1}$; \\ TEÓFILO MIGUEL DE SOUZA'; THAIS SANTOS CASTRO ${ }^{3}$ \\ 1 - FACULDADE DE TECNOLOGIA DE SÃO JOSÉ DOS CAMPOS - PROFESSOR JESSEN VIDAL; \\ 2 - INSTITUTO FEDERAL DE EDUCAÇÃO, CIÊNCIA E TECNOLOGIA DE SÃO PAULO; \\ 3 - UNIVERSIDADE ESTADUAL PAULISTA \\ natashamartinsj@outlook.com; rsoares1995@gmail.com; rita.sales@fatec.sp.gov.br; teofilo.souza@unesp.br; \\ thais.castro@unesp.br
}

\begin{abstract}
Resumo - O objetivo deste artigo foi gerar o projeto de aplicação do método de administração japonesa que reúne os sensos de utilização, organização, limpeza, normalização e disciplina conhecido como metodologia $5 S$ para melhorar a produtividade, otimizar o trabalho e a aumentar a segurança de um laboratório de pesquisa e tecnologia na área de materiais compósitos. Para este trabalho adotou-se como passos metodológicos, a coleta de dados que foi realizada por meio de um estudo do local antes da sua aplicação, sessões de brainstorming, auditorias e observações sobre o processo de trabalho do grupo de pesquisa. E por último foi definido um modelo de trabalho para criar uma estrutura $5 \mathrm{~S}$ e um processo de aplicação também foi estabelecido. Utilização dessa metodologia, o laboratório foi adaptado para as condições de segurança e saúde necessárias e incorporada uma nova rotina de organização. Com o trabalho finalizado, foi possível chegar a uma conclusão de quais os desafios a serem enfrentados $e$ os ganhos obtidos no processo.
\end{abstract}

Palavras-chave: Materiais Compósitos. Laboratório. PDCA.

Abstract - The objective of this article was to generate the project for the application of the Japanese administration method that brings together the senses of use, organization, cleanliness, standardization and, discipline known as $5 S$ methodology to improve productivity, optimize work and increase the safety of a laboratory. research and technology in composite materials. For this work, it was adopted as methodological steps, the collection of data that was carried out through a study of the place before its application, brainstorming sessions, audits, and observations about the work process of the research group. Finally, a working model was defined to create a $5 S$ structure and an application process was also established. Using this methodology, the laboratory was adapted to the necessary health and safety conditions and incorporated a new organizational routine. With the work completed, it was possible to reach a conclusion of the challenges to be faced and the gains obtained in the process.

Keywords: Composite Materials. Laboratory. PDCA.

\section{INTRODUÇÃO}

Segundo Silva e Mendoza (2020), ressalta a grande importância da formação de um aluno em uma instituição de ensino superior, tendo como principais ganhos, pesquisas e projetos que podem ser direcionados diretamente para utilização de forma positiva para a sociedade. Segundo Severino (2017) as instituições de ensino superior têm três principais objetivos dos quais seriam a formação profissional dentro de diversas áreas, a formação de cientistas para os diversos setores e a formação de pessoas em relação a questão social. Mesmo com essas importantes funções, têm se notado uma questão crítica na adoção de práticas para melhorar a produtividade e a eficiência dos processos universitários.

Os motivos para a adoção lenta da natureza descentralizada destas instituições incluem: falta de knowhow sobre o assunto, aplicação de ferramentas da qualidade em ambiente de ensino; desinteresse por parte da comunidade docente e, geralmente, da alta administração; o pouco tempo disponível dos professores; a resistência das pessoas envolvidas no setor a mudanças de paradigma e novos procedimentos; e, a falta de pressão da sociedade. Isso torna um desafio orientar a implantação de novas práticas (MARINHO, GONÇALVES e KIPERSTOK, 2014).

De acordo com Hes e Benjamin (2015), como resultado, há pouca pesquisa disponível sobre como as metodologias de melhoria contínua, como por exemplo o lean manufacturing, podem contribuir para aperfeiçoar os processos dentro das universidades. Deve-se isso ao fato de se ter à visão de que essas práticas são aplicáveis somente no setor de manufatura e serviços, não sendo aplicáveis ao setor de ensino.

No entanto, segundo Simons (2013), a metodologia lean pode ser implantada da mesma maneira do que em qualquer outra indústria, incluindo processos acadêmicos e não acadêmicos. A aplicação de princípios e práticas lean oferecem para as universidades, oportunidades para realizarem melhorias significativas na forma como o ensino superior e os seus serviços de apoio são entregues, assegurando a continuidade da relevância de seis universidades em nossa estrutura societária (DOMAN, 2011). A implementação do lean tem como principal 
objetivo aprimorar a qualidade dos processos, segundo Silva et al, (2020) demonstrou em sua pesquisa o conceito de qualidade baseando-se em Armand Vallin Feigenbaum, definindo a qualidade como "a qualidade é o que o cliente diz que é", ou seja, qualidade se resume em a organização direcionar seus esforços para agradar o cliente.

Para que estas barreiras sejam vencidas, inicialmente devem ser propostas pequenas mudanças diárias nas operações, incorporando novas rotinas. Assim, ações de indivíduos e pequenos grupos podem ajudar a induzir o processo (MARINHO, GONÇALVES e KIPERSTOK, 2014).

Neste contexto, o $5 \mathrm{~S}$ destaca-se por ser uma das metodologias lean mais conhecida, de fácil aplicação e amplamente utilizada quando se refere a processos de melhoria. O principal motivo para isso é que os resultados provenientes da sua implantação surgem imediatamente e estão bem destacados (HO, 1998).

O $5 \mathrm{~S}$ pode ser facilmente adotado e contribui para a relação custo-benefício ao maximizar produtividade, melhorando a saúde e segurança no ambiente de trabalho (GAPP, FISHER e KOBAYASHI, 2008). A implementação da metodologia $5 \mathrm{~S}$ em laboratórios de uma universidade veio através de JIMÉNEZ et al. (2015). A nova cultura resultou em uma melhoria do ambiente de trabalho e um aumento na motivação da equipe envolvida. Os laboratórios que foram adaptados às condições de saúde e segurança; ocorreu uma redução de erros sistemáticos; aumentou o espaço disponível; reduziu o tempo de busca de materiais; e, melhorou o aproveitamento dos recursos, resultando na redução de custos.

Sendo assim, o objetivo deste estudo foi desenvolver uma projeção de aplicação da metodologia $5 \mathrm{~S}$ em um laboratório de pesquisa tecnológica na área de materiais compósitos a fim de melhorar a produtividade, otimizar o trabalho do grupo de pesquisa e aumentar a saúde e segurança do ambiente de trabalho.

\section{METODOLOGIA}

Como principal fundamento, sabe-se a organização e otimização dos recursos internos de modo inovador e o aproveitamento de oportunidades que o mercado oferece, alcança-se uma base essencial para edificação de uma qualificação diferencial competitiva da organização (MOTTA et al., 2021). Oliveira e Melo (2020) afirma a existência de múltiplas ferramentas elaboradas e implementadas nas indústrias para promover a qualidade. Entre elas encontra-se o método de organização $5 \mathrm{~S}$, e em conjunto para otimização do planejamento o método $5 \mathrm{~W} 2 \mathrm{H}$ e para a proposta de aplicação da melhoria continua o ciclo PDCA.
O projeto foi realizado em um laboratório de materiais compósitos de uma instituição de ensino superior. Neste laboratório foi implementada a metodologia $5 \mathrm{~S}$ onde são desenvolvidas pesquisas tecnológicas na área de processamento e reciclagem de materiais compósitos. Neste laboratório também são ministradas aulas práticas para alunos dos cursos de áreas correlatas a Manutenção de Aeronaves, Projetos de Estruturas Aeronáuticas e Automação e Manufatura Digital.

De acordo com Santana e Loureiro (2020) aplica-se o método $5 \mathrm{~W} 2 \mathrm{H}$ com o propósito de auxiliar no planejamento das ações. A metodologia utilizada para auxiliar o planejamento e ações em todas as etapas de implantação do programa foi o Método $5 \mathrm{~W}$ e $2 \mathrm{H}$. Segundo Faria e Longhini (2021) consiste em uma técnica de estruturação de ações, considerando os seguintes questionamentos sobre o que deve ser feito: WHAT? (O QUE?), WHY? (POR QUÊ?), WHO? (QUEM?), WHERE? (ONDE?), WHEN? (QUEM?), HOW? (COMO?), HOW MUCH (QUANTO CUSTA?), em cada situação ou problema, de acordo com o proposto por Rebello (2005). Aplicando essa técnica na elaboração de um plano de ação, a chance de sucesso na fase de execução aumenta consideravelmente, pois a ação fica mais clara.

Com o propósito de diagnosticar a situação do laboratório, detectando-se os principais problemas, causas, possíveis soluções, visando conhecer os recursos disponíveis e estabelecer as prioridades será realizado um levantamento sobre os equipamentos (estado de conservação, frequência de uso), consumíveis (tipos, quantidade, uso) e mobiliário existente através de observações do ambiente do laboratório.

Um procedimento adotado será a entrevista com os alunos usuários do laboratório em relação a sua rotina operacional para identificar quais itens são críticos.

Para comparar e registrar os resultados, o ambiente será fotografado antes e após cada intervenção, com o brainstorming nas situações que serão citadas. O conceito do ciclo PDCA (Plan, Do, Check and Act) será utilizado para verificar necessidades de correções do processo de intervenção a cada etapa definida pelo cronograma de atividades.

\section{III.RESULTADOS}

\section{1 - Aplicação do método de qualidade $5 W$ e $2 H$ para estudo de caso e melhoria do estado atual}

Para aplicação do $5 \mathrm{~W}$ e $2 \mathrm{H}$, observou-se as questões levantadas para melhor organização e layout estudado. Conforme a Tabela 1, compara e analisa os fatos observados. 
Tabela 1 - Ferramenta de qualidade 5W 2H

\begin{tabular}{|c|c|c|c|c|c|c|}
\hline $\begin{array}{l}\text { O QUE? } \\
\text { (WHAT?) }\end{array}$ & QUEM? (WHO?) & $\begin{array}{l}\text { QUANDO? } \\
\text { (WHEN?) }\end{array}$ & $\begin{array}{c}\text { ONDE? } \\
\text { (WHERE?) }\end{array}$ & $\begin{array}{l}\text { POR QUÊ? } \\
\text { (WHY?) }\end{array}$ & COMO? (HOW?) & $\begin{array}{l}\text { QUANTO } \\
\text { CUSTA? } \\
\text { (HOW } \\
\text { MUCH?) }\end{array}$ \\
\hline $\begin{array}{l}\text { Desordem do } \\
\text { Laboratório }\end{array}$ & $\begin{array}{l}\text { Todos que usam o } \\
\text { Laboratório }\end{array}$ & Todos os dias & $\begin{array}{l}\text { Laboratório de } \\
\text { processamento de } \\
\text { materiais } \\
\text { compósitos }\end{array}$ & $\begin{array}{l}\text { Falta de organização } \\
\text { e limitação na } \\
\text { realização de } \\
\text { experimentos }\end{array}$ & $\begin{array}{c}\text { Através da } \\
\text { organização do } \\
\text { local }\end{array}$ & $\begin{array}{c}\text { Objetivar } \\
\text { nenhum custo }\end{array}$ \\
\hline $\begin{array}{l}\text { Desordem dos } \\
\text { armários }\end{array}$ & $\begin{array}{c}\text { Todos que usam o } \\
\text { Laboratório }\end{array}$ & Todos os dias & $\begin{array}{l}\text { Laboratório de } \\
\text { processamento de } \\
\text { materiais } \\
\text { compósitos }\end{array}$ & Falta de organização & $\begin{array}{c}\text { Através da } \\
\text { definição e } \\
\text { separação de } \\
\text { materiais }\end{array}$ & $\begin{array}{c}\text { Objetivar } \\
\text { nenhum custo }\end{array}$ \\
\hline $\begin{array}{l}\text { Local de trabalho } \\
\text { inadequado }\end{array}$ & $\begin{array}{l}\text { Falta de técnico/ } \\
\text { orientado } \\
\text { para cuidar do } \\
\text { Laboratório }\end{array}$ & Todos os dias & $\begin{array}{l}\text { Laboratório de } \\
\text { processamento } \\
\text { de materiais } \\
\text { compósitos }\end{array}$ & $\begin{array}{c}\text { Falta de organização } \\
\text { e limitação na } \\
\text { realização de } \\
\text { experimentos }\end{array}$ & $\begin{array}{l}\text { Organização das } \\
\text { bancadas, ar } \\
\text { condicionado, } \\
\text { pedestal }\end{array}$ & $\begin{array}{l}\text { De acordo com } \\
\text { o orçamento }\end{array}$ \\
\hline $\begin{array}{c}\text { Bancadas } \\
\text { ocupadas por } \\
\text { caixas } \\
\text { guardando } \\
\text { materiais }\end{array}$ & $\begin{array}{l}\text { Falta de técnico/ } \\
\text { orientado } \\
\text { para cuidar do } \\
\text { Laboratório }\end{array}$ & Todos os dias & $\begin{array}{l}\text { Laboratório de } \\
\text { processamento } \\
\text { de materiais } \\
\text { compósitos }\end{array}$ & $\begin{array}{l}\text { Falta de organização } \\
\text { e limitação na } \\
\text { realização de } \\
\text { experimentos }\end{array}$ & $\begin{array}{l}\text { Organização e } \\
\text { localização de } \\
\text { materiais }\end{array}$ & $\begin{array}{c}\text { De acordo com } \\
\text { o orçamento }\end{array}$ \\
\hline $\begin{array}{l}\text { Chão ocupado por } \\
\text { sacolas guardando } \\
\text { retalhos de } \\
\text { reciclados }\end{array}$ & $\begin{array}{l}\text { Falta de técnico/ } \\
\text { orientado } \\
\text { para cuidar do } \\
\text { Laboratório }\end{array}$ & Todos os dias & $\begin{array}{l}\text { Laboratório de } \\
\text { processamento } \\
\text { de materiais } \\
\text { compósitos }\end{array}$ & $\begin{array}{l}\text { Limitação na } \\
\text { realização de } \\
\text { experimentos e } \\
\text { locomoção no } \\
\text { laboratório }\end{array}$ & $\begin{array}{c}\text { Através de } \\
\text { bombonas para os } \\
\text { retalhos }\end{array}$ & $\begin{array}{l}\text { De acordo com o } \\
\text { orçamento }\end{array}$ \\
\hline
\end{tabular}

Fonte: Autores, 2020.

- WHAT? - Foi necessária a realização de uma reestruturação do laboratório de processamento de materiais compósitos, ou seja, a criação e implementação de um novo layout e a aquisição de equipamentos adequados para os processos.

- WHY? - Com o laboratório organizado e com recursos, foi possível a realização de atividades didáticas práticas aos alunos e ainda possibilitará atividades extracurriculares na área de compósitos.

- WHO? - Esta reestruturação foi realizada pelos alunos designados para tal tarefa, juntamente a um responsável pelo laboratório com o auxílio da instituição.

- WHERE? - Foi aplicado no laboratório de processamentos de materiais compósitos.

- WHEN? - Quando a instituição prover recursos necessários para a implantação de tal projeto.

- HOW? - Este projeto foi realizado inicialmente com o desenvolvimento de uma proposta de reestruturação e organização do laboratório de processamentos de materiais compósitos, realizado por aluno designado.

- HOW MUCH? - Essa proposta em conjunto com a metodologia anterior envolve modificações no layout da sala e dos componentes que a estrutura, as mudanças são:

- armários para equipamentos e matéria prima;

- bancadas para os processos;

- mesa de escritório;

- bombonas;

- pedestal para roletes com tecidos e retalhos.

3.2 - Brainstorming e desenvolvimento do laboratório de processamento de materiais compósitos utilizando o software Catia V5®

O laboratório foi estudado e projetado virtualmente ergonomicamente correto e organizado, baseado no pensamento em que o profissional não desperdiçasse tempo com ações desnecessárias, ganhando movimentos e com o maior conforto. Desta forma aumentaria a produtividade diminuiria riscos de acidentes e os fatores que causavam a fadiga dos profissionais, sabendo que há movimentos repetitivos.

A ergonomia ocasionou-se com estudos e pesquisas na área da fisiologia do trabalho, especificamente em estudar fatores que causaram a fadiga no trabalho e no consumo energético provocado do mesmo modo, tendo como objetivo buscar soluções para tais problemas como, fisiologistas e psicólogos que tinham o propósito de colaborar no setor industrial, para que a produção tornasse aumentada sem adoentar profissionais (AMADIO e SERRÃO, 2011).

O layout sugerido para a modelagem foi de formato em linha, também conhecido em processo por produto, por ser um layout muito produtivo na área industrial e que tem relativamente alta produção em trabalhar por fluxo, e retrata em muitas outras áreas um ótimo desempenho em diversidades de produtos. O que favoreceria também na utilização do layout em outros processos.

\section{3 -Projeto e modelagem de um laboratório ergonomicamente correto como posto de trabalho para montagem de materiais compósito.}

Para dirimir riscos de acidentes e fatores que provocam a fadiga dos profissionais, sabendo que há movimentos repetitivos, foi possível estudar e projetar virtualmente um laboratório ergonomicamente correto e organizado baseado no pensamento em que o profissional não desperdice tempo com ações desnecessárias. Com isso ganhou-se movimentos com o maior conforto para o usuário.

Baseando-se na análise de fatores que causam a fadiga no consumo energético, buscou-se soluções para otimizar o desempenho e bem-estar humano e, do sistema como um todo. Através desses estudos e pesquisas na esfera da 
fisiologia do trabalho desenvolveu-se o conceito da ergonomia. Está ação foi realizada por fisiologistas e psicólogos que tinham o propósito de colaborar no setor industrial, para que a produção aumenta sem adoentar profissionais (AMADIO e SERRÃO, 2011).

$\mathrm{O}$ arranjo físico conhecido como processo por produto e, também como processo em linha trabalha com grandes volumes de encomenda/produto em fluxo contínuo, tanto na área industrial como também para diversas outras áreas e produtos. Dessa forma, foi proposta a utilização desta modelagem.

Na Figura 1 está enumerada os pontos da modelagem que foram realizadas alterações aplicando a metodologia do trabalho desenvolvido.

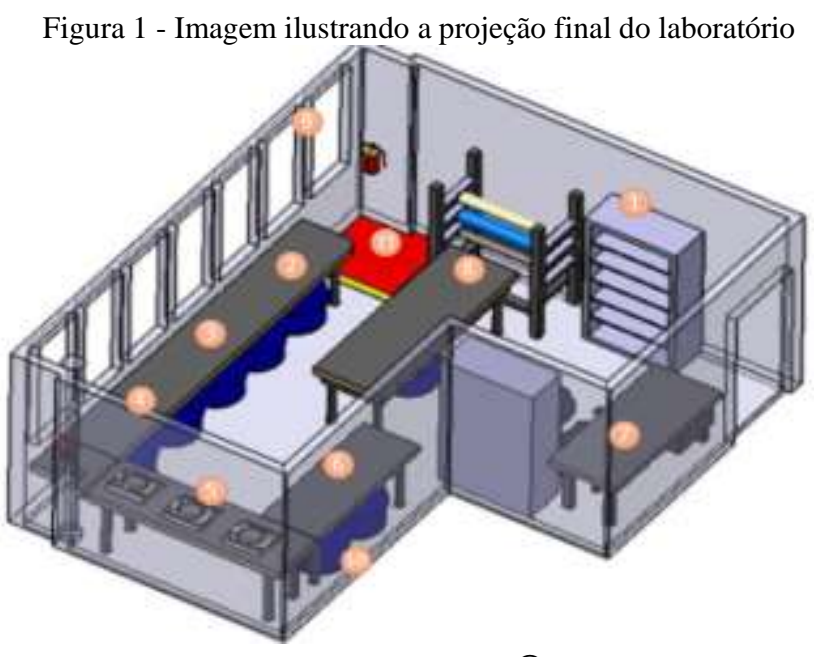

Fonte: Autores (Catia V5®), 2020.

Seguindo a mesma enumeração estão descritas todas as mudanças.

Item 1: Projeto e modelagem de um armário para matéria-prima e equipamentos. Reaproveitou e reconfigurou-se os armários do laboratório para suas especificidades. Cada armário foi direcionado para um uso específico: uma para uso e organização de matéria prima e papelaria dispondo de materiais utilitários, sendo que cada prateleira será reaproveitada e etiquetadas com todos os componentes e, o outro, para organização de equipamentos e ferramental. Os que são utilizados com bastante frequência é desejável que já tenham lugares definidos cada equipamento para não haver desperdícios de movimentos e de tempo procurando. Esse armário também foi reaproveitado e não necessitará de porta para facilitar a visualização dele como um todo, assim os equipamentos e ferramentas ficam mais fácil de serem visualizados.

Item 2: Projeto e modelagem de uma bancada para corte e laminação. O laboratório de Materiais Compósitos não possuía uma bancada adequada para o processo de laminação levando em conta quesitos de ergonomia considerando a área de trabalho, altura da bancada e luz adequada. Para que isto fosse possível, seria necessário projetar uma bancada dedicada para corte e laminação para o laboratório. Para atender os requisitos dos processos de laminação, esta bancada deverá ter 3500×254x945 mm para um melhor aproveitamento de espaço e movimentação do profissional. Desta forma, ainda sobrou espaço na bancada que pode ser utilizado nas operações subsequentes. A área útil para corte e laminação será de 2000x254x954 mm.
Item 3: Projeto e modelagem de uma bancada para usinagem; O laboratório de Materiais Compósitos não possui uma bancada adequada para o processo de usinagem levando em conta quesitos de ergonomia considerando a área de trabalho, altura da bancada e iluminação adequada. Para que isto seja possível, seria necessário projetar uma bancada dedicada às operações de usinagens para o laboratório. Para atender os requisitos dos processos de laminação, esta bancada deverá ter 1500x254x954 mm para um melhor aproveitamento de espaço e movimentação do profissional. Próximo à mesa de usinagem seria instalado um aspirador para a limpeza dos vestígios presentes a usinagem. As bancadas ocupariam toda a lateral do laboratório, seguindo o estudo do layout em linha. A colocação do aspirador de pó em cima da bancada, facilitaria a utilização do sugador no local da limpeza e seria aproveitado também, para realizar a limpeza no local da seladora quando solicitado.

Item 4: Projeto e modelagem de uma bancada seladora: O laboratório de materiais compósitos não possuía uma bancada adequada para o processo de selagem levando em conta quesitos de ergonomia considerando a área de trabalho, altura da bancada e iluminação adequada. Para que isto seja possível, seria necessário projetar uma bancada dedicada às operações para a seladora para o laboratório. Para atender os requisitos dos processos de laminação, esta bancada deverá ter 2200x254x954 mm para um melhor aproveitamento de espaço e movimentação do profissional.

Item 5: Projeto e modelagem de uma bancada para balanças de precisão. O laboratório de materiais compósitos não possuía uma bancada adequada para o processo de pesagem levando em conta quesitos de ergonomia considerando a área de trabalho, altura da bancada e iluminação adequada. Para que isto seja possível, seria necessário projetar uma bancada dedicada às operações para as balanças de precisão para o laboratório. Para atender os requisitos dos processos de laminação, esta bancada terá $1550 \times 254 \times 954 \mathrm{~mm}$ para um melhor aproveitamento de espaço e movimentação do profissional.

Item 6: Projeto e modelagem de uma bancada livre para atividades necessárias. O laboratório de materiais compósitos não possuía uma bancada livre para atividades que julgarem ser necessárias conforme o uso dela nos quesitos de ergonomia considerando a área de trabalho, altura da bancada e iluminação adequada. É notória que nessa área da sequência das bancadas, essa parte fique sem uma atividade específica justamente para que haja liberdade no espaço. Para que isto seja possível, seria necessário projetar uma bancada dedicada às operações para as atividades livres no laboratório. Para atender os requisitos dos processos, esta bancada sempre deverá ter $1550 \times 254 \times 954 \mathrm{~mm}$ para um melhor aproveitamento de espaço e movimentação do profissional.

Item 7: Projeto e modelagem de uma mesa de escritório: O laboratório de materiais compósitos possuía uma mesa de escritório que será reaproveitada para estar à disposição do uso de profissionais do local para atividades como monitoramento e arquivamento. Para atender os requisitos dessas atividades, esta mesa de escritório deverá ter 1550x670x690 mm para um melhor aproveitamento de espaço, movimentação e uso do profissional. 
Item 8: Projeto e modelagem de um pedestal para roletes das fibras e tecidos: O laboratório de materiais compósitos não possuía um pedestal para roletes adequado para o processo de retalhos de fibras, puxar, esticar e armazenar os tecidos, levando em conta quesitos de ergonomia considerando a área de trabalho e altura da bancada. Para que isto seja possível, seria necessário projetar um pedestal dedicado à organização e para facilitar o manuseio dos tecidos no laboratório. Para atender os requisitos dos processos de puxar, esticar e armazenar este pedestal deverá ter de 500x1500x1800 mm para um melhor aproveitamento de espaço e movimentação do profissional. O pedestal será acoplado em uma bancada para o apoio e estiramento dos tecidos. Essa bancada deverá dar suporte ao pedestal e a área ocupada por essa bancada necessitará de 2000x670x954mm.

Item 9: Projeto e modelagem de um ar-condicionado: O laboratório de materiais compósitos não possui arcondicionado, mas sendo necessário para a circulação e ventilação do laboratório. Sua importância se dá devido a limpeza dos ambientes para execução dos processos em um laboratório de materiais compósitos. O laboratório possui janelas viradas para a rua proporcionando a entrada de impurezas, tornando inviável a colocação de equipamentos de precisão em cima das bancadas de trabalho. As dimensões do ar-condicionado deverá ser as seguintes 500x250x100mm, que são ideais para um melhor aproveitamento de espaço e circulação de ar sem a necessidade de abrir as janelas. É necessário também fechar o telhado da sala com um revestimento com forro de PVC ou Isopor, para melhorar iluminação no laboratório. Para proteção dos equipamentos e matérias-primas que fiquem expostos a poeira e goteiras existentes no local.

Item 10: Projeto e modelagem dos reservatórios plástico rígido para retalho e rebarba: O laboratório de materiais compósitos não possuía reservatório plástico rígido. São necessários reservatórios de 180 litros com dimensões de $\varnothing 430 \times 700 \mathrm{~mm}$ ou reservatório de 200 litros com dimensões de $\emptyset 1000 \times 750$ mm. Eles são essenciais para servir de armazenagem de retalhos e rebarbas derivados residuais de processos de produção de materiais compósitos e posteriormente deverá ser reciclado. Dispostos adequadamente embaixo das bancadas para serem acessíveis aos usuários do laboratório que necessitar fazer descarte, são necessários oito tambores de 200 litros.

Item 11: Aplicação da NR12 e da NR23: É notória a necessidade na aplicação da NR12, pois há um extintor no laboratório longe da área demarcada. A Norma Regulamentadora 12 (GUIA TRABALHALISTA, 2019a) e a Norma Regulamentadora 23 (GUIA TRABALHISTA, 2019b) são direcionadas para o bem-estar e segurança do operador que trabalha com máquinas e/ou equipamentos. A seguir as normas que foram utilizadas neste trabalho.

\section{4 - A NR-12 Máquinas e Equipamentos}

A NR-12 tem como objetivo garantir a prevenção de acidentes e doenças do trabalho nas fases de projeto e de utilização de máquinas e equipamentos, estabelecendo referências técnicas, princípios fundamentais e medidas de proteção que devem ser observados para garantir a saúde e a integridade física dos trabalhadores.
12.1.5 É obrigatória a adoção de medidas de proteção para o trabalho em máquinas e equipamentos, capazes de garantir a integridade física e a saúde dos trabalhadores.

12.2.2 Os espaços em torno das máquinas e equipamentos devem ser adequados ao tipo de operação e ao tipo de máquina ou equipamento, de forma a prevenir a ocorrência de acidentes e doenças do trabalho.

12.2.2.1 Deve ser mantida uma distância mínima entre máquinas e equipamentos, em conformidade com suas características e aplicações, que garanta a segurança dos trabalhadores durante sua operação e manutenção, permitindo a movimentação dos segmentos corporais e respeitando a natureza da tarefa.

12.2.4 Os pisos dos locais de trabalho onde se instalam máquinas e equipamentos e os das áreas de circulação devem:

a) Ser mantidos limpos e ter características de modo a prevenir riscos provenientes de graxas, óleos e outras substâncias e materiais que os tornem escorregadios;

b) Ser mantidos livres de objetos, ferramentas e quaisquer materiais que ofereçam riscos de acidentes;

c) Ser nivelados e resistentes às cargas a que estão sujeitos.

12.13 Sinalizações

12.13.1.2 A sinalização das máquinas e equipamentos utilizados nos setores alimentícios, médicos e farmacêuticos deve respeitar a legislação sanitária vigente, sem prejuízo da segurança e saúde dos trabalhadores ou terceiros.

\section{5 - Localização e Sinalização dos Extintores.}

23.17.1 Os extintores deverão ser colocados em locais: (123.055-7 / I1)

a) de fácil visualização;

b) de fácil acesso;

c) onde haja menos probabilidade de o fogo bloquear o seu acesso.

23.17.2 Os locais destinados aos extintores devem ser assinalados por um círculo vermelho ou por uma seta larga, vermelha, com bordas amarelas. (123.056-5 / I1)

23.17.3 Deverá ser pintada de vermelho uma larga área do piso embaixo do extintor, a qual não poderá ser obstruída por forma nenhuma. Essa área deverá ser no mínimo de 1,00m x 1,00m (um metro x um metro). (123.057-3 / I1)

23.17.4 Os extintores não deverão ter sua parte superior a mais de $1,60 \mathrm{~m}$ (um metro e sessenta centímetros) acima do piso. Os baldes não deverão ter seus rebordos a menos de 0,60m (sessenta centímetros) nem a mais de 1,50m (um metro e cinquenta centímetros) acima do piso. (123.058-1/ I1)

23.17.5 Os extintores não deverão ser localizados nas paredes das escadas. (123.059-0 / I1)

23.17.6 Os extintores sobre rodas deverão ter garantido sempre o livre acesso a qualquer ponto de fábrica. (123.0603 / I1)

23.17.7 Os extintores não poderão ser encobertos por pilhas de materiais. (123.061-1/ I1).

Para essas sugestões segue a Figura 2. 
Figura 2 - Ilustração do laboratório de materiais compósito com aplicação da NR23 e NR12

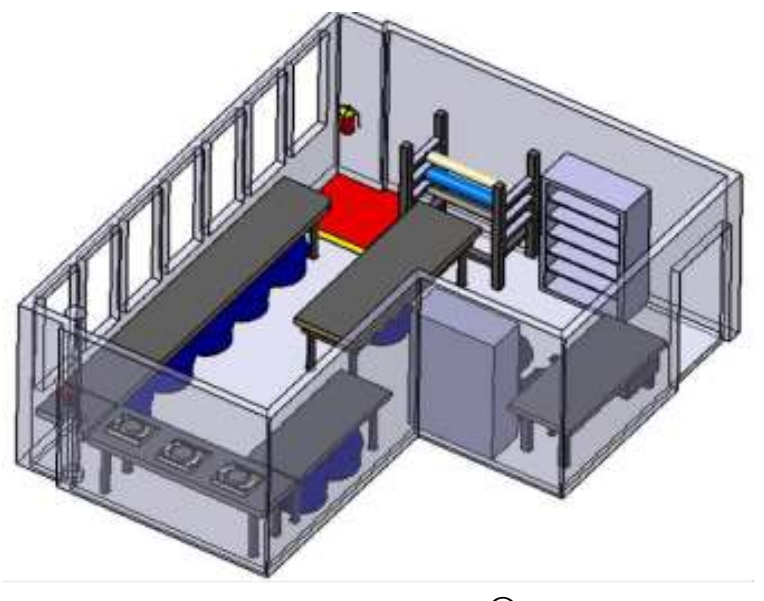

Fonte: Autores (Catia V5®), 2020.

3.6 - Visualização do processo utilizando a arquitetura tecnológica e conceitual dos recursos do laboratório de processamento de materiais compósitos com suas atividades

O laboratório de materiais compósitos não possui um layout adequado para os processos desenvolvidos em conta de quesitos de ergonomia considerando a área de trabalho, altura das bancadas e iluminação adequada envolvidos diretamente com as atividades realizadas no laboratório, esses fatores causam atrasos no processo final. Para que isso seja possível, seria necessário projetar o arranjo físico do laboratório dedicado às operações possibilitando as menores movimentações seguindo uma sequência de operações, como ilustra a Figura 3.

Figura 3 - Ilustração do laboratório de Processamento de Materiais Compósitos na vista superior

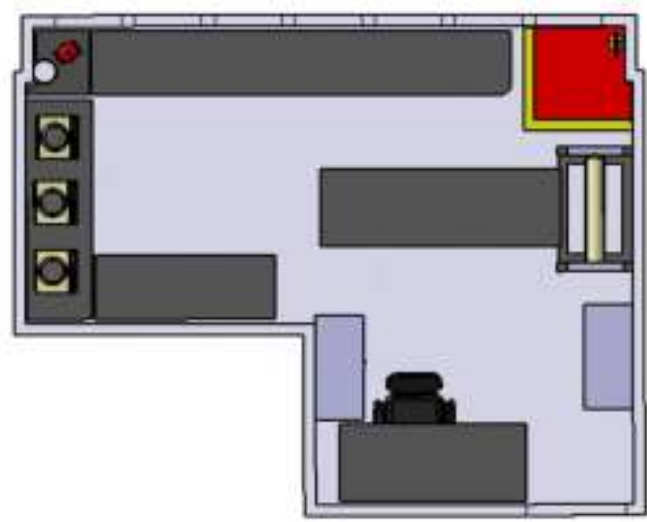

Fonte: Autores (Catia V5), 2020.

3.7 - Cotação dos itens necessários para otimização do laboratório materiais compósitos

A Tabela 2, mostra a média da cotação dos materiais necessários para realizar as modificações.

Tabela 2 - Cotação dos Materiais necessários para realizar as modificações

\begin{tabular}{c|c}
\hline MATERIAIS & Preços médio \\
\hline Bombonas de 200/180 Litros & $\mathrm{R} \$ 80,00$ \\
\hline Forro de PVC ou isopor & $\mathrm{R} \$ 1.028,33$ \\
\hline Barra de aço 80x80 (quadrada) & $\mathrm{R} \$ 85,00$ \\
\hline Ar-condicionado & $\mathrm{R} \$ 1.745,67$ \\
\hline Tampo para bancadas & $\mathrm{R} \$ 190,95$ \\
\hline
\end{tabular}

Fonte: Autores, 2020.
3.8 - Método de qualidade PDCA aplicado no processo de melhoria no laboratório de processamento de materiais compósitos.

Notou-se a necessidade fundamental da aplicação das ferramentas de qualidade para a melhoria desejada no laboratório citado neste trabalho. E a que foi utilizada foi a ferramenta de qualidade que tem como principal objetivo auxiliar nas decisões, no planejamento da operação e consequentemente no alcance das metas, para que haja uma mudança de patamar (SAMPAIO et al., 2020).

O uso imediato para definir metas e identificar falhas (plan), realizar ações de correção (do), realizar um novo diagnóstico (check) e padronizar as ações que obtiveram resultados (act). Estas foram os planos inclusos para a confecção do PDCA, conforme o Quadro 1.

\section{Quadro 1 - Ciclo PDCA aplicado ao Laboratório de Materiais Compósitos}

\begin{tabular}{l|l}
\hline PLAN: & DO: \\
Estruturação do novo & Implementação do novo \\
layout do novo & layout;Compra de itens \\
laboratório; & cotados;
\end{tabular}

Listagem de itens a serem comprados para compor a melhoria dos processos;

\section{CHECK:}

Inspeção do layout implementado;

Averiguação dos itens adquiridos;

Propor ações de eliminação ou redução dasocorrências encontradas;

\section{ACT:}

Buscar ações de melhorias contínuas;

Análise se os processos são eficientes;

Fonte: Autores, 2020.

\section{IV.CONCLUSÃO}

No decorrer da execução deste trabalho, concluiu-se que a decisão da aplicação da metodologia $5 \mathrm{~S}$ em colaboração com as ferramentas da qualidade $5 \mathrm{~W}$ e $2 \mathrm{H}$ e PDCA em um laboratório de pesquisa e ensino pode encontrar desafios devido as mudanças no layout $\mathrm{e}$ especialmente da verba aplicada. O plano de ação ou $5 \mathrm{~W} 2 \mathrm{H}$ foi a ferramenta utilizada como medida corretiva para as causas relacionadas com problema identificado, nos quais os avanços alcançados por esta implementação foram visivelmente significativos, visto que isto, contribuiu para a organização, facilidade e melhor desempenho das atividades do laboratório.

Com a projeção e o projeto final realizado, foi possível visualizar os possíveis ganhos em relação a cada item trabalhado, tendo que o laboratório de materiais compósitos tem de ser flexível a ponto de estar apto tanto atividades produtivas quanto experimental com interação homemmáquina.

Destacando cada ponto desenvolvido durante o trabalho temos como ganhos específicos, a bancada móvel que possui um conceito abrangente pelo fato de sua simplicidade com a característica de ser ajustável dentro das especificações e particularidade das operações laboratoriais, o pedestal que tem o propósito de organização e melhorar o uso dos novos produtos de fibras ou tecidos para compósitos, e por último a utilização de bombonas para armazenamento de materiais, que tornará possível a criação de um ambiente adequado as normas exigidas em relação a saúde e segurança do indivíduo. 


\section{REFERÊNCIAS}

AMADIO A. C.; SERRÃO JC. A Biomecânica em Educação Física e Esporte. São Paulo, Escola de Educação Física e Esporte - USP, 2011.

DOMAN, M. S. A new lean paradigm in higher education: a case study. Quality Assurance in Education, 19, 148-262, 2011.

FARIA, G. N. de L.; LONGHINI, T. M. Ciclo PDCA Aplicado à Gestão da Manutenção de Equipamentos Laboratoriais de Uma Indústria de Celulose. Produto \& Produção, [s. 1.], v. 22, n. 2, p. 10-26, 2021. Disponivel em: $<$ https://www.seer.ufrgs.br/ProdutoProducao/article/view/10 $1859 / 61485>$.

GAPP, R.; FISHER, R.; KOBAYASHI, K. Implementing $5 \mathrm{~S}$ within a Japanese context: an integrated management system. Management Decision, 46, 565-579, 2008.

GUIA TRABALHISTA. NR-12 - Segurança no trabalho em máquinas e equipamentos. 2019a. Disponível em: http://www.guiatrabalhista.com.br/legislacao/nr/nr12.htm. Acesso em: 20 maio. 2021.

GUIA TRABALHISTA. NR-23 - Proteção contra Incêndios. 2019b. Disponível em: <http://www.guiatrabalhista.com.br/guia/nr23.htm>. Acesso em: 20 maio. 2021.

HES, J. D.; BENJAMIN, B. A. Applying Lean Six Sigma within the university: opportunities for process improvement and cultural change. International Journal of Lean Six Sigma, 6, 249-262, 2015.

HO, S. K. M. 5S practice: a new tool for industrial management. Industrial Management \& Data Systems, 98, 55-62, 1998.

JIMÉNEZ, M. et al. 5S methodology implementation in the laboratories of an industrial engineering university school. Safety Science, 78, 163-172, 2015.

MARINHO, M.; GONÇALVES, M. D. S.; KIPERSTOK, A. Water conservation as a tool to support sustainable practices in a Brazilian public university. Journal of Cleaner Production, 62, 98-106, 2014.

MOTTA, E. F. R. O. et al. Gestão do conhecimento: um conceito integrando inovação, liderança e recursos para sustentabilidad e organizacional. Revista Sodebras [on line], [s. 1.], v. 16, n. 181, p. 05-10, 2021. Disponível em: <http://www.sodebras.com.br>. Acesso em: 23 jun. 2021.

OLIVEIRA, S. A.; MELO, N. S. Eficácia e impacto da auditoria interna na certificação de laboratórios clínicos: uma revisão integrativa. Revista eletrônica Evidência \& Enfermagem, [s. 1.], v. 6, n. 1, p. 27-39, 2020. Disponível em:<https://revistaevidenciaenfermagem.com.br/files/2000 00124-07f0707f0a/Eficácia e impacto da auditoria interna na certificação de laboratórios clínicos uma revisão integrativa.pdf>. Acesso em: 15 jul. 2021

REBELLO, M. A. F. R. Implantação do programa 5S para a conquista de um ambiente de qualidade na Biblioteca do Hospital da Universidade de São Paulo. Relato de Experiência. RDBCI v. 3, n. 1, p. 165-182, 2005.

SAMPAIO, N. A. S. et al. Avaliação do sistema de gestão da qualidade para o mercado atual. [s. 1.], p. 34-45, 2020.
Disponível em: <http://www.sodebras.com.br>. Acesso em: 23 jun. 2021.

SANTANA, M. K. A.; LOUREIRO, G. Gestão de Riscos e Oportunidades em Laboratório de Calibração do Setor Aeroespacialalmtc-m16d.sid.inpe.br. [s.l: s.n.]. Disponível em:<https://bityli.com/LnPsl>. Acesso em: 16 jul. 2021. [s. 1.], v. 11, 2020.

SEVERINO, A. J. Metodologia do Trabalho Científico. São Paulo: Cortez. 2017.

SILVA, M. D. B. et al. Emprego de ferramentas da qualidade, para reduzir o indice de avarias e os custos com seguro no processo logístico de uma automobilística. Revista Sodebras [on line], [s. 1.], v. 15, n. 170, p. 52-61, 2020. Disponível em: <http://www.sodebras.com.br>. Acesso em: 23 jun. 2020.

SILVA, M. F. da; MENDOZA, C. C. G. A importância do ensino, pesquisa e extensão na formação do aluno do Ensino Superior. Revista Científica Multidisciplinar Núcleo do Conhecimento, [s. 1.], v. 08, n. 06, p. 119-133, 2020. Disponível em: <https://www.nucleodoconhecimento.com. br/educacao/pesquisa-e-extensao>. Acesso em: 17 jul. 2021.

SIMONS, N. The business case for Lean Six Sigma in higher education. ASQ Higher Education Brief, 6, 1-6, 2013.

\section{COPYRIGHT}

Direitos autorais: Os autores são os únicos responsáveis pelo material incluído no artigo. 


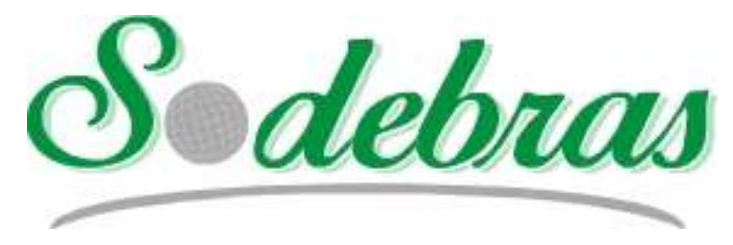

\author{
Revista SODEBRAS - Volume 16 \\ $\mathrm{N}^{\circ} 187$ - JULHO/ 2021
}

\title{
ESTIMATIVA NUMÉRICA DA GERAÇÃO DE ENERGIA SOLAR- FOTOVOLTAICA NA COBERTURA DO ESTACIONAMENTO DA BIBLIOTECA DA FZEA - USP
}

\section{NUMERICAL ESTIMATE OF SOIL-PHOTOVOLTAIC ENERGY GENERATION IN THE PARKING COVERAGE OF FZEA - USP LIBRARY}

\author{
FERNANDO DE LIMA CANEPPELE'; EMMANUEL ZULLO GODINHO²; \\ LUIS FERNANDO SOARES ZUIN ${ }^{1}$; JAIR ANTONIO CRUZ SIQUEIRA ${ }^{3}$ \\ 1 - FZEA/USP, CAMPUS DE PIRASSUNUNGA; 2 - UNESP/FCA, CAMPUS DE BOTUCATU; \\ 3 - UNIOESTE, CAMPUS DE CASCAVEL. \\ caneppele@usp.br;emmanuel.godinho@unesp.br;lfzuin@usp.br; jair.siqueira@unioeste.br
}

\begin{abstract}
Resumo - A geração de energia elétrica, partindo-se de fontes renováveis e sustentáveis vêm tendo cada vez mais foco nas pautas de discussão pelos mais diversos países. Principalmente quando é utilizado a energia fotovoltaica, ou seja, energia provinda do sol. Diante disso, o objetivo foi desenvolver um projeto de cobertura para o estacionamento da biblioteca da Faculdade de Zootecnia e Engenharia de Alimentos da USP de Pirassununga com placas fotovoltaicas. Foram utilizados diversos estudos científicos para desenvolver este modelo de produção de energia fotovoltaica no estacionamento. Conclui-se que a participação da biblioteca no consumo energético do campus é equivalente a 3,1, sendo que a geração de energia fotovoltaica é $202,4 \%$ maior que a da biblioteca e a participação da geração do estacionamento é de aproximadamente 6,27\%.
\end{abstract}

Palavras-chave: Cobertura Fotovoltaica. Estacionamento Fotovoltaico. Sistema Conectado à Rede.

Abstract - The generation of electricity, starting from renewable and sustainable sources, has been increasingly focused on the agendas of discussion by the most diverse countries. Especially when photovoltaic energy is used, that is, energy from the sun. Therefore, the objective was to develop a roofing project for the parking of the library of the Faculty of Animal Science and Food Engineering of USP of Pirassununga with photovoltaic plates. Several scientific studies were used to develop this model of photovoltaic production in the parking lot. It is concluded that the participation of the library in the energy consumption of the campus is equivalent to 3.1, and the generation of photovoltaic energy is $202.4 \%$ higher than that of the library and the participation of the parking generation is approximately $6.27 \%$.

Keywords: Photovoltaic Coverage. Photovoltaic Parking. System Connected to the Network.

\section{INTRODUÇÃO}

De sistemas fotovoltaicos, tratam-se toda e qualquer forma de se obter energia elétrica proveniente da luz solar (LIMA et al., 2020). Uma maneira de converter energia proveniente do sol em energia elétrica pressupõe um efeito conhecido por "efeito fotovoltaico", sempre convergente à tecnologia disponível no mercado, aplicando novas tecnologias (LIMA et al., 2018).
Qualquer sistema de energia solar fotovoltaica possui duas formas distintas, e igualmente adequadas, em termos de sua confiabilidade técnica e estrutural (LIRA et al., 2019). Existem duas formas usuais de instalação, a forma off-grid e a on-grid (PERIASAMY; JAIN; SINGH, 2015). Off-grid é mais conhecido como sistema isolado e o on-grid como sistema de conexão com a rede da provedora local (RAJNIKANTH; SANTHOSH KUMAR, 2017).

De acordo com (SHEN; CHUNG, 2021), todos os sistemas fotovoltaicos que são conectados à rede elétrica também recebem outra denominação e são chamados de sistemas grid-tie e operam em paralelismo com a rede de eletricidade. Diferentemente, os sistemas ditos "autônomos", são aqueles empregados em localidades que já estão contando com energia elétrica proveniente da concessionária local (TERCAN et al., 2020).

Por não serem portadores de dispositivos eletroeletrônicos, destinados a serem armazenadores energia elétrica, todo o excedente de potência elétrica, deve ser então produzida por este tipo de sistema e que é comissionado e injetado na linha da concessionária, em sentido oposto ao do fornecimento de potência, ou quando for o caso, de haver outras usinas fotovoltaicas (RODRIGUES; LIRA; SOUSA NETO, 2020).

Os sistemas fotovoltaicos on-grid são os mais comumente encontrados na atualidade no âmbito do aproveitamento de energia solar (AREVALO; TERRAZZAN, 2020). Além da extensiva oferta de mercado, constata-se a existência de grandes facilitadores no que diz respeito aos métodos de aquisição, instalação e manutenção destes sistemas junto aos profissionais técnicos especializados (LAGO; DELABENETA, 2018).

Os funcionamentos dos painéis baseiam-se no uso de placas fotovoltaicas fabricadas modularmente com silício, geralmente amorfo ou cristalino (IMAI et al., 2020). Como consequência há a produção de energia elétrica diretamente em corrente contínua (CC) já utilizável por equipamentos deste modelo (ABRANTES; MAIA, 2013). A posteriori, a corrente contínua CC gerada pelo dispositivo semicondutor adquire movimento oscilatório, em corrente alternada, através do uso de inversores de corrente, dispostos 
adequadamente, alimentando a rede elétrica da residência, comércio ou indústria, conforme retrata a Figura 1.

Figura 1 - Detalhe característico da ligação on-grid

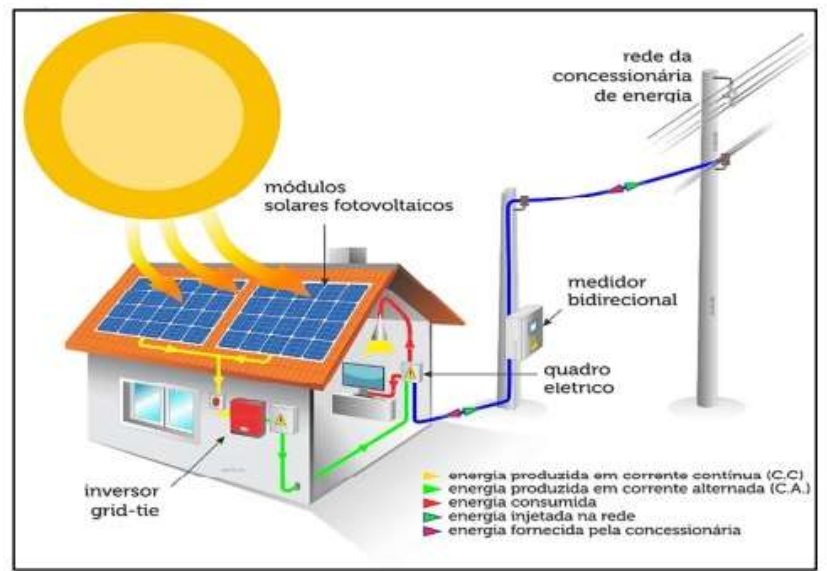

Fonte: Adaptado de (ABRANTES; MAIA, 2013).

Durante o ano de 2020, a Empresa de Pesquisa Energética (EPE) apontou que dentre os 428 projetos que foram cadastrados, dentre as diversas modalidades de fornecimento padrão de energia elétrica, a energia fotovoltaica foi a que mais se destacou com aproximadamente 300 projetos que juntos somaram 9.210 MW da energia ofertada (EPE, 2020).

Em relação a todos os estados no território nacional, a Bahia é considerada a região com a maior oferta de projetos "movidos à energia solar fotovoltaica", projetos estes que juntos somam 1.593 MW de potência total fornecida (EPE, 2020).

A Resolução Normativa ANEEL No 482 de 17 de abril de 2012 trouxe melhorias importantes e incentivadoras na geração de energia distribuída junto à sociedade (ANEEL, 2012), com isso foram definidos dois modelos de micro geração distribuída com uma central geradora de energia elétrica, sendo uma com potência instalada menor ou igual a $75 \mathrm{~kW}$ e outra superior a $75 \mathrm{~kW}$ e menor ou igual a $3 \mathrm{MW}$ para fontes hídricas ou menor ou igual a 5 MW.

Mudanças ocorridas pela Resolução Normativa ANEEL N ${ }^{\circ}$ 687, de 24 de novembro de 2015, alterou a Resolução Normativa $n^{\circ} 482$, de 17 de abril de 2012, e os Módulos 1 e 3 dos Procedimentos de Distribuição (PRODIST), que diz que os estabelecimentos das modalidades de autoconsumo remoto e geração compartilhada, possam compensar créditos de energia entre matrizes e filiais (ANEEL, 2015).

Nesta mesma linha de raciocínio, esta resolução surgiu como um grande estímulo às pequenas centrais geradoras em todo o país, por sua vez, oportunizou a diversificação da matriz energética e, resultando a diversos benefícios ao meio ambiente como a redução as perdas com a extensão de linhas de transmissão e a distribuição da energia gerada por recursos renováveis (LIMA et al., 2020).

Diante disso, o objetivo geral deste trabalho foi desenvolver um projeto de cobertura para o estacionamento da biblioteca da Faculdade de Zootecnia e Engenharia de Alimentos da USP de Pirassununga com placas fotovoltaicas.

\section{METODOLOGIA}

Este trabalho foi realizado na Faculdade de Zootecnia e Engenharia de Alimentos (FZEA), campus da Universidade de São Paulo (USP) na cidade de Pirassununga/SP. Para a definição do melhor local de estudo para a instalação de um estacionamento fotovoltaico foi avaliada vários locais da FZEA.

A localidade geográfica do local o qual foi utilizado para o trabalho foi de latitude $21^{\circ} 56^{\prime} 34,3$ Sul e longitude $47^{\circ} 43^{\prime} 52,3$ Oeste para a Biblioteca do campus da USP de Pirassununga.

O local escolhido para o mapeamento energético teve como principal motivo a pouca interferência geração de energia devido à ausência de obstáculo que gerem sombra, além disso não possui obstáculos que possa diminuir a incidência de radiação e pode servir de divulgação do campus.

Todos os painéis que compõem o sistema fotovoltaico serão instalados em estruturas metálicas adequadas projetadas sobre o telhado convencional. As estruturas escolhidas dispõem de terminais para apropriado aterramento e resistência especialmente projetada para suportar as condições de exposição às intempéries.

A estrutura do estacionamento atual encontra-se na frente da biblioteca, possuindo vagas descobertas que são divididas em duas fileiras, uma do lado oposto à outra. $\mathrm{O}$ acesso para a biblioteca pode ser realizado através de escada ou rampa, tornando viável o uso da mesma por deficientes físicos. Sua cobertura além de tornar viável a produção de energia, permite ainda um melhor conforto térmico para os usuários, diminuindo danos à pintura dos carros causados pelas intempéries climáticas.

A base de cálculos para instalação do projeto de estacionamento fotovoltaico foi utilizada como base o trabalho de conclusão de curso sobre "Estabelecimento de índices de eficiência energética na biblioteca do campus da USP de Pirassununga. 2015" (ROSA, 2015).

Como no trabalho mencionado, o mês de novembro de 2014 foi referência para o cálculo das demandas obtidas, esta mesma data continuará sendo a referência para o atual trabalho. Nesta data, costuma-se consumir maior quantidade de energia, pois há maior utilização de ar condicionado durante a primavera, além de ser época de provas, onde aumenta a quantidade de frequentadores da biblioteca.

Para a realização do cálculo de consumo diário é necessário saber os horários de funcionamento da biblioteca, segunda a sexta durante todos os períodos e aos sábados no período matutino. Além disso é necessário o valor de consumo mensal local $\left(\mathrm{C}_{\mathrm{m}}\right)$, que deve ser obtido a partir de dados recolhidos do trabalho de (ROSA, 2015).

A partir disso, pode-se calcular o consumo diário $\left(\mathrm{C}_{\mathrm{d}}\right)$, conforme a equação (1), dividindo o consumo mensal pela quantidade de dias de funcionamento $\left(\mathrm{d}_{\mathrm{f}}\right)$ :

$$
C_{d}=C_{m} / d_{f}
$$

Uma das etapas no dimensionamento do estacionamento é realizada a partir da determinação do número de placas fotovoltaicas a serem utilizadas para a geração de energia.

Como o número de painéis depende da potência total exigida pelo sistema $\left(\mathrm{P}_{\text {ptotal }}\right)$ e da potência do painel (PP painel), a equação (2) permite calcular o número de painéis 
$\left(\mathrm{N}_{\mathrm{P}}\right)$ necessários para suprir a demanda local (BOQUIMPANI et al., 2019):

$$
N_{\text {ptotal }}=P_{\text {ptotal }} / P_{\text {ppainéis }}
$$

Contudo, é necessário primeiramente obter a irradiação solar local, que pode ser obtida através de um programa chamado SunData v3.0 (CRESESB, 2018), que disponibiliza a tabela de irradiação do local. Outro dado que deve ser recolhido é o número de horas de sol (HSP), que deve ser referente ao mês de pior índice de irradiação obtida na tabela do SunData v3.0 para calcular o sistema com maior eficiência. O HSP pode ser reconhecido no Atlas Solarimétrico de acordo com a região e mês desejado (TIBA et al., 2000).

Para o cálculo de painéis, deve-se obter a potência do sistema gerador conforme equação (3). Sendo que para isso deve-se saber o rendimento total do sistema, dado pela equação (4), que calcula o rendimento do sistema através da multiplicação dos rendimentos dos componentes existentes (BOQUIMPANI et al., 2019):

$$
\begin{aligned}
& P_{\text {ptotal }}=E / H S P_{\min } \\
& \eta_{\text {sistema }}=\eta_{p v} * \eta_{p v-b a t} * \eta_{c c} * \eta_{\text {dist }} * \eta_{\text {inv }}
\end{aligned}
$$

Para a configuração dos módulos deve-se levar em conta que quando os painéis são conectados em série conforme equação (5), e quando conectado em paralelo na qual se utiliza a equação (6). Então, a área final do estacionamento fotovoltaico pode ser obtida através da equação (7) que multiplica o número de painéis pela área de estacionamento disponível.

Para a realização do cálculo de potência instalada foi utilizado a equação (8), deve-se utilizar o número total de painéis que serão instalados multiplicado pela potência máxima do painel. Já com a equação (9), a potência instalada é usada na obtenção da percentagem de utilização de energia fotovoltaica gerada para suprir a demanda da biblioteca:

$$
\begin{aligned}
& V_{\text {inversor }}=V_{\text {max }} * N_{\text {painéis em série }} \\
& I_{\text {inversor }}=I_{\text {max }} * N_{\text {painéis em paralelo }} \\
& A_{\text {estacionamento }}=N_{\text {pescolhido }} * A_{\text {painel }} \\
& P_{\text {inst }}=\eta_{\text {pescolhido }} * P_{\text {pescolhido }} \\
& \%_{\text {equaçãofv }}=P_{\text {inst }} * 100 / P_{\text {pbiblioteca }}
\end{aligned}
$$

Conforme mencionado anteriormente, o inversor deve ser dimensionado a partir da potência do sistema fotovoltaico escolhido. Neste caso, a potência do inversor é diretamente dependente da potência do gerador de 105,6 $\mathrm{kW}$, sendo assim, a potência do inversor escolhido deve se encontrar entre $70 \%$ e $120 \%$ da potência do sistema, além de ser um inversor grid-tie para sincronizar a frequência com a rede elétrica.

Pela equação (10), pode-se dimensionar o inversor utilizado para cada módulo utilizado nesse projeto, ou seja, serão utilizados dez inversores em que cada um deles terá sua potência definida pela equação citada (GREENPRO, 2004):

$$
0,7 * P_{\text {inst }} / 10<P_{\text {inst } D C}<1,2 * P_{\text {inst } / 10}
$$

A estrutura de suporte para a instalação do estacionamento fotovoltaico é proposta com base na estrutura do estacionamento da USP São Paulo, que é mencionado no trabalho de (LISITA JÚNIOR, 2005), e na inclinação ideal dos painéis que devem seguir a latitude local para um melhor aproveitamento energético.

Outro ponto importante é a delimitação das vagas, em que necessitasse verificar os tamanhos mínimos das vagas para tamanhos específicos de carros, além de verificar vagas para deficientes físicos.

Para os cálculos desta seção, foram utilizados os dados obtidos por (ROSA; GASPARIN, 2016), tendo assim base para demonstrar a participação da energia fotovoltaica no campus.

Com o valor do consumo energético da biblioteca em comparação com o consumo do campus tem-se a percentagem da participação da biblioteca (\% biblioteca) no consumo total. Desta maneira, utilizou-se a equação (11) para comparar a produção de energia fotovoltaica através da percentagem de participação do gerador (AVACI et al., 2013):

$$
P V=\left(\%_{\text {geraçãofv }} * \%_{\text {biblioteca }}\right) * 100
$$

As placas fotovoltaicas escolhidas para a utilização foram a REM36-6 150P, monocristalino, com as especificações Módulo Fotovoltaico 150P (potência de pico: $150 \mathrm{~W}$; voltagem máxima $16,9 \mathrm{~V}$; corrente máxima: 7,21A e preço em torno de $\mathrm{R} \$ 390,00)$.

\section{RESULTADOS}

Sabendo que o valor do consumo mensal obtido no trabalho de referência foi calculado com base no consumo do local e no número de horas de funcionamento da biblioteca durante o mês de novembro, pode-se calcular a projeção do consumo diário com base nos 30 dias respectivos ao mesmo mês.

Como a utilização da biblioteca acontece apenas de segunda a sexta, e aos sábados por meio período, são desconsiderados os horários em que a mesma se encontra fechada, ou seja, aos sábados após meio dia, gerando 2 dias ao mês, e aos domingos, gerando 4 dias ao mês, totalizando 6 dias ao mês com a biblioteca fora de seu horário de funcionamento.

Desta maneira, foram considerados apenas 24 dias para o cálculo de consumo de energia no mês de novembro, obtendo 493,6 kWh de consumo mensal (ROSA, 2015).

Deve-se levar em consideração que os cálculos aqui realizados para obter uma melhor eficiência de captação energética foram correspondentes ao menor índice de radiação, que ocorre no mês de julho de 7 horas de sol (HSP) de acordo com o Atlas Solarimétrico (TIBA et al., 2000).

Escolha justificada pelo maior rendimento de conversão de energia solar em energia elétrica quando comparado com outros tipos de painéis, possuindo um rendimento de ordem superior.

Também deve-se observar que o rendimento total do sistema é calculado através da multiplicação dos rendimentos dos componentes do sistema, que ao final participarão da potência total do sistema, os resultados provindos das equações anteriormente explicadas.

Aplicando os dados nas equações, o $\eta_{\text {sistema }}$ foi de 0,74 , sendo o $\mathrm{P}_{\text {pbiblioteca }}$ igual a $52,12 \mathrm{~kW}$, resultando a necessitar de 435 painéis, entretanto, a área disponibilizada pelo estacionamento possibilita a instalação de mais painéis que o necessário para abastecer apenas a biblioteca. 
Recalculando os valores, dá-se necessário 935 painéis em todo o estacionamento.

A partir do número máximo de painéis obtido, precisase verificar se a configuração de ligação dos painéis estará dentro da dimensão do estacionamento.

Para respeitar a área delimitada, os painéis serão associados em módulos. Como pode ser visto no Tabela 1 , cada módulo deve possuir 22 painéis ligados em série, formando uma linha de painéis totalizando 14,54 metros; e para concluir o módulo, 4 linhas de painéis devem ser associadas em paralelo totalizando aproximadamente 5,80 metros. Então, o estacionamento deve ser composto por 2 fileiras, sendo cada uma dela constituída por 5 módulos de 88 painéis fotovoltaicos cada.

Tabela 1 - Dimensão do módulo fotovoltaico

\begin{tabular}{ccccc}
\hline Estacionamento & PV $(\mathbf{m})$ & PA & DM $(\mathbf{m})$ & DE/F (m) \\
\hline Comprimento & 0,661 & 22 & 14,54 & 72,7 \\
Largura & 1,447 & 4 & 5,80 & 5,80 \\
\hline
\end{tabular}

Dados: PV: placas fotovoltaicas; PA: placas associadas; DM: dimensão do módulo e DE/F: dimensão do estacionamento/fileira

A partir da Tabela 1, foi calculado o número de painéis escolhido, sendo 880 painéis, 22 em série e 4 em colunas.

Como o inversor escolhido possui corrente máxima de entrada de 33,3A e faixa de tensão entre 345 e 480V, a configuração foi projetada com o intuito de se enquadrar dentro dos requisitos dados pelo inversor, obtendo uma tensão de entrada de $371,8 \mathrm{~V}$ e uma corrente máxima de entrada de 28,4A no equipamento. Conforme as resoluções (1 a 3), onde apresentam os cálculos realizados para a tomada de decisão na configuração de instalação:

Em série: $V_{\text {inversor }}=16.9 \mathrm{~V} * 22=371,8 \mathrm{~V}$

Em paralelo: $I_{\text {inversor }}=7,1 \mathrm{~A} * 4=28,4 \mathrm{~A}$

$A_{\text {estacionamento }}=880 * 0,661 * 1,477= \pm 860 \mathrm{~m}^{2}$

Para o cálculo efetivo da potência instalada é necessário multiplicar a quantidade de painéis instalados pela sua potência nominal, atingindo uma potência total de $105,6 \mathrm{~kW}$ que equivale a cerca de $202 \%$ da energia demandada pela biblioteca, conforme visto a seguir, conforme apresentado nas resoluções matemáticas (4 a 7):

$$
\begin{aligned}
& P_{\text {inst }}=880 * 120=105600 \mathrm{~W}=105,6 \mathrm{~kW} \\
& \%_{\text {Geraçãofv }}=105,6 * 100 / 52,183 \\
& A_{\text {estacionamento }}=880 * 0,661 * 1,477= \pm 860 \mathrm{~m}^{2} \\
& \%_{\text {Geraçãofv }}=105,6 * 100 / 52,183=202,4 \%
\end{aligned}
$$

O inversor deve ser dimensionado a partir da potência do sistema fotovoltaico escolhido. Neste caso, a potência do inversor é diretamente dependente da potência do gerador de $105,6 \mathrm{~kW}$, sendo assim, a potência do inversor escolhido deve se encontrar entre $70 \%$ e $120 \%$ da potência do sistema.

Como o inversor escolhido possui potência de 11.500 W e a potência instalada é de 105,6 kW, optou-se por utilizar 10 inversores, ou seja, $1150 \mathrm{~W}$ para cada inversor, onde cada um corresponde a um módulo do estacionamento, com as especificações, a seguir: inversor SUNNY BOY 11000 TL-US (Entrada (CC): potência máxima: 11500W; voltagem máxima de entrada: $600 \mathrm{~V}$; faixa de tensão: $345 \mathrm{~V}-$ 480V/379V; corrente máxima: 33,3A com rendimento de $98 \%$ ), conforme resolução matemática (8):
Um ponto importante da instalação das placas fotovoltaicas no estacionamento é a sua estrutura geral, pois para ser um sistema duradouro, a mesma deve ser feita por um material resistente a intempéries climáticas como a exposição ao sol e ou à chuva ao longo dos anos.

Desta maneira a utilização de uma estrutura de alumínio é a mais indicada, além de ser uma estrutura leve, fácil transportá-la e de instalá-la.

Conforme o estacionamento fotovoltaico do campus USP São Paulo, a estrutura também pode ser composta por modelos tubulares de 3 polegadas para os postes de sustentação e em formato de "U" para os perfis longitudinais e transversais. Já as dimensões do estacionamento serão de $5,48 \mathrm{~m}$ por $14,54 \mathrm{~m}$ por módulo, totalizando cerca de $86 \mathrm{~m}^{2}$ de área por módulo instalado.

Segundo (MACHADO et al., 2005), para se ter o melhor aproveitamento da irradiação solar é necessário que a placa fotovoltaica seja instalada com inclinação igual a latitude do local escolhida, neste caso a inclinação foi de $22^{\circ}$. Para a delimitação da vaga foram utilizadas as normas do boletim técnico da Companhia de Engenharia de Tráfego, considerando os dados da Tabela 02 (MARTINS et al., 2019).

Tabela 2 - Dimensão de vagas e vias de acesso

\begin{tabular}{ccc}
\hline \multicolumn{3}{c}{ Veículo - tipo passeio e utilitário } \\
\hline Tamanho & Comprimento & Largura \\
\hline Pequeno e médio & 4,50 & 2,20 \\
Grande e utilitário & 5,00 & 2,40 \\
\hline \multicolumn{3}{c}{ Largura da via em relação à posição da vaga } \\
$\begin{array}{c}\text { Posição da vaga } \\
90^{\circ}\end{array}$ & $6,00 \mathrm{~m}$ \\
\hline Fonte: (MARTINS et al., 2019$)$
\end{tabular}

Como os módulos possuem 14,54 metros de comprimento e 5,48 metros de largura, nesta metragem pode-se cobrir 3 vagas por módulo, totalizando 30 vagas em todo o estacionamento.

A participação fotovoltaica do campus (PF) é apresentada na equação matemática (9):

$$
P F=(202,365 * 3,1) / 100=6,27 \%
$$

Como os dados apontam que a participação da biblioteca no consumo energético do campus é equivalente a 3,1 , pode-se concluir que se a geração de energia fotovoltaica é $202,4 \%$ maior que a da biblioteca, a participação da geração do estacionamento é de aproximadamente $6,27 \%$.

\section{CONCLUSÃO}

O desenvolvimento do que foi proposto neste trabalho permitirá estimular o crescimento da geração de energia sustentável e limpa no país e principalmente em órgãos governamentais de diversos setores, principalmente na educação, contribuindo para o desenvolvimento das pessoas em utilizar um sistema gerador de energia limpa, sendo fotovoltaico ou não, como fonte de estudo para as diversas matérias que envolvem desde circuitos elétricos a eficiência energética.

Corroborando com as explicações em que a participação da biblioteca no consumo energético do campus é equivalente a 3,1 , sendo que a geração de energia 
fotovoltaica é $202,4 \%$ maior que a da biblioteca e a participação da geração do estacionamento é de aproximadamente $6,27 \%$

Como sugestão recomenda-se o desenvolvimento de estudos de viabilidade econômica e de eficiência energética ligados a este trabalho, além da possibilidade de estendê-lo para atender todo o campus, utilizando as áreas de estacionamento e os telhados dos prédios como área de instalação após os devidos estudos de viabilidade.

\section{REFERÊNCIAS}

ABRANTES, A. C. T. G.; MAIA, F. A. Análise de viabilidade técnico-econômica de implantação de sistema fotovoltaico no centro integrado de educação profissional de Itaparica. Revista Técnico-Científica do CREA-PR, v. 1, n. 23, p. 1-16, 2013.

ANEEL. Agência Nacional de Energia Elétrica - ANEEL. Resolução Normativa No 414/2010 - Condições Gerais de Fornecimento de Energia Elétrica. Agência Nacional De Energia Elétrica, p. 18, 2015.

ANEEL, A. N. D. E. E.-. Resolução Normativa ANEEL No 482 DE 17/04/2012. Disponível em: <https://www.legisweb.com.br/legislacao/?id=342518>.

Acesso em: 11 abr. 2021.

AREVALO, D. F. V.; TERRAZZAN, E. A. Meanings of physics mathematization in pre-service physics teachers. Revista Lasallista de Investigacion, v. 17, n. 1, p. 358-370, 2020.

AVACI, A. B. et al. Avaliação econômico-financeira da microgeração de energia elétrica proveniente de biogás da suinocultura. Revista Brasileira de Engenharia Agrícola e Ambiental, v. 17, n. 4, p. 456-462, 2013.

BOQUIMPANI, C. L. et al. Eficiência energética: sistemas de iluminação com LEDs, distribuídos em corrente contínua e utilizando energia fotovoltaica. Ambiente Construído, v. 19, n. 4, p. 303-316, dez. 2019.

CRESESB, C. DE R. PARA E. S. E E. S. B. Potencial Solar $\begin{array}{lllll}\text { SunData } & \mathbf{3 . 0} & \text { Disponível }\end{array}$ <http://www.cresesb.cepel.br/index.php?section=sundata\&>. Acesso em: 11 abr. 2021.

EPE. Balanço Energético Nacional 2020: Relatório síntese, ano base 2019. Empresa de Pesquisa Energética, p. 73, 2020.

IMAI, H. E. et al. Simulação computacional como ferramenta de otimização na geração de energia solar fotovoltaica. urbe. Revista Brasileira de Gestão Urbana, v. 12, 2020.

LAGO, S. M. S.; DELABENETA, C. a Produção Científica Brasileira Sobre Energia Solar Fotovoltaica No Período De 2007 a 2017. Revista de Administração de Roraima RARR, v. 8, n. 2, p. 416, 2018.

LIMA, A. A. et al. Uma revisão dos princípios da conversão fotovoltaica de energia. Revista Brasileira de Ensino de Física, v. 42, 2020.

LIMA, R. DE M. C. et al. Caracterização de células solares de filmes finos de CIGS. Matéria (Rio de Janeiro), v. 22, n. suppl 1, 8 jan. 2018.

LIRA, M. A. T. et al. Contribution of photovoltaic systems connected to the electrical network for reducing $\mathrm{CO} 2$ in the state of Ceará. Revista Brasileira de Meteorologia, v. 34, n. 3, p. 389-397, 2019.

LISITA JÚNIOR, O. Sistemas fotovoltaicos conectados à rede : Estudo de caso - $3 \mathrm{kWp}$ instalados no estacionamento do IEE-USP Sistemas fotovoltaicos conectados à rede : Estudo de caso - $3 \mathrm{kWp}$ instalados no estacionamento do IEE-USP. [s.l: s.n.].

MACHADO, E. C. et al. Photosynthetic responses of three citrus species to environmental factors. Pesquisa Agropecuaria Brasileira, v. 40, n. 12, p. 1161-1170, 2005.

MARTINS, S. R. C. et al. Manual de sinalização urbanaCompanhia de Engenharia de Tráfego CETSão Paulo, SP, 2019.

PERIASAMY, P.; JAIN, N. K.; SINGH, I. P. A review on development of photovoltaic water pumping system. Renewable and Sustainable Energy Reviews, v. 43, p. 918 925, 2015

RAJNIKANTH, M.; SANTHOSH KUMAR, M. Tapping of lost velocity of air for wind mill with second rotor set -UP. International Journal of Mechanical and Production Engineering Research and Development, v. 7, n. 5, p. 21-28, 2017.

RODRIGUES, L. M.; LIRA, M. A. T.; SOUSA NETO, M. L. DE. Mitigação dos Efeitos das Mudanças Climáticas a partir da Substituição Gradual de Termelétricas a Carvão por Usinas Fotovoltaicas. Revista Brasileira de Meteorologia, v. 35, n. 3, p. 415-424, set. 2020.

ROSA, A. R. O. DA; GASPARIN, F. P. Panorama Da Energia Solar Fotovoltaica No Brasil. Revista Brasileira de Energia Solar, v. 7, n. 2, p. 140-147, 2016.

ROSA, R. G. Estabelecimento de índices de eficiência energética na biblioteca do campus da USP de Pirassununga. 2015. [s.1.] Universidade de São Paulo, 2015.

SHEN, R.; CHUNG, H. S. H. Mitigation of Ground Leakage Current of Single-Phase PV Inverter Using Hybrid PWM with Soft Voltage Transition and Nonlinear Output Inductor. IEEE Transactions on Power Electronics, v. 36, n. 3, p. 2932 2946, 2021.

TERCAN, E. et al. Geographic information system-based investment system for photovoltaic power plants location analysis in Turkey. Environmental Monitoring and Assessment, v. 192, n. 5, 2020.

TIBA, C. et al. Atlas Solarimétrico do Brasil: Banco de Dados Terrestres. Atlas Solarimétrico do Brasil, v. 1, p. 111, 2000.

USP, U. DE S. P.-. Frequência às Bibliotecas da USP, distribuída por Unidade, em 2019. Disponível em: <https://uspdigital.usp.br/anuario/AnuarioControle\#>.

\section{AGRADECIMENTOS}

Item não obrigatório, onde os autores poderão agradecer as instituições de financiamento e fomento, colaboradores, entre outras.

\section{COPYRIGHT}

Direitos autorais: Os autores são os únicos responsáveis pelo material incluído no artigo. 


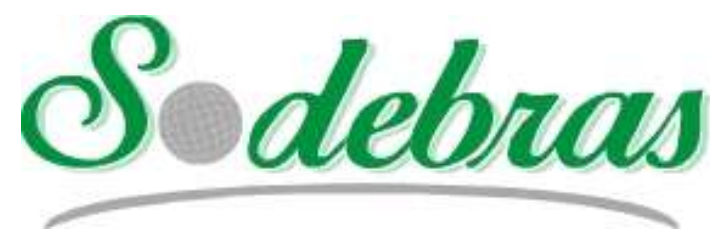

Revista SODEBRAS - Volume 16

$\mathrm{N}^{\circ} 187-\mathrm{JULHO} / 2021$

\title{
MODELOS DE OTIMIZAÇÃO PARA DETERMINAR AS LOCALIZAÇÕES DOS PONTOS DE ACESSO SEM FIO
}

\author{
MODELS OF OPTIMIZATION TO DETERMINE LOCATIONS OF THE \\ WIRELESS ACCESS POINTS
}

\author{
LUCAS BARCELOS MENDES $^{1}$; MÁRIO MESTRIA ${ }^{1}$ \\ 1 - COORDENADORIA DE ENGENHARIA ELÉTRICA, CAMPUS VITÓRIA, INSTITUTO FEDERAL \\ DO ESPÍRITO SANTO, AV. VITÓRIA, No 1729 - BAIRRO JUCUTUQUARA, 29040-780 \\ VITÓRIA, ES \\ barcelosmendeslucas@hotmail.com;mmestria@ifes.edu.br;mmestria@uol.com.br
}

\begin{abstract}
Resumo - Este trabalho propõe modelos para o problema de localização de dispositivos em uma rede em malha sem fio. Esse artigo é uma extensão de um trabalho da literatura. Dois modelos distintos da literatura são abordados: o primeiro considera fixa a capacidade de transmissão de dados de um dispositivo em malha para os clientes; o segundo considera os efeitos da interferência de diferentes fontes oriundas. As soluções do problema consistem em minimizar os custos de instalação, determinar a localização de pontos de acesso e dos roteadores na malha e garantir a cobertura de todos os clientes da rede. As qualidades das soluções são discutidas considerando os efeitos dos diferentes parâmetros da rede em malha sem fio. Conclui-se que os modelos propostos são eficazes devidos: permitir reduzir número de dispositivos, diminuir custos de implantação e reduzir os efeitos de interferências.
\end{abstract}

Palavras-chave: Rede em Malha sem Fio. Programação Matemática. Otimização Combinatória. Desempenho da Rede.

\begin{abstract}
This paper proposes models to the problem of locating devices in a wireless mesh network. This paper is an extension of a work of the literature. Two different models from literature are approached: the first considers a fixed capacity of data transmission from a mesh device to the mesh clients; the second considers the effects of interference from different way forms. The solutions of problem consist in minimizing the installation costs, determine the location of mesh access points and mesh routers, and guarantee the coverage of all clients. The qualities of solutions are discussed considering the effects of different parameters in wireless mesh network. It was concluded that the proposed models are effective due: to permit reducing the number of devices, decrease costs of implementation, and to reduce the effects of interference.
\end{abstract}

Keywords: Wireless Mesh Network. Mathematical Programming. Combinatorial Optimization. Network Performance.

\section{INTRODUÇÃO}

Em diversas áreas tecnológicas requerem tomar decisões para localizar facilidades numa determinada localização física com a finalidade de adquirir melhor aproveitamento destas escolhas e com o objetivo de minimizar custos operacionais. $\mathrm{O}$ termo facilidade pode ser aplicado num sentido mais amplo da palavra de acordo a Current et al. (2002): aeroportos, portos marítimos, fábricas, armazéns, escolas, hospitais, pontos de ônibus, estações de metrô, sirenes de alerta de emergência, dentre outras. Especificamente, este trabalho se delimita ao problema de localização de pontos de acesso à rede em malha sem fio.

Há quatro componentes que descrevem problemas de localização segundo Farahani e Hekmatfar (2009): os clientes, as facilidades, uma localização nos quais os clientes e as facilidades estarão localizados e uma métrica padrão que indica distância, tempo ou custo entre clientes e facilidades.

De acordo com Amaldi et al. (2008), redes em malha sem fio são amplamente reconhecidas como uma solução promissora e rentável para fornecer conectividade sem fio para usuários móveis. Os autores reforçam que eventualmente a rede em malha sem fio pode competir com tecnologias de acesso de banda larga com fio. Tal sucesso se deve, principalmente, à alta flexibilidade do paradigma de rede em malha, que tem muitas vantagens em termos de capacidade de autoconfiguração e custo de instalação reduzido.

Em uma configuração tradicional de LAN (Local Area Network) com fio 802.11 (IEEE 802, 1999), Conjuntos de Serviços Básicos (CSB) estão ligados via Ethernet LAN. Tal arquitetura de rede fixa limita a flexibilidade de implantação da rede e aumenta seus custos. No entanto, mobilidades do CSBs e rede de múltiplos saltos são necessárias para maior flexibilização (WANG; LIM, 2008).

Segundo Akyildiz et al. 2005 uma tendência para redes em malha sem fio será a rede composta por uma infraestrutura que inclui roteadores de malha, backbones cabeados e sem fios e uma rede cliente em malha sem fio. Clientes em malha podem acessar a rede por meio de roteadores de malha, bem como acessar diretamente com outros clientes da malha. Enquanto a infraestrutura fornece conectividade com outras redes, como a Internet, Wi-Fi, WiMAX, redes celulares e sensores, as capacidades de roteamento de clientes proporcionam melhor conectividade e cobertura dentro da rede em malha sem fio.

Em Amaldi et al. (2008), foram propostos modelos de otimização para a cobertura e planejamento topológico de redes em malha sem fio com várias interfaces de rádio e múltiplos canais ortogonais disponíveis em cada interface. Além disso, os autores apresentam uma heurística para resolver instâncias de grandes portes com precisão de 5\% 
em relação ao custo da solução ótima. As instâncias foram avaliadas através de simulações em nível de sistema com o simulador ns-2 (ISI, 2021).

No trabalho de Silva et al. (2010), o planejamento de uma rede em malha, além de tentar satisfazer as necessidades dos clientes, oferece um serviço de qualidade, levando em conta a minimização de custos e a verificação do respeito a uma taxa tolerada de perda de pacotes. Através do problema de $p$-medianas capacitado, são escolhidos $p$ gateways e, usando uma verificação dos clientes que ainda não estão cobertos pela rede, novos APs (Access Points) são ativados para compor a topologia inicial.

É utilizado o algoritmo de simulação de Monte Carlo aplicado ao modelo hipercubo para determinar a taxa atual de perda de pacotes e se os valores do parâmetro de QoS (Quality of Service) fornecidos pelo algoritmo são maiores do que a taxa tolerada que se espera atingir. A topologia da rede, então, deve ser alterada de modo a incluir novos APs.

No trabalho de Santos et al. (2011), foi proposta uma solução a partir da implementação de heurísticas GRASP para o problema de localização de pontos de acesso numa rede em malha sem fio, o qual é tratado como um problema de localização de $p$-medianas capacitado baseado na estrutura de uma nova rede que será implantada.

Os autores Santos et al. (2011), consideraram que as antenas transmissoras são onidirecionais, irradiando o sinal igualmente em todas as direções e ainda todas as antenas possuem o mesmo custo e o mesmo alcance de transmissão. Em Araújo e Mestria (2017) foi proposta a metaheurística GRASP para resolver o problema de planejamento de redes em malha sem fio através do modelo clássico das $p$ medianas.

Já no trabalho de Lwin et al. (2017) foi proposto uma abordagem para otimizar a condição de configuração de uma rede em malha sem fio em termos dos ângulos e da altura em um ambiente interno usando medições de rendimento. Primeiro, foi detectado gargalos nos hosts que recebe o sinal mais fraco do AP usando o modelo de estimativa de rendimento.

Para explorar os valores ideais de parâmetros para este modelo de Lwin et al. (2017), foi adotado uma ferramenta de otimização de parâmetros. Em seguida, foi otimizado a configuração do AP alterando os ângulos e a altura enquanto foi medida a taxa de transferência.

Em Sanguino e Betancourt (2018) descreve um algoritmo de otimização baseado em estratégia evolutiva para a tomada de decisão na implantação real de LANs sem fio. $\mathrm{O}$ algoritmo desenvolvido permite automatizar o projeto, tradicionalmente feito à mão por técnicos de rede, de forma a economizar tempo e custo. Para tanto, foi implementado um Algoritmo Genético multiobjectivo com a finalidade de atender a dois objetivos de projeto simultâneos: minimizar o número de APs e maximizar o sinal de cobertura em toda uma área de planejamento.

Em Tang et. (2019) foi proposto que todos os terminais de usuário devem estar dentro da cobertura de pelo menos um roteador wireless, e com mínimo de roteadores mesh para cobrir todos os terminais do usuário. Portanto, os roteadores de malha selecionados se conectam entre si, mas geralmente os roteadores candidatos formam apenas várias subredes conectadas locais, sem se conectar entre si.

Em Ren et al. (2020) destaca que o crescimento da carga de tráfego representa um gargalo nas redes com desafios na infraestrutura, sendo que os usuários enfrentam ainda os congestionamentos e atrasos nas redes. Ainda de acordo ao trabalho de Ren et al. (2020), embora tenham ocorrido grandes melhorias nas taxas de dados ao longo de sucessivas gerações de sistemas sem fio, os ganhos não são suficientes para compensar o aumento explosivo na demanda de dados. Desta forma, planejamentos nas redes são necessários, tanto para localização de APs, como também as análises dos sinais gerados em torno desses pontos.

No artigo de Abdulwahid et al. (2020) investigou-se o desempenho da rede num prédio de uma universidade com base para a implantação de APs no referido prédio. Tal investigação foi realizada usando um software, com base no cálculo dos parâmetros de perda de caminho e potência recebida.

Os resultados obtidos em Abdulwahid et al. (2020) mostram uma variação significativa no desempenho e cobertura da rede em uma parte edifício. Como resultado, houve melhoria no desempenho da rede, reduzindo o número de dispositivos APs de 13 para 8. Além disso, reduziu os custos de implantação e os efeitos de interferência no interior do edifício.

Outro problema de localização de facilidades foi tratado no trabalho de Lauar, Oliveira e Mestria (2020) que resolve o problema de alocação de agregadores de dados em redes inteligentes. Para resolver esse problema um modelo baseado na cobertura do conjunto e que incorpora as restrições de dispersão entre agregadores foi utilizado.

Desta forma, o objetivo desse trabalho é modelar e implementar método de solução para o problema de localização de pontos de acesso numa rede em malha sem fio com base em dois modelos apresentados na literatura em Amaldi et al. (2008). Um modelo adota a estratégia de considerar fixa a taxa de transmissão de dados dos dispositivos da malha em relação às distâncias entre o ponto de transmissão e o ponto de recepção do sinal.

Outro modelo considera os efeitos da interferência da sinalização de canal. Essa modelagem se faz interessante por ser mais completa para os sistemas em malha com clientes dentro da área de cobertura de determinado dispositivo de rede. E ainda considera as interferências sobre os enlaces na rede em malha determinando quais links podem estar ativos ao mesmo tempo.

Ressalta-se que esse trabalho é uma extensão do trabalho de Mendes e Mestria (2016) e propõem um novo modelo que considera os efeitos da interferência de diferentes fontes oriundas. A nova modelagem compara com o modelo que fixa a capacidade de transmissão de dados de um dispositivo em malha para os clientes.

Nesse sentido, o atendimento a demanda dos clientes deverá ser satisfeito, com minimização dos custos de instalação. O trabalho irá avaliar os modelos de otimização da literatura, fazendo uma releitura dos parâmetros da rede sem fio. Desta forma, podem-se determinar as localizações dos pontos de acesso sem fio numa rede em malha, com alguns parâmetros diferentes das redes mesh da literatura.

$\mathrm{O}$ artigo é organizado como segue. Na segunda seção, há uma breve apresentação de uma rede em malha sem fio; na terceira seção, são discutidos os modelos com suas devidas formulações matemáticas; na quarta seção, os resultados obtidos são apresentados e analisados. Na quinta seção, uma discussão dos resultados desse trabalho é comparada aos da literatura e na última seção contém as conclusões. 


\section{REDES EM MALHA SEM FIO}

As Redes em Malha sem Fio (Wireless Mesh Networks- WMNs), que são compostas, basicamente, por três categorias de aparelhos: Pontos de Acesso em Malha (PAMs), Roteadores em Malha (RM) e Clientes em Malha (CMs). Numa conexão em rede, a configuração ideal é tal qual a apresentada na Figura 1, como consta na diagramação apresentada por Amaldi et al. (2008) com o backbone de dados do sistema. Os aparelhos PAM são os que apresentam conexão por enlaces com fío ao backbone.

Os demais aparelhos permitam aos clientes, o acesso à rede com os RMs. Devido a fatores técnicos como a presença de tal conexão por fio, os PAMs apresentam um custo mais elevado de instalação que os RMs.

Figura 1 - Diagramação de uma Rede em Malha Sem Fio

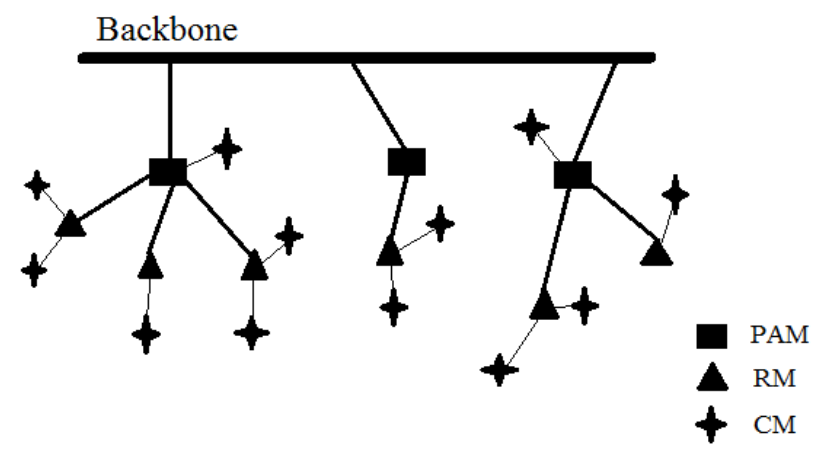

Fonte: Adaptado de Amaldi et al. (2008).

A determinação da localização ótima de cada aparelho PAM ou RM leva em consideração um conjunto de locações possíveis, ou locações candidatas para instalação de tais aparelhos, os quais devem ser dispostos de forma a atender todos os CMs da rede, proporcionando o menor custo possível de instalação.

\section{TIPOS DE MODELOS}

Nesse trabalho, abordam-se o problema de localização de pontos de acesso em uma rede em malha sem fio de acordo as estratégias em Mendes e Mestria (2016). A metodologia utilizada é baseada em análises qualitativa e quantitativa, baseado em dois modelos matemáticos de otimização descritos em Amaldi et al. (2008).

As análises serão realizadas através de dados empíricos com testes e simulação. Serão gerados novos dados (como a distribuição aleatória em uma região quadrada, números de clientes mesh e conjuntos de locações candidatas). Esses dados são diferentes dos encontrados em Amaldi et al. (2008), mas se mantém as mesmas características da rede em malha sem fio daqueles autores. Essas características incluem taxa de transferência de dados, números de PAMs e RMs, dentre outras.

Em Mendes e Mestria (2016), mostra um modelo considera fixa a taxa de transmissão de dados dos aparelhos pertencentes à malha, a despeito das distâncias entre o ponto de transmissão e o ponto de recepção do sinal. A esse modelo será dado nome de Modelo de Transmissão em Taxa Fixa (MTTF). Apesar de ser um modelo de utilização nas WMNs e simples, permite as aproximações matemáticas necessárias para se considerar uma taxa fixa de transmissão.

Pode-se prevê o decaimento da potência do sinal de dados com a distância para o ponto de transmissão. Nesse caso, esse parâmetro aproxima melhor as redes. Outro modelo proposto para a rede em malha sem fio considera os efeitos da interferência na comunicação wireless sobre a estrutura da rede. O modelo foi denominado de Modelo com Sujeição à Interferência (MSI).

Esse último modelo (MSI) é o diferencial nesse trabalho por abordar também as interferências, seja de todos os clientes dentro da área de cobertura de determinado dispositivo de rede, seja pelos efeitos da interferência sobre os enlaces na rede em malha determinando quais links podem estar ativos ao mesmo tempo.

A seguir, são mostrados os dois modelos MTTF e MSI mostrando as variáveis de decisão, as restrições, os parâmetros das redes sem fio como de cobertura e conectividade descritos em Amaldi et al. (2008) e Mendes e Mestria (2016), e a modelagem para os efeitos da interferência nos links no modelo MSI.

\section{1 - Modelo de Transmissão em Taxa Fixa}

Para modelagem e otimização do problema, define-se um conjunto $S$ de locações candidatas (LCs) a receber um aparelho da rede mesh. Este conjunto é dado por $S=\{1, \ldots, m\}$. Além disso, o conjunto $I=\{1, \ldots, n\}$ denota os clientes mesh que serão atendidos pela rede em questão. $\mathrm{O}$ custo de instalação de um PAM ou RM à locação $j$ do conjunto de LCs são $c_{j}$ e $\left(p_{j}+c_{j}\right)$, respectivamente, com $j \in S$. Isso porque $p_{j}$ refere-se ao custo adicional de instalação de um PAM com relação ao RM, devido a alguns fatores, como a conexão por fio ao backbone.

A demanda de dados gerada por cada cliente é denotada por $d_{\mathrm{i}}$, com $i \in I$. A capacidade máxima da interface de acesso de Locação Candidata $j$ (no qual serão denotada por $\mathbf{L} \mathbf{C} \boldsymbol{j}$ daqui em diante), é dada por $\boldsymbol{v}_{\boldsymbol{j}}$ (com $j \in S$ ), ou seja, $v_{j}$ é a capacidade máxima de tráfego de dados entre um aparelho mesh instalado em $\mathbf{L C} \boldsymbol{j}$ e todos os clientes atendidos por ele. A capacidade de tráfego suportada por cada link sem fio entre LC $\boldsymbol{j}$ e LC $\boldsymbol{l}$ é dada por $\boldsymbol{u}_{j l}$, com $j$ e $l \in S$. Em outras palavras, esta é a capacidade máxima de transferência de dados entre duas LCs conectadas. A máxima capacidade de transferência de dados entre um PAM e ao backbone da rede é referida por M.

Além dos parâmetros já apresentados, a modelagem do problema possui ainda parâmetros de cobertura, de conectividade e varáveis de decisão. Estes parâmetros são elucidados a seguir. O parâmetro de cobertura $a_{i j}$ é definido para cada $\operatorname{par} i \in I$ e $j \in S_{\text {como: }}$

$a_{i j}\left\{\begin{array}{l}1 \text { se PAM ou RM em j cobre Cliente Mesh i } \\ 0 \text { caso contrário }\end{array}\right\}$

O parâmetro de conectividade $b_{j l}$ é definido para todo je $l \in S$ como:

$b_{\mathrm{ij}}\left\{\begin{array}{c}1 \text { se LC } j \text { e } l \text { podem ser conectados por link sem fio } \\ 0 \text { caso contrário }\end{array}\right.$

Já as variáveis de decisão incluem: a variável $x_{i j}$ de atribuição do cliente $i \in I$ à $\operatorname{LC} j, \operatorname{com} j \in S$. 
$x_{i j}\left\{\begin{array}{c}1 \text { se cliente mesh i é atribuído à LC } j \\ 0 \text { caso contrário }\end{array}\right.$

A variável $z_{j}$ que indica utilização de $\operatorname{LC} j, \operatorname{com} j \in S$. $z_{i}\left\{\begin{array}{l}1 \text { se PAM ou RM é instalado em } \mathrm{j} \\ 0 \text { caso contrário }\end{array}\right\}$

A variável $w_{j}$ que permite a diferenciação entre PAM e $\mathrm{RM}$ caso haja um aparelho mesh instalado em $j \in S$.

$w_{i j}\left\{\begin{array}{l}1 \text { se PAM é instalado em } \mathrm{j} \\ 0 \text { caso contrário }\end{array}\right\}$

A variável $y_{j l}(j e l \in S)$, referente à conexão sem fio entre duas LCs.

$y_{i j}\left\{\begin{array}{l}1 \text { se PAM ou RM em j cobre cliente i } \\ 0 \text { caso contrário }\end{array}\right\}$

É utilizada ainda a variável $f_{j l}$ para indicação da taxa de transferência de dados nos links sem fio entre duas LCs, link $(l, j)$. Além disso, uma variável específica $f_{j N}$ indica a taxa de transferência de dados nas conexões com fio entre PAM $j$ e o backbone da rede. A partir da determinação desses parâmetros, o problema de otimização da localização dos pontos de acesso à rede em malha sem fio pode ser modelado em função objetivo e restrições. Baseando-se no modelo proposto por Amaldi et al. (2008), a função objetivo e as restrições utilizadas para modelar o MTTF neste trabalho são apresentadas a seguir:

$\min \sum_{j \in S}\left(c_{j} z_{j}+p_{j} w_{j}\right)$

Sujeito a:

$$
\begin{aligned}
& \sum_{j \in S} x_{i j}=1 \quad \forall i \in I, \\
& x_{i j} \leq z_{j} a_{i j} \quad \forall i \in I, \\
& \sum_{i \in I} d_{i j} x_{i j}+\sum_{l \in S}\left(f_{l j}-f_{j l}\right)-f_{j N}=0 \quad \forall j \in S, \\
& f_{l j}+f_{j l} \leq u_{j l} y_{j l} \quad \forall j, l \in S, \\
& \sum_{i \in I} d_{i j} x_{i j} \leq v_{j} \quad \forall j \in S, \\
& f_{j N} \leq M w_{j} \quad \forall j \in S, \\
& y_{j l} \leq z_{j}, y_{i j} \leq z_{l} \quad \forall j, l \in S, \\
& y_{j l} \leq b_{j l} \quad \forall j, l \in S, \\
& x_{i j}, z_{j}, y_{j l}, w_{j} \in\{0,1\} \quad \forall i \in I, \forall j, l \in S
\end{aligned}
$$

A função objetivo (1) busca minimizar o custo total de instalação de todos PAMs e RMs na rede em malha sem fio.

Para isso, são contabilizados os custos $c_{j}$ e $p_{j}$ da seguinte maneira: caso um RM seja instalado em LC $j$, apenas $z_{j}$ possui valor $1\left(w_{j}=0\right)$, logo, contabiliza-se o custo $c_{j}$. Caso um PAM seja instalado em LC $j$, ambos $z_{j}$ e $w_{j}$ serão 1 , agregando-se o valor $\left(c_{j}+p_{j}\right)$ à referida locação.
E caso não haja aparelho instalado em $\mathrm{LC} j$, então $z_{j}=$ $w_{j}=O$ e não há custo referente nessa locação. As restrições (2) garantem a cobertura de todos os clientes pertencentes à rede.

As restrições (3) garantem que um cliente $i$ só seja atribuído à LC $j$ caso um PAM ou RM esteja instalado em LC $j$. Além disso, tal cliente deve estar dentro da área de cobertura do respectivo aparelho instalado. As restrições (4) asseguram a coerência na transmissão de dados para cada LC. Ou seja, denota-se por $f_{l j}$ o fluxo de dados transmitidos para a LC $l$ pela LC $j$ e por $f_{j l}$ o fluxo de dados recebido pela LC $j$ da LC $l$. Logo, essa restrição garante que o fluxo de dados transmitido por uma LC seja equivalente ao fluxo de dados recebido pela mesma (seja este fluxo entre tal LC e um cliente, ou outra LC ou ainda o backbone, no caso de PAMs).

As restrições (5) garantem que o fluxo de dados no link $(l, j)$ não exceda a capacidade máxima desse link. Já as restrições (6) não permitem que a capacidade do link sem fio entre cliente e LC seja excedida. As restrições (7) determinam que, caso não haja um PAM instalado em LC $j$ $\left(w_{j}=0\right)$, então o fluxo de LC $j$ para o backbone deve ser nulo. E esta restrição ainda dita a capacidade de instalação de PAMs na rede. Isso porque o fluxo de dados de um PAM para o backbone é limitado por $\mathrm{M}$, logo, quanto menor o valor de M, mais PAMs serão necessárias para suprir um mesmo sistema.

Um link $(j, l)$ só é permitido entre dois aparelhos mesh caso um PAM ou RM esteja instalado tanto em $j$ quanto em l. Tal condição são asseguradas pelas restrições (8). Já as restrições (9) garantem que o link $(j, l)$ só será possível se houver a possibilidade de conectividade entre LC $j$ e LC $l$. Por fim, as restrições (10) determinam que as variáveis de decisão neste modelo assumam valor binário (zero ou um).

\section{2 - Modelo com Sujeição à Interferência}

Deve-se levar em consideração que a capacidade de um PAM ou RM em atender um cliente, mais especificamente a taxa de transferência de dados a um determinado cliente, está relacionada à distância do cliente mesh ao aparelho em questão. Quanto mais distante, menor a capacidade dessa interface sem fio para atender o cliente.

Figura 2 - Representação das regiões de cobertura de LC j

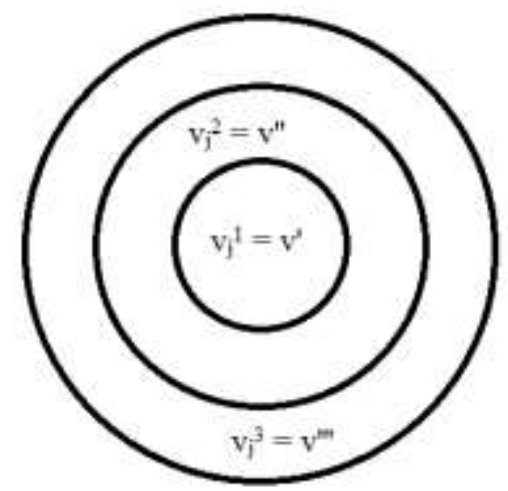

Fonte: Adaptado de Amaldi et al. 2008.

Para implementação do modelo, define-se o conjunto $D_{j}=\{1, \ldots, k\}, \forall j \in S$ de regiões concêntricas a cada LC $j$. E cada uma das $k$ regiões apresentará um valor $\mathrm{v}_{\mathrm{j}}^{\mathrm{k}}$ 
referente à capacidade da interface de acesso para um cliente localizado nesta região. Além disso, o conjunto $I_{j}^{k} \subseteq I, \forall j \in S$ contém todos os clientes que se encontram na região $\mathrm{k}$ de $\mathrm{LC} j$.

A Figura 2 ilustra a existência de diferentes regiões e suas respectivas capacidades máximas de acesso. Determinado o parâmetro dependente de distância $\mathrm{v}_{\mathrm{j}}^{\mathrm{k}}$, as restrições são obtidas a partir das restrições (2) a (10), substituindo-se (6) pela inequação (11), com a introdução de outro modelo. Desta forma, poderá ter um modelo com taxa adaptativa. Esse último modelo não será discutido nesse trabalho devido supor que todos os clientes estarão a uma distância que permitam transmitir os dados a uma taxa fixa.

$$
\sum_{k \in D_{j}} \frac{\sum_{i \in I_{j}^{k}} d_{i} x_{i j}}{v_{j}^{k}} \leq 1 \quad \forall j \in S
$$

Ainda que os efeitos da interferência possam ser minimizados ou até mesmo suprimidos com a utilização de sistemas de rede em malha sem fio com múltiplos canais, onde se utilizam diferentes frequências e diferentes portadoras de sinalização de canal, se faz interessante para uma modelagem mais completa de os sistemas considerarem-se tais efeitos.

Para isso, como proposto em Amaldi et al. (2008), supõe-se que as transmissões entre PAMs ou RMs e CMs ocorrem em um mesmo canal, de modo que apenas é permitida a realização de uma transmissão por vez para cada área de cobertura. Dessa maneira, é possível modelar os efeitos da interferência sobre os pontos de acesso modificando-se a restrição (11) da seguinte maneira:

$$
\sum_{k \in D_{j}} \frac{\sum_{i \in I_{j}^{k}} d_{i}}{v_{j}^{k}} \leq 1+\mathrm{M}_{j}\left(1-z_{j}\right) \quad \forall j \in S
$$

$\mathrm{Na}$ inequação em (12), $M_{j}$ é a menor constante suficientemente grande para garantir que a desigualdade seja verdadeira quando $z_{j}=0$, independente do valor das demais variáveis. Nesta nova restrição, a despeito de (11), todos os clientes dentro da área de cobertura de determinado dispositivo de rede são considerados para se contabilizar os efeitos da interferência, não apenas aqueles designados a determinado dispositivo.

Já os efeitos da interferência sobre os enlaces na rede em malha devem ser contabilizados determinando-se quais links podem estar ativos ao mesmo tempo.

Com base no modelo de protocolo de interferência de Gupta e Kumar (2000), o estudo de Amaldi et al. (2008) determina um conjunto $C_{j l}$ associado a um link $(j, l)$ composto por todos os links que não poderão ser ativos caso $(j, l)$ seja ativo.

No entanto, $C_{j l}$ inclui todo os links $(k, j)$ ou $(k, l)$ que conectam um dispositivo $k$ diretamente a $j$ ou $l$ e ainda todos os links que conectam um dispositivo da rede ao dispositivo $k$.

A Figura 3 exemplifica um conjunto $C_{j l}$ como proposto no estudo citado. Os links marcados em negrito representam os que compõem $C_{j l}$.

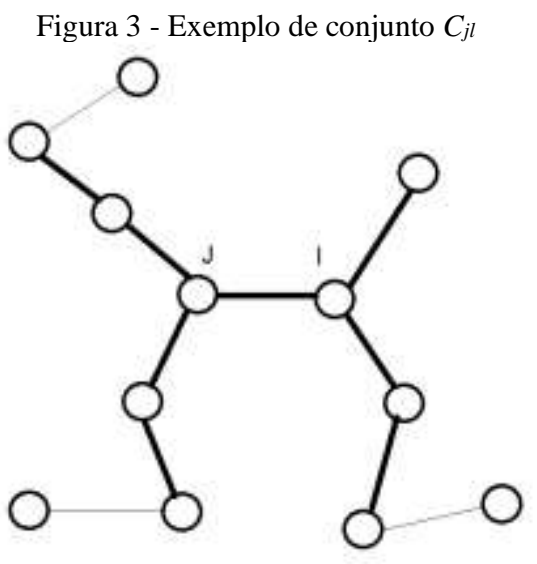

Fonte: Autores, 2021.

A partir desta diagramação do problema é definida a restrição para que se contabilizem os efeitos da interferência nos links da rede em malha sem fio. Esta restrição é apresentada a seguir:

$$
\sum_{(k, h) \in C_{j l}} \frac{f_{k h}}{u_{k h}} \leq 1+\mathrm{M}_{j l}\left(1-y_{j l}\right) \forall j, l \in S
$$

A constante $M_{j l}$ é tal que a desigualdade seja sempre verdadeira quando $y_{j l}=0$. Segundo o estudo base, para uma modelagem mais completa com respeito à análise de interferência, ainda é necessária uma redução de $5 \%$ no valor da capacidade de tráfego entre links $\left(u_{k h}\right)$ com relação ao valor adotado para o MTTF.

Segundo os autores Amaldi et al. (2008), isto garante uma aproximação mais precisa do problema discreto por um modelo contínuo. Portanto, alterando-se (11) por (12) e acrescentando-se (13) é possível obter o Modelo Sujeito à Interferência para as redes em malha sem fio. Para obtenção dos resultados concernentes a tal modelagem, os efeitos da transmissão em taxa adaptativa serão desconsiderados. Sendo assim, o MSI torna-se uma variação direta de MTTF.

\section{RESULTADOS COMPUTACIONAIS}

Para aquisição dos resultados utilizou-se uma máquina de arquitetura 64 bits, processador INTEL ${ }^{\circledR}$ Core $^{\mathrm{TM}}$ i5, de $1,8 \mathrm{GHz}$ e $4 \mathrm{~GB}$ de memória RAM. As instâncias foram geradas a partir da distribuição de clientes e LCs de forma aleatória em uma região quadrada de lado $\mathrm{L}=1000 \mathrm{~m}$.

Para obtenção dos pontos randômicos e diagramação das soluções foi utilizado o software MatLab release 2015a (MATLAB, 2021). Para a solução do problema de otimização foi empregado o solver IBM ILOG CPLEX Optimization Studio (IBM, 2021).

Como ponto de partida para uso de dados reais foi utilizado características das redes sem fio presentes na literatura, mas alguns parâmetros foram definidos de acordo com os utilizados no trabalho de (AMALDI et al., 2008).

Além disso, para formulação das tabelas apresentadas, a seguir, cada dado é calculado a partir de uma média entre 10 instâncias distintas com os mesmos parâmetros, mas com locações candidatas em diferentes pontos físicos gerados na região quadrada.

Nas subseções a seguir, serão apresentados e discutidos os resultados para cada um dos modelos propostos neste trabalho. 


\section{1 - Modelo de Transmissão em Taxa Fixa}

As instâncias do modelo MTTF consistem na distribuição de $n=100$ clientes mesh, com tráfego de dados entre LCs limitado em $u_{f l}=54 \mathrm{bits} / \mathrm{s}$. Este mesmo valor limita o tráfego na interface de acesso de uma LC (parâmetro $v_{\mathrm{jl}}$ ). A distância máxima para que um cliente esteja no raio de cobertura de uma LC é de 100 metros e a distância máxima para que possa haver conexão entre duas LCs é de 250 metros.

Definidos tais parâmetros, sabe-se que as soluções obtidas serão função da relação de custo $\beta=c_{j} /\left(c_{j}+p_{j}\right)$ entre um PAM e um RM; da variável $\mathrm{M}$, que limita a instalação de PAMs; do número $m$ de LCs escolhidas para receber um equipamento mesh e da taxa de demanda $d_{i}$ de cada cliente. Com base nisso, foram gerados diferentes resultados variando-se cada um desses parâmetros, como elucidado a seguir.

Para uma relação de custo fixa $\beta=1 / 10$, a Figura 4 ilustra o efeito do aumento da demanda $d_{i}$ sobre uma rede mesh com $\mathrm{m}=30$ e $\mathrm{M}=128 \mathrm{Mb} / \mathrm{s}$. A Figura 4 (a) refere-se a uma demanda de $600 \mathrm{~Kb} / \mathrm{s}$ e a Figura 4 (b) refere-se à demanda de $3 \mathrm{Mb} / \mathrm{s}$.

$\mathrm{Na}$ ilustração, os retângulos, triângulos e cruzes, representam PAMs, RMs e clientes da rede, respectivamente. As linhas cheias denotam links entre LCs e as linhas pontilhadas representam a interface de acesso dos clientes à rede.

Como esperado, quanto maior a demanda de cada cliente, mais PAMs serão necessárias na rede, caso o acesso ao backbone seja limitado por um $M$ finito. Isso porque o tráfego de dados a partir do backbone deverá ser maior para suprir todos seus usuários.

As Figuras 5 (a) e (b) ilustram a ocorrência das mesmas demandas para o caso de não haver limitação na conexão com o backbone ( $M$ infinito). Nesse caso, menos PAMs serão necessárias para compor a rede, reduzindo seu custo total.

Figura 4 - Solução do MTTF para $\mathrm{M}=128 \mathrm{Mb} / \mathrm{s}$ com demanda (a) $\mathrm{d}=600 \mathrm{~Kb} / \mathrm{s}$ e (b) $\mathrm{d}=3 \mathrm{Mb} / \mathrm{s}$.

(a) $\mathrm{d}=600 \mathrm{~Kb} / \mathrm{s}$.

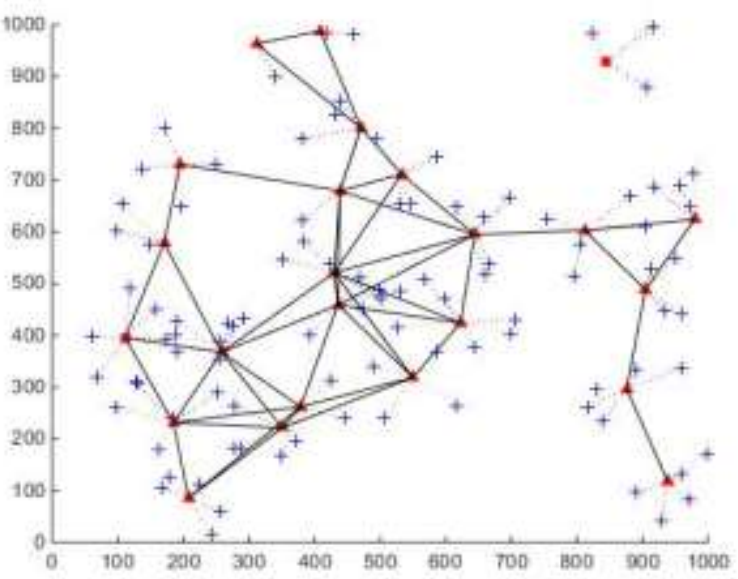

(b) $\mathrm{d}=3 \mathrm{Mb} / \mathrm{s}$.

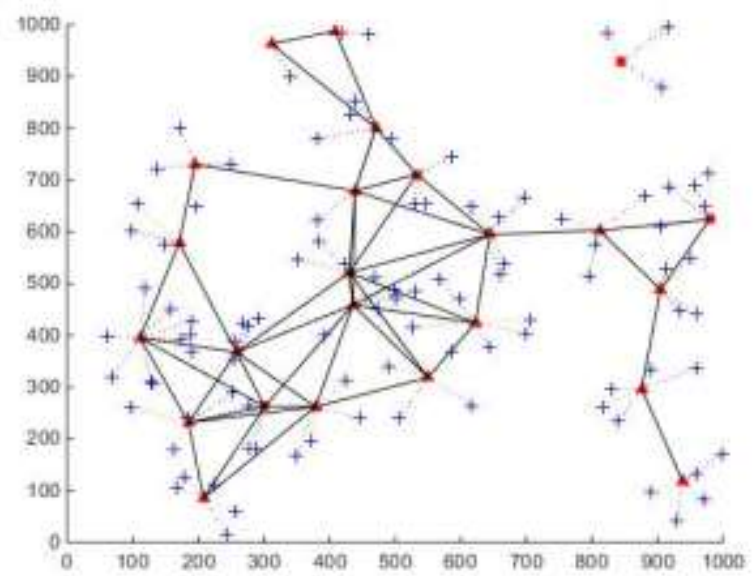

Fonte: Autores, 2021.

Portanto, a instalação de PAMs se torna mais independente da demanda de cada cliente. Ou seja, nota-se que o número de PAMs instalados não se altera significativamente com o aumento de $d_{i}$.

Figura 5 - Solução do MTTF para M ilimitado com demanda (a) d $=600 \mathrm{~Kb} / \mathrm{s} \mathrm{e} \mathrm{(b)} \mathrm{d=} 3 \mathrm{Mb} / \mathrm{s}$

(a) $\mathrm{d}=600 \mathrm{~Kb} / \mathrm{s}$.

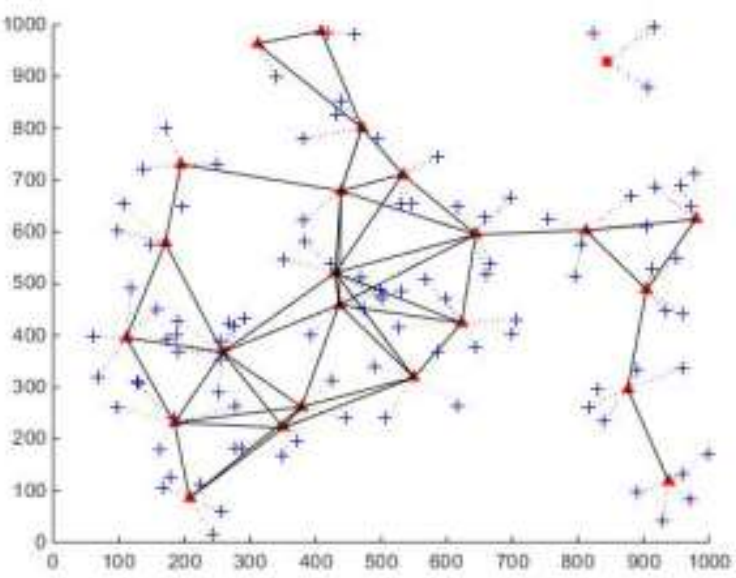

(b) $\mathrm{d}=3 \mathrm{Mb} / \mathrm{s}$.

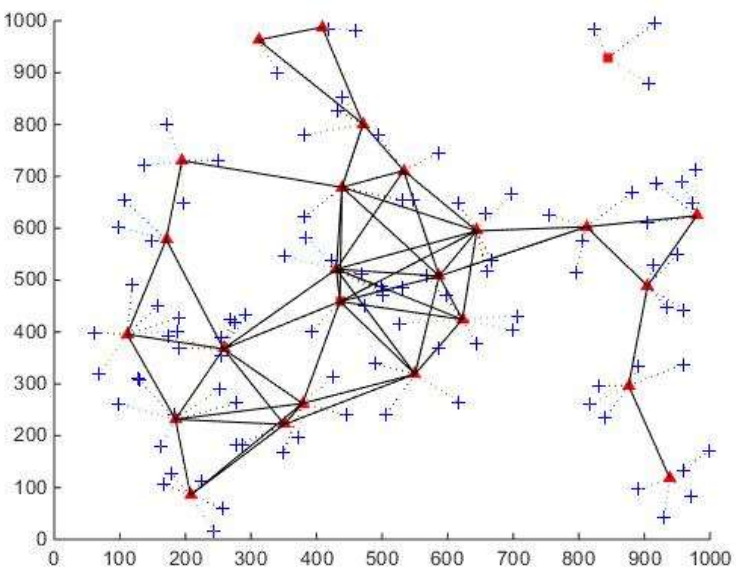

Fonte: Autores, 2021. 
A Tabela 1 apresenta os resultados para diferentes instâncias com $m$ variando entre 30 e 50. Além disso, são analisados os casos onde $d_{i}=600 \mathrm{~Kb} / \mathrm{s}$ e $d_{i}=3 \mathrm{Mb} / \mathrm{s}$. A Tabela 1 confirma os resultados observados na Figura 4. Nota-se um aumento no número de PAMs com o aumento da demanda, elevando também o resultado final da função objetivo. Não são observadas alterações significativas no número de links entre LCs e no tempo de processamento do solver, dado em segundos.

\begin{tabular}{lrrrrr}
\multicolumn{5}{c}{ Tabela 1 - Soluções ótimas do MTTF com M $=128 \mathrm{Mb} / \mathrm{s}$} \\
\hline \multicolumn{7}{c}{ PAM } & RM & Links & \multicolumn{1}{c}{ Tempo } & $\begin{array}{c}\text { Função } \\
\text { (s) }\end{array}$ & Objetivo \\
\hline $\mathrm{d}=600 \mathrm{~Kb} / \mathrm{s}$ & & & & & \\
$\mathrm{m}=30$ & 2,0 & 22,3 & 41,85 & 8,747 & 42,3 \\
$\mathrm{~m}=40$ & 1,7 & 25,6 & 46,85 & 7,960 & 42,6 \\
$\mathrm{~m}=50$ & 1,1 & 28,9 & 54,65 & 10,288 & 39,9 \\
$\mathrm{~d}=3 \mathrm{Mb} / \mathrm{s}$ & & & & & \\
$\mathrm{m}=30$ & 4,0 & 20,3 & 41,55 & 8,556 & 60,3 \\
$\mathrm{~m}=40$ & 3,5 & 23,8 & 47,50 & 7,448 & 58,8 \\
$\mathrm{~m}=50$ & 3,1 & 26,8 & 56,10 & 11,808 & 57,8 \\
\hline
\end{tabular}

A Tabela 2 complementa o exposto na Figura 5. Os mesmos casos analisados na construção da Tabela 1 agora são analisados considerando-se ilimitada a capacidade de conexão de uma PAM com o backbone ( $M$ infinito).

Novamente percebe-se uma menor dependência do número de PAMs instaladas com a demanda de cada cliente mesh. Nota-se, portanto, uma redução considerável dos valores finais da função objetivo para $d_{i}=3 \mathrm{Mb} / \mathrm{s}$ na Tabela 2 com relação à Tabela 1 .

Tabela 2 - Soluções ótimas do MTTF com M ilimitado

\begin{tabular}{lrrrrr}
\hline & PAM & RM & Links & \multicolumn{1}{c}{ Tempo } & $\begin{array}{c}\text { Função } \\
\text { Objetivo }\end{array}$ \\
\hline $\mathrm{d}=600 \mathrm{~Kb} / \mathrm{s}$ & & & & & \\
$\mathrm{m}=30$ & 2,0 & 22,3 & 41,90 & 8,322 & 42,3 \\
$\mathrm{~m}=40$ & 1,7 & 25,6 & 47,35 & 7,091 & 42,6 \\
$\mathrm{~m}=50$ & 1,1 & 28,9 & 55,40 & 9,818 & 39,9 \\
$\mathrm{~d}=3 \mathrm{Mb} / \mathrm{s}$ & & & & & \\
$\mathrm{m}=30$ & 2,6 & 21,7 & 41,80 & 8,320 & 47,7 \\
$\mathrm{~m}=40$ & 2,0 & 25,5 & 49,15 & 7,918 & 45,5 \\
$\mathrm{~m}=50$ & 1,2 & 29,2 & 59,65 & 10,303 & 41,2 \\
\hline
\end{tabular}

Pode-se ainda observar nas Tabelas 1 e 2 que, aumentando-se o número de LCs, a função objetivo é, em geral, reduzida. Isso se dá, pois uma maior quantidade de aparelhos mesh na rede oferece uma cobertura mais eficiente. Desta forma, no sentido de se reduzir o tráfego de dados em cada conexão, fazendo com que haja maior possibilidade de instalação de RMs, a despeito dos PAMs.

A Tabela 3 tem por finalidade observar os efeitos da variação da relação de custo $\beta$ nas redes em malha sem fio. Esses efeitos são observados em dois casos: $M$ ilimitado e $M$ igual a $128 \mathrm{Mb} / \mathrm{s}$.

Espera-se como resultado para a variação de $\beta$ que, para valores de $\beta$ mais próximos da unidade, mais PAMs sejam instaladas, uma vez que o custo de tal instalação terá um impacto menor no valor final da função objetivo. O modelo possui preferência por instalação de PAMs para melhor suprir os clientes da rede. Isso pode ser observado mais claramente na situação de $M$ ilimitado na Tabela 3, onde para $\beta=2 / 3$ ou $\beta=10 / 11$ o número de PAMs instaladas foi cerca de $42,7 \%$ superior que para os casos de $\beta=1 / 10$ ou $\beta=1 / 2$.

Já para os casos em que $\mathrm{M}=128 \mathrm{Mb} / \mathrm{s}$, esse acréscimo na ocorrência de PAMs não foi superior a 6,7\%. Essa diferença se deve ao fato de que em uma rede com capacidade $M$ finita, ainda que o custo de um PAM seja elevado, se faz necessária uma instalação de um número maior de Pontos de Acesso em Malha para garantir o fluxo coerente de dados entre a rede sem fio e o backbone.

Tabela 3 - Soluções ótimas do MTTF $\operatorname{com} \beta$ variável

\begin{tabular}{|c|c|c|c|c|}
\hline \multirow{2}{*}{$\beta$} & \multicolumn{4}{|c|}{ M ilimitado } \\
\hline & PAM & RM & Links & Tempo(s) \\
\hline $1 / 10$ & 1,2 & 29,2 & 59,65 & 10,303 \\
\hline $1 / 2$ & 1,2 & 30,3 & 62,65 & 8,873 \\
\hline $2 / 3$ & 1,7 & 28,1 & 58,25 & 10,384 \\
\hline $10 / 11$ & 1,7 & 28,1 & 57,85 & 10,253 \\
\hline \multirow{2}{*}{$\beta$} & \multicolumn{4}{|c|}{$\mathrm{M}=128 \mathrm{Mb} / \mathrm{s}$} \\
\hline & PAM & RM & Links & Tempo(s) \\
\hline $1 / 10$ & 3,1 & 26,8 & 56,10 & 11,808 \\
\hline $1 / 2$ & 3,0 & 30,3 & 61,75 & 8,963 \\
\hline $2 / 3$ & 3,2 & 26,6 & 55,55 & 10,565 \\
\hline $10 / 11$ & 3,2 & 26,6 & 56,05 & 11,726 \\
\hline
\end{tabular}

Portanto, uma maior paridade entre os custos de RMs e PAMs e uma menor limitação da conexão com o backbone permitem a construção de uma rede com maior número de RMs, menor número de PAMs. Por conseguinte, um maior número de conexões construídas por múltiplos saltos, ponto característico de redes em malha sem fio.

\section{2 - Modelo com Sujeição à Interferência}

Os resultados do modelo MSI são obtidos a partir das mesmas instâncias utilizadas nos modelos anteriores. Mas, como discutido na seção de modelagem, foi adotada uma redução de $5 \%$ no valor da capacidade de tráfego entre links $\left(u_{k h}\right)$ com relação ao valor adotado para o MTTF, de modo a garantir uma aproximação mais precisa do problema discreto por um modelo contínuo.

Além disso, são desconsiderados os efeitos de uma taxa adaptativa $\left(v_{j}^{k}=54 \mathrm{Mb} / \mathrm{s} \forall j, k\right)$ e para obtenção dos resultados aqui apresentados utilizou-se $\mathrm{M}=128 \mathrm{Mb} / \mathrm{s}$ e $\beta=$ $1 / 10$.

Os resultados apresentados na Tabela 4 foram obtidos a partir de uma adaptação das restrições (13), onde o conjunto $C_{j l}$ deixa de ser composto pelos links a um ou dois saltos de distância do link $(j, l)$ e passa a ser composto apenas pelos links diretamente ligados a $(j, l)$.

Esta foi à solução encontrada para que os resultados pudessem ser obtidos em um tempo hábil de processamento, visto que com a definição original de $C_{j l}$ o tempo de processamento do computador utilizado neste estudo se tornava elevado demais.

\begin{tabular}{lccccc}
\multicolumn{6}{c}{ Tabela 4 - Soluções para MSI } \\
\hline & PAM & RM & Links & $\begin{array}{c}\text { Tempo } \\
\text { (s) }\end{array}$ & $\begin{array}{l}\text { Função } \\
\text { Objetivo }\end{array}$ \\
\hline $\mathrm{d}=600 \mathrm{~Kb} / \mathrm{s}$ & & & & & \\
$\mathrm{m}=30$ & 3,2 & 20,30 & 33,10 & 11,672 & 52,3 \\
$\mathrm{~m}=40$ & 2,9 & 25,00 & 22,50 & 20,793 & 54,0 \\
$\mathrm{~m}=50$ & 2,2 & 25,50 & 43,40 & 65,964 & 47,5 \\
$\mathrm{~d}=3 \mathrm{Mb} / \mathrm{s}$ & & & & & \\
$\mathrm{m}=30$ & 8,2 & 15,10 & 34,40 & 20,205 & 97,1 \\
$\mathrm{~m}=40$ & 7,7 & 20,60 & 25,70 & 55,008 & 97,6 \\
$\mathrm{~m}=50$ & 7,1 & 21,22 & 48,11 & 340,882 & 92,2 \\
\hline
\end{tabular}




\section{DISCUSSÃO}

Os resultados da Tabela 4 podem ser comparados diretamente com os da Tabela 1 por apresentarem instâncias e parâmetros equivalentes. Nota-se um aumento no número de PAMs instalados e uma redução no número de links. Isso se deve à redução da capacidade de fluxo entre os links, fazendo com que as soluções com um menor número de links. E ainda, um maior número de dispositivos está diretamente conectado ao backbone, como era de se esperar em uma configuração sujeita às interferências, dado a necessidade de ter uma qualidade melhor nos sinais wireless.

Além disso, nota-se um aumento do valor da função objetivo, o que está diretamente relacionado ao aumento do número de PAMs. E ainda, há significante aumento no tempo de processamento, relacionado à maior complexidade das restrições adicionadas ao problema.

Os resultados obtidos nesse trabalho vão de encontro aos resultados apresentados na literatura em Amaldi et al. (2008) e com o trabalho de Abdulwahid et al. (2020) que reduziram os números de dispositivos. Com isso, se reduz os custos de implantação e os efeitos de interferências. Desta forma, conclui-se que os dados adotados para simulação são condizentes.

Apesar do trabalho de Araújo e Mestria (2017) resolver o problema de planejamento de redes em malha sem fio, com o modelo das $p$-medianas, pode-se verificar que esse último modelo não incorpora as interferências.

No entanto, nesse trabalho, um estudo de engenharia mais aprofundado se faz necessário para a determinação dos valores práticos de $y_{j l}$ (que refere à conexão sem fio entre duas locações candidatas). Devem-se levar em consideração diversos casos específicos de aplicações reais. Além disso, nesse trabalho não foi considerado modelos em que os clientes poderão estar em distâncias nos quais as transmissões dos dados ocorrem em taxas adaptativas.

\section{CONCLUSÃO}

Neste trabalho foram abordadas as modelagens e as soluções com dois modelos de localização de pontos de acesso em rede em malha sem fio. O primeiro é denominado de Modelo de Transmissão em Taxa Fixa que considera que os clientes estejam dentro do raio de cobertura de um dos pontos de acesso da rede.

Nesse caso, a transferência de dados ocorre numa velocidade fixa, independente da distância entre clientes e dispositivos de rede. O segundo de nome Modelo com Sujeição a Interferência, considera nas transmissões os efeitos de interferência que podem acontecer nas redes em malha sem fio.

Conclui-se por meio dos resultados desse trabalho e comparados com o da literatura que os modelos propostos são eficazes devido: permitir reduzir número de dispositivos, diminuir custos de implantação e reduzir os efeitos de interferências. Nesse sentido, os dados adotados para simulação são condizentes com dados encontrados no mundo real.

Por meio desses modelos, esse estudo propôs a análise qualitativa e quantitativa dos efeitos sobre a distribuição dos pontos de acesso em rede em malha sem fio ocasionado por: (1) mudança na demanda de dados dos clientes; (2) variação das capacidades de comunicação dos dispositivos da rede com os clientes e com o backbone de serviço. Também foi considerada a variação entre a relação de custo de dispositivos RM e PAM, além de analisar os efeitos de interferência na rede.

Ainda que para determinadas aplicações os modelos MTTF e MSI apresentados sejam suficientes, eles não representam fielmente a realidade das redes em malha sem fio. Estudos que levem em consideração redes mais complexas, como as que apresentam múltiplos canais, por exemplo, possibilita uma maior fidedignidade dos resultados às aplicações práticas.

Outra limitação do trabalho deve-se ao fato que foram utilizados em um dos casos, nos enlaces do PAMs a rede com fio o valor de $\mathrm{M}=128 \mathrm{Mbps}$ e sabe-se que existem conexões para rápida da ordem de $300 \mathrm{Mbps}$ ou mais. Entretanto, isso não invalida a metodologia adotada para alocar os pontos de acesso sem fio a PAM ou a RM, nesse caso específico.

Além disso, outras abordagens de solução, como as heurísticas usando Relaxação Lagrangeana, metaheurísticas e métodos híbridos de otimização podem ser aplicadas aos modelos descritos nesse trabalho.

Desta forma, soluções alcançadas por outras técnicas podem ser comparadas aos resultados apresentados nesse trabalho, assim como, análises de eficiência podem ser realizadas.

\section{REFERÊNCIAS}

ABDULWAHID, M. M.; AL-HAKEEM, M. S.; MOSLEH, M. F.; ABD-ALHMEED, R. A. Investigation and optimization method for wireless AP deployment based indoor network. IOP Conference Series: Materials Science and Engineering, vol. 745, p. 012031, 2020.

AKYILDIZ, I. F.; WANG, X.; WANG, W. Wireless mesh networks: a survey. Computer Networks, vol. 47, n. 4, p. 445-487, 2005.

AMALDI, E.; CAPONE, A.; CESANE, M.; FILIPPINI, I.; MALUCELLI, F. Optimization models and methods for planning wireless mesh networks. Computer Networks, vol. 52, n. 11, p. 2159-2171, 2008.

ARAÚJO, M. L.; MESTRIA, M. Método GRASP para Planejamento de Redes em Malha Sem Fio. Revista Sodebras [on line]. v. 12, n.144, Dez./2017, p. 171-176. ISSN 1809-3957. Disponível em: <http://www.sodebras.com.br/edicoes/N1

44.pdf>. Acesso em 07 mai. 2021.

CURRENT, J.; DASKIN, M.; D. SCHILLING. Discrete Network Location Models. In Drezner, Z.; Hamacher, H. (Ed.). Facility Location Theory: Applications and Methods, capítulo 3. Springer-Verlag, Berlin, p. 81-118, 2002.

FARAHANI, R. Z.; HEKMATFAR, M. Facilities location: Concepts, models, algorithms and case studies, Contributions to Management Science, Physica-Verlag, Heidelberg, 549 pp, 2009.

GUPTA P.; KUMAR, P. R. The capacity of wireless networks. IEEE Trans. Inform. Theory, vol. 46, n. 2, p. 388-404, 2000.

IBM. CPLEX. ILOG CPLEX Optimization Studio Product Documentation, 2021.

IEEE 802. IEEE 802 LAN/MAN Standards Committee, 
1999. Disponível em: http://grouper.ieee.org/groups/802/. Acesso: 04 abril 2016.

ISI. The Network Simulator - ns-2. Disponível em: http://www.isi.edu/nsnam/ns/. Acesso: 07 mai 2021.

LAUAR, S. N.; OLIVEIRA, T. R.; MESTRIA, M. Problema de Alocação de Agregador de Dados em Redes Elétricas Inteligentes. Revista Sodebras [on line]. v. 15, n.179, Nov./2020, p. 981-104. ISSN 1809-3957. Disponível em: <http://www.sodebras.com.br/edicoes/N179.pdf>. Acesso em 07 mai. 2021.

LWIN, K. S; FUNABIKI, N.; TANIGUCHI, C.; ZAW, K. K.; MAMUN, M. S. A; KURIBAYASHI, M.; KAO, W-C. A Minimax Approach for Access Point Setup Optimization in IEEE 802.11n Wireless Networks. International Journal of Networking and Computing, vol. 7, n.2, p. 187-207, 2017.

MATLAB. MATLAB (release 2015a). MathWorks, Inc. Massachussetts, United States. Acesso 07 mai 2021.

MENDES, L. B.; MESTRIA, M. Localização de Pontos de Acesso numa Rede em Malha Sem Fio: Modelos e Otimização. In: Simpósio Brasileiro de Pesquisa Operacional (SBPO), 2016, Vitória - ES. Anais do Simpósio Brasileiro de Pesquisa Operacional. Rio de Janeiro: SOBRAPO, p. 2266-2277, 2016.

REN, J.; HOU, T.; WANG, H.; REN, H.; ZHANG, X. Increasing network throughput based on dynamic caching policy at wireless access points. Wireless Networks (10220038), vol. 26, n. 3, p. 1577-1585, 2020.

SANGUINO, T. J. M.; BETANCOURT, J. C. M. Optimal Modeling of Wireless LANs: A Decision-Making Multiobjective Approach. Complexity, vol. 2018, Article ID 7560717, 15 pages, 2018.

SANTOS, T. A.; VIANNA, D. S.; SILVA, R. M. Proposta de Heurísticas GRASP para o Problema de Alocação de Pontos de Acesso em uma Rede em Malha sem Fio. VII Congresso Nacional de Excelência em Gestão, Niterói e Rio de Janeiro, ISSN 1984-9354, 13pp, 2011.

SILVA, M.; SENNE, E. L. F.; VIJAYKUMAR, N. L. Planejamento de redes mesh com aplicação do modelo hipercubo para verificação de parâmetros de QoS. XLII Simpósio Brasileiro de Pesquisa Operacional, Bento Gonçalves, RS, 12pp, 2010.

TANG, L.; WANG, Z; HUANG, J.; BIAN, L. A general purpose deployment method for wireless mesh network. International Journal of Internet Protocol Technology (IJIPT), vol. 12, n. 1, 2019.

WANG, X.; LIM, A. O. IEEE 802.11s wireless mesh networks: Framework and challenges. Ad Hoc Networks, vol. 6, n. 6, p. 970-984, 2008.

\section{COPYRIGHT}

Direitos autorais: Os autores são os únicos responsáveis pelo material incluído no artigo. 


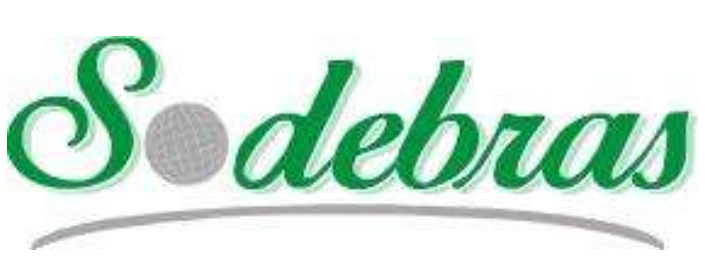

Revista SODEBRAS - Volume 16

$\mathrm{N}^{\circ} 187-\mathrm{JULHO} / 2021$

\title{
INFLUENCIA DO RAIO DE PONTA NO DESGASTE DA FERRAMENTA DE CORTE E NA CORRENTE ELÉTRICA CONSUMIDA NO TORNEAMENTO DO AÇO ABNT 1045
}

\author{
INFLUENCE OF TOOL NOSE RADIUS ON THE TOOL WEAR AND ELECTRIC \\ CURRENT CONSUMED DURING TURNING OF THE ABNT STEEL 1045
}

\author{
ANDRÉ LUÍS PEDROZA DE OLIVEIRA ${ }^{1}$; MARCOS GUILHERME CARVALHO BRAULIO BARBOSA ${ }^{1}$; \\ LÍVIO BRUNO NERY DA SILVA VIANA ${ }^{2}$; PATRICK ABREU DE OLIVEIRA ${ }^{1}$; \\ LÍVIA FERNANDA NERY DA SILVA ${ }^{1}$ \\ 1 - UNIVERSIDADE FEDERAL DO PIAUÍ; 2 - UNIVERSIDADE FEDERAL DO CEARÁ \\ andre.pedroza@yahoo.com.br,marcosguilherme@ufpi.edu.br,livio.bruno@alu.ufc.br,patrick@ufpi.edu.br, \\ livianery02@gmail.com
}

\begin{abstract}
Resumo - Uma das formas de prolongar a vida útil de uma ferramenta de corte é a utilização da geometria adequada. Nesse contexto o raio de ponta é um fator que exerce influência tanto no acabamento superficial da peça, quanto na vida útil da ferramenta de corte. $O$ objetivo deste estudo foi investigar a influência do raio de ponta no desgaste de ferramentas de aço rápido e na corrente elétrica consumida pelo motor da máquina-ferramenta. Para tanto, ferramentas de torneamento foram afiadas com raios de ponta de 1 $\mathrm{mm}, 2 \mathrm{~mm}, 3 \mathrm{~mm}$ e $4 \mathrm{~mm}$ e o desgaste de flanco máximo foi medido através de imagens de microscopia óptica e a corrente elétrica consumida foi medida através de sensores de efeito Hall conectados aos cabos de alimentação do motor da máquina. Os resultados mostraram que maiores valores de raio de ponta foram eficientes na redução do desgaste das ferramentas de corte. A mediçãa de corrente elétrica, por sua vez, não foi capaz, de indicar a influência do raio de ponta na potência requerida pela máquina para a realização do corte de material.
\end{abstract}

Palavras-chave: Desgaste. Corrente Elétrica. Ferramenta de Corte.

Abstract - A way to extend the life of a cutting tool is to use the appropriate geometry. In this context, the nose radius is a factor that influences both the surface finish of the work piece and the life of the cutting tool. The aim of this study was to investigate the influence of the nose radius on the wear of high-speed steel tools and the electric current consumed by the machine tool's motor. For this purpose, turning tools were sharpened with $1 \mathrm{~mm}, 2 \mathrm{~mm}, 3 \mathrm{~mm}$ and

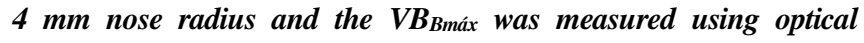
microscopy images and the electrical current consumed was measured using Hall effect sensors connected to the machine's engine power cables. The results showed that higher nose radius values were efficient in reducing the wear of the cutting tools. The measurement of electric current, in turn, was not able to indicate the influence of the nose radius on the power required by the machine to perform the material cut.

Keywords: Wear. Electric Current. Cutting Tool.

\section{INTRODUÇÃO}

A disputa no mercado demanda produtos com melhores acabamentos e cada vez mais acessíveis, que atendam às necessidades dos consumidores. De acordo com TRENT; WRIGHT (2000), a usinagem é o processo mais utilizado na indústria metal mecânica, com custos superiores a $15 \%$ do valor de todos os produtos manufaturados em todos os países industrializados. MEDEIROS; EICH; MACHADO (2015) mostraram que aperfeiçoando parâmetros para usinagem pode-se alcançar uma melhora significativa de produtividade e uma grande economia de tempo e custos para uma indústria que busca otimizar seu processo de fabricação. A indústria de manufatura deseja a melhora da qualidade dos produtos finalizados ao mesmo tempo que se busca um menor gasto com a ferramenta de corte.

RODRIGUES (2005) cita que o estudo da ferramenta de corte é relevante quando se deseja o aumento da vida útil desse material. Sabe-se que a geometria da ferramenta é bastante complexa e pequenas alterações angulares e dimensionais provocam diferentes resultados na peça em contato com a aresta da ferramenta de corte. Vários elementos que compõem a ferramenta de corte podem sofrer alterações para melhorar o desempenho do processo, são eles: ângulo de saída, raio de ponta, ângulo de folga, ângulo de posição, ângulo de inclinação, chanfro da aresta de corte e raio da aresta de corte.

Conforme MACHADO; SILVA (2004), o raio de ponta influencia no acabamento superficial das peças e na resistência da aresta de corte da própria ferramenta, grandes valores para o raio de ponta podem aumentar a vibração da ferramenta no processo de usinagem, afetando o acabamento superficial da peça.

Poucos artigos se aprofundam no estudo sobre raio de ponta, CHOU; SONG (2004) investigaram o efeito do raio de ponta $(0,8 \mathrm{~mm}, 1,6 \mathrm{~mm}, 2,4 \mathrm{~mm})$ em ferramentas cerâmicas no torneamento do aço AISI 52100. Os resultados mostraram que os valores de raio de ponta utilizados não apresentaram efeito de redução do desgaste da ferramenta de corte e geraram uma tendência de maior potência requerida para o corte, sendo efetivos somente para um melhor acabamento da superfície usinada.

GÜRGEN; TALI; KUSHAN (2019) estudaram a influência de diversos fatores na usinagem da liga de níquel 718. Neste caso, foram empregados raios de ponta de $0,4 \mathrm{~mm}$, $0,8 \mathrm{~mm}$ e 1,2 mm. Em relação ao desgaste, os autores se apoiaram nos argumentos de CHOU; SONG (2004) para 
afirmar que maiores valores de raio de ponta não proporcionaram menor desgaste para a ferramenta de corte.

BHUSHAN (2020) estudou a influência do raio de ponta em ferramentas de metal duro na usinagem do compósito AA7075/SiC. Os valores de raio de ponta utilizados foram $0,4 \mathrm{~mm}, 0,8 \mathrm{~mm}$ e $1,2 \mathrm{~mm}$. Em termos de desgaste da ferramenta de corte, segundo o autor, o valor que se mostrou mais apropriado foi $0,4 \mathrm{~mm}$, que proporcionou maior vida útil à ferramenta de corte. Neste caso, uma possibilidade de explicação para a menor vida útil das ferramentas com maior raio de ponta seja a maior vibração gerada durante o corte com estas, que causa um desgaste mais severo (MACHADO et al., 2015).

O objetivo deste trabalho é estudar a relação entre o raio de ponta e o comportamento de ferramentas de aço rápido em relação ao desgaste, além de avaliar a corrente elétrica consumida durante a realização do experimento. Para tanto, o desgaste de flanco máximo ( $\mathrm{VB}_{\mathrm{Bmáx}}$ ) foi medido através de imagens da superfície de folga das ferramentas de corte obtidas através de microscopia óptica e a corrente elétrica foi medida nos cabos de alimentação principal da máquina ferramenta utilizada através de sensores não invasivos de efeito Hall.

\section{METODOLOGIA}

O material utilizado para o torneamento foi o aço ABNT 1045, peças com $40 \mathrm{~mm}$ de diâmetro e $120 \mathrm{~mm}$ de comprimento foram preparadas, conforme a Figura 1.

Figura 1 - Dimensões das peças de trabalho de aço ABNT 1045 utilizadas na execução dos experimentos

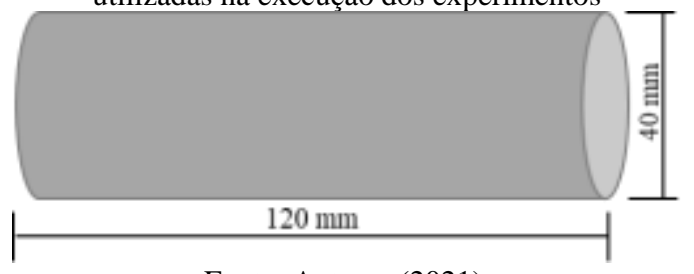

Fonte: Autores (2021).

A composição do aço ABNT 1045, de acordo com a NBR 87:2000, é mostrada na Tabela 1.

Tabela 1 - Composição química do aço ABNT 1045

\begin{tabular}{c|c|c|c|c}
\hline $\begin{array}{c}\text { Classificação } \\
\text { ABNT/SAE/AISI }\end{array}$ & C \% & Mn \% & $\begin{array}{c}\text { P \% } \\
\text { máx }\end{array}$ & $\begin{array}{c}\text { S \% } \\
\text { máx }\end{array}$ \\
\hline 1045 & $\begin{array}{c}0,43- \\
0,50\end{array}$ & $\begin{array}{c}0,60- \\
0,90\end{array}$ & 0,040 & 0,050 \\
\hline \multicolumn{5}{c}{ Fonte: ABNT (2000). }
\end{tabular}

A caracterização do aço ABNT 1045 foi realizada no laboratório de metalografia e ensaios mecânicos da Universidade Federal do Piauí. Para evidenciar a microestrutura do aço foi necessária a eliminação de riscos e marcas profundas, logo, utilizou-se o processo de lixamento. Foram utilizadas lixas de granulação 220, 400, 600 e 1200, rotacionando a amostra em $90^{\circ}$ ao trocar de lixa para que haja a descontaminação da amostra com a lixa usada anteriormente. Foi necessário um embutimento da amostra para facilitar o manuseio durante o lixamento.

Aplicou-se uma pasta de diamante na granulometria de $1 \mu \mathrm{m}$, a fim de obter um acabamento superficial mais fino da amostra, para facilitar sua análise microscópica. A micrografia obtida pode ser vista na Figura 2, onde podem ser destacadas a ferrita e a perlita na microestrutura da amostra de aço ABNT 1045.
Figura 2 - Microestrutura do aço ABNT 1045 utilizado na execução dos experimentos

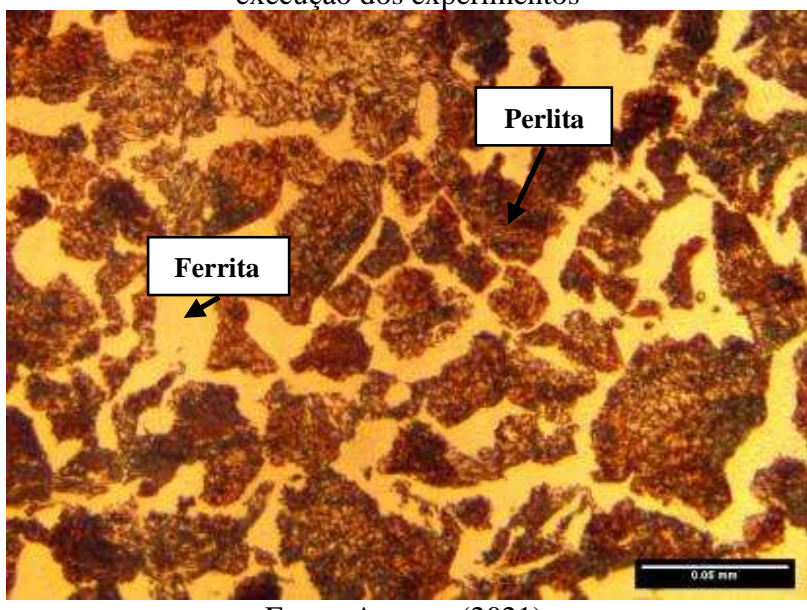

Fonte: Autores (2021).

As ferramentas de corte utilizadas neste trabalho foram bits de aço rápido (4 $3 / 8$ de polegadas) com a seguinte afiação: $\gamma_{\mathrm{o}}=0 ; \chi_{\mathrm{r}}=75^{\circ} ; \chi^{\prime}{ }_{\mathrm{r}}=15^{\circ}$ e $\alpha_{\mathrm{o}}=8^{\circ}$.

As ferramentas foram preparadas com quatro diferentes valores de raio de ponta, a saber: $1 \mathrm{~mm}, 2 \mathrm{~mm}$, $3 \mathrm{~mm}$ e $4 \mathrm{~mm}$. Com o calibrador de raio, desejou-se alcançar os valores teorizados para os experimentos. A Figura 3 apresenta as ferramentas utilizadas. A Tabela 2 apresentas os valores desejados e os valores medidos com o auxílio de um projetor de perfil.

Figura 3 - Ferramentas de aço rápido utilizadas na execução dos experimentos

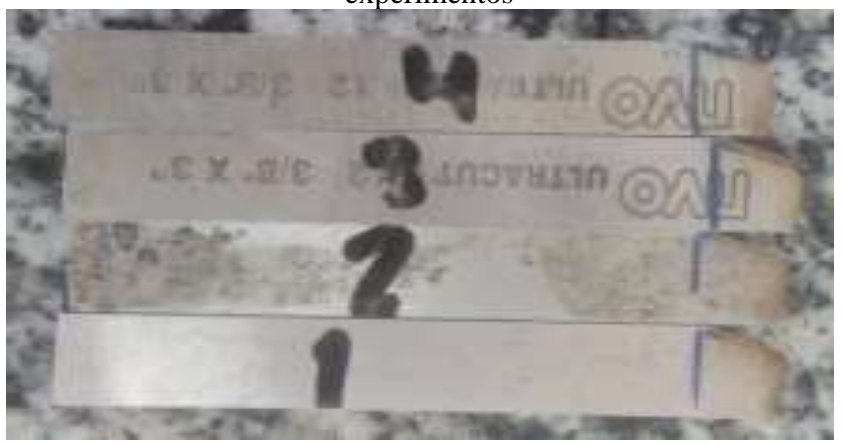

Fonte: Autores (2021).

Tabela 2 - Valores de raio de ponta desejados e medidos

\begin{tabular}{c|c|c}
\hline & $\mathbf{r}_{\varepsilon}$ desejado $(\mathbf{m m})$ & $\begin{array}{c}\mathbf{r}_{\varepsilon} \text { medido } \\
(\mathbf{m m})\end{array}$ \\
\hline Ferramenta 1 & 1 & 1,2990 \\
Ferramenta 2 & 2 & 2,6820 \\
Ferramenta 3 & 3 & 3,5810 \\
Ferramenta 4 & 4 & 3,9505 \\
\hline
\end{tabular}

Fonte: Autores (2021).

Os ensaios foram realizados no torno mecânico horizontal de modelo TVK-1660ECO, rotação máxima de $1800 \mathrm{rpm}$, fabricado pela empresa Veker S.A. Os parâmetros determinados para os ensaios foram: Avanço (f) $0,1772 \mathrm{~mm} /$ volta, rotação $(\mathrm{n}) 255 \mathrm{rpm}$, profundidade de corte $\left(a_{p}\right)$ de $0,25 \mathrm{~mm}$ e velocidade de corte $\left(v_{c}\right)=30$ $\mathrm{m} / \mathrm{min}$. O comprimento de corte de $300 \mathrm{~mm}$ foi adotado como critério de parada dos experimentos.

As micrografias da superfície de folga das ferramentas de corte foram realizadas com o auxílio de uma câmera Moticam 2500 acoplada em um microscópio fabricado pela empresa Alltion, de modelo SZM-45B2. Posteriormente, o 
desgaste de flanco máximo foi medido com o auxílio do software livre Image J, como mostra a Figura 4.

Figura 4 - Ferramenta de pré-teste com desgaste de flanco máximo medido

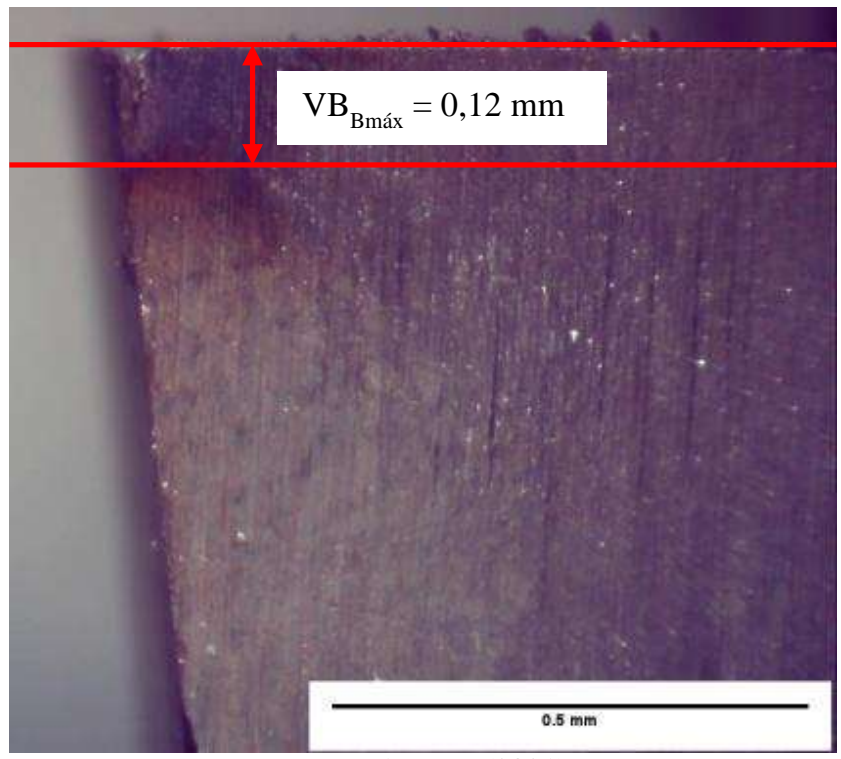

Fonte: Autores (2021).

Para a coleta de dados de corrente elétrica utilizou-se componentes e sensores conectados a uma placa de Arduíno ATmega 2560. Um sensor de efeito Hall modelo SCT-013000 foi adicionado para colher valores de corrente elétrica RMS, com resistores para divisão de tensão de $10 \mathrm{k} \Omega$, resistor de carga de $33 \Omega$ e capacitor de filtro de $10 \mathrm{nF}$. A Figura 5 (a) apresenta o esquema do circuito de aquisição de sinais de corrente elétrica e a Figura 5 (b) a placa montada para coleta de dados.

Figura 5 - a) Esquema do circuito de aquisição de sinais de corrente elétrica; b) Circuito montado

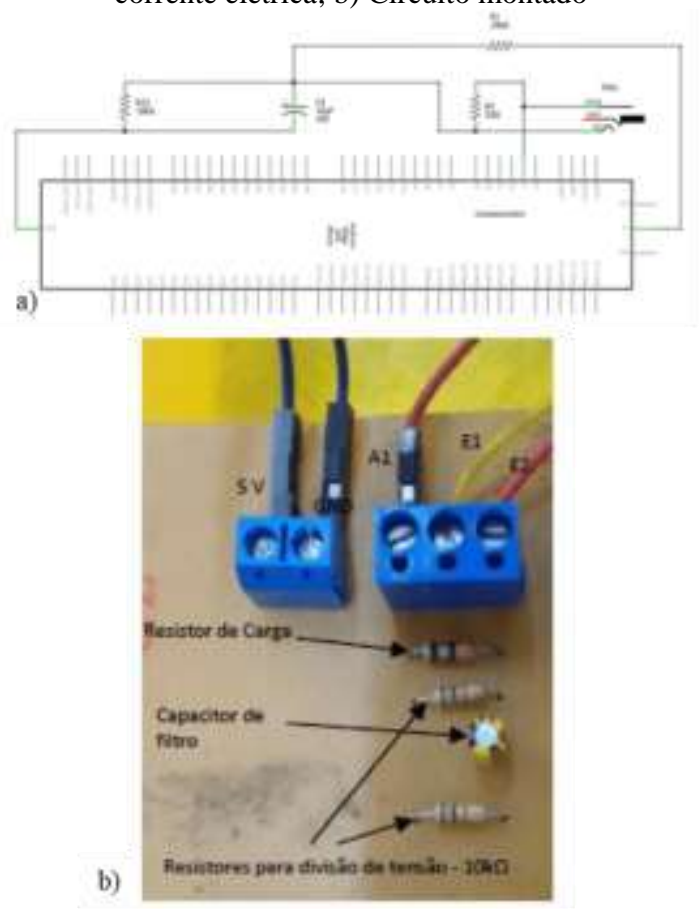

Fonte: adaptado de PAIVA; BARBOSA (2018).
A Figura 6 apresenta a montagem dos sensores de efeito Hall nos cabos de alimentação do motor da máquinaferramenta.

Figura 6 - Montagem dos sensores de efeito Hall nos cabos de alimentação da máquina-ferramenta

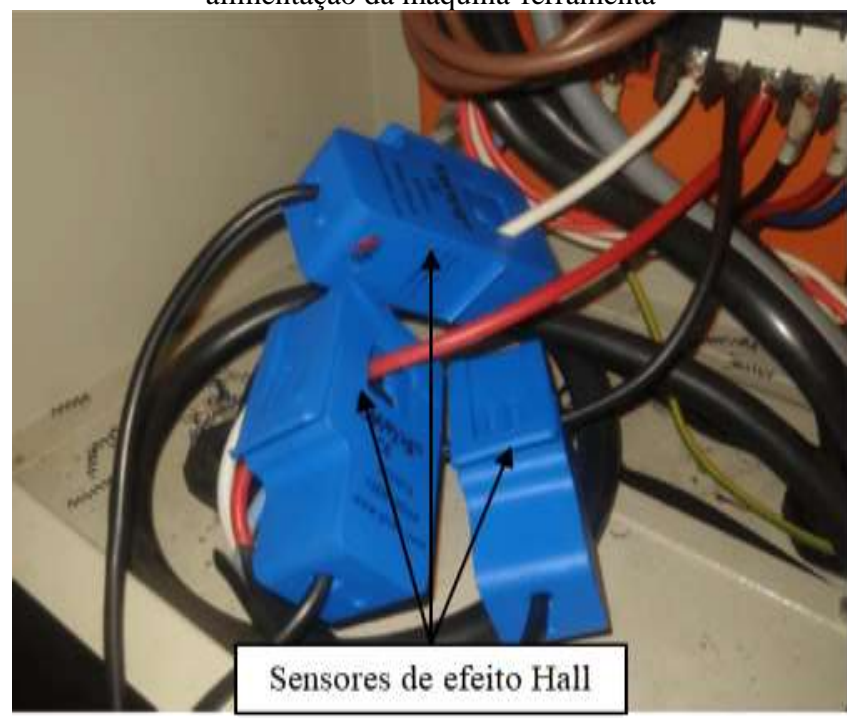

Fonte: Autores (2021).

O sistema utilizado para a aquisição dos valores de corrente elétrica possui taxa de aquisição de sinais de $1 \mathrm{~Hz}$.

\section{RESULTADOS}

\section{1 - Desgaste}

A Figura 7 apresenta as curvas de evolução do desgaste de flanco máximo das ferramentas de corte de aço rápido. Uma primeira constatação que pode ser feita é em relação ao comportamento das mesmas. Para todas as condições de corte, nos primeiros $50 \mathrm{~mm}$ percorridos houve um desgaste que pode ser dito "acentuado", seguindo, após esse momento, de uma estabilização do desgaste, principalmente quando se observam as ferramentas com raio de ponta de $3 \mathrm{~mm}$ e $4 \mathrm{~mm}$, onde este comportamento de estabilização do desgaste se manteve até o fim do experimento. No caso da ferramenta com raio de ponta de 2 $\mathrm{mm}$, o período de estabilização do desgaste foi menos perceptível, no entanto existente. E para a ferramenta com raio de ponta de $1 \mathrm{~mm}$, o comportamento de estabilização do desgaste se manteve do comprimento de $50 \mathrm{~mm}$ até 200 $\mathrm{mm}$, e foi seguido de uma tendência de aumento do desgaste até a finalização do experimento. $\mathrm{O}$ fato é que observandose as curvas presentes na Figura 7, é possível constatar aquilo que é descrito na literatura por MACHADO et al. (2015), em que a vida da ferramenta de corte é dividida em três estágios, o primeiro correspondendo a um desgaste inicial acentuado, o segundo referente a uma fase de estabilização do desgaste, onde a ferramenta de corte estaria adaptada aos mecanismos de desgaste atuantes, e um terceiro estágio onde o desgaste volta a evoluir acentuadamente. Neste caso, apenas a ferramenta de corte com raio de ponta igual a $1 \mathrm{~mm}$ apresentou curva de evolução do desgaste em que os três estágios são claros. As ferramentas com raio de ponta de $3 \mathrm{~mm}$ e $4 \mathrm{~mm}$ apresentaram apenas os dois primeiros estágios descritos. Este comportamento sugere que estas ferramentas, de fato, pelo maior raio de ponta empregado, terão maior vida útil 
em relação às ferramentas de corte com menor raio de ponta.

Figura 7 - Curvas de evolução do desgaste

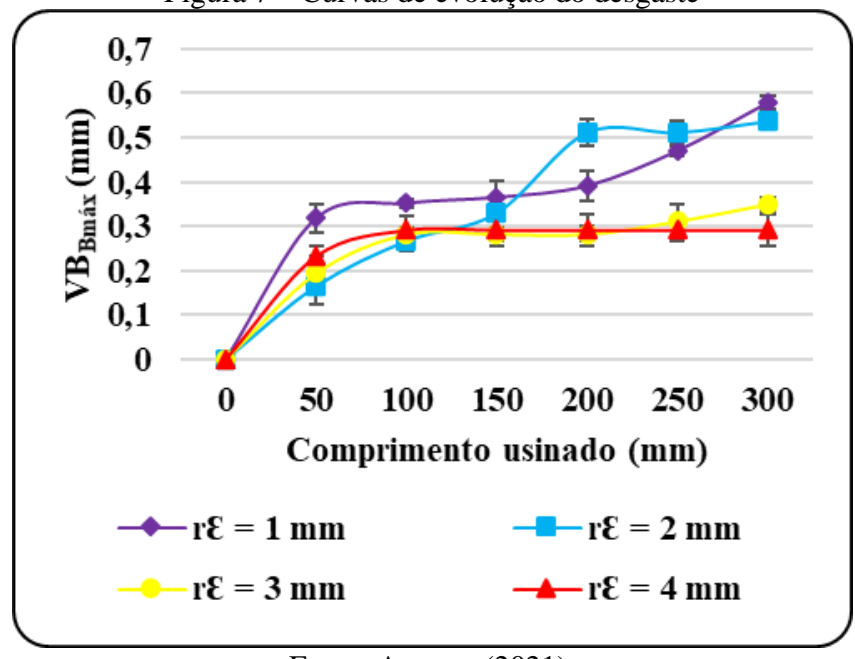

Fonte: Autores (2021).

A Figura 8 apresenta o desgaste de folga máximo ao final do experimento. Analisando os dados é possível perceber que as ferramentas com raio de ponta de $3 \mathrm{~mm}$ e 4 mm foram mais resistentes ao desgaste até a conclusão do experimento, sugerindo que para estas condições de corte e para este tipo de material de ferramenta de corte (aço rápido) o raio de ponta tem efeitos que colaboram com a diminuição do desgaste de flanco.

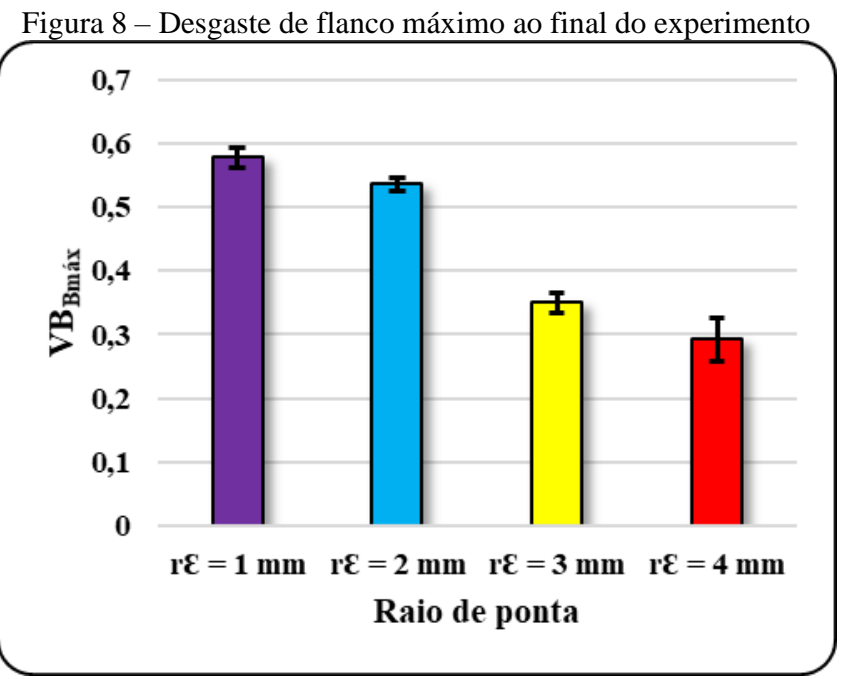

Fonte: Autores (2021).

A Figura 9 apresenta as micrografias das superfícies de folga das ferramentas de corte de aço rápido para todas as condições de corte testadas. Nas imagens é possível observar a presença de material aderido às superfícies da ferramenta. Esse comportamento sugere a presença da aresta postiça de corte, que, segundo FERRARESI (1986), é um fator fundamental para a potencialização do desgaste de flanco da ferramenta de corte. Segundo o autor, uma porção de material do cavaco gerado se deposita na superfície de saída, aumentando em volume com o decorrer do corte de material, mudando a geometria da ferramenta e consequentemente a dinâmica do processo como um todo. A aresta postiça de corte é um evento cíclico, e dependendo das condições de corte adotadas pode ter maior ou menor influência no desgaste. O fato é que este evento é inerente do material usinado (FERRARESI, 1970), e não pode ser completamente extinto para materiais dúcteis, como é o caso do material utilizado neste estudo. Portanto, é razoável afirmar que a aderência de material foi a principal responsável pelo desgaste das ferramentas. É preciso compreender que a natureza cíclica da formação da aresta postiça de corte faz com que o material depositado na superfície de saída, em determinado momento, seja arrancado da mesma, e em consequência partículas duras atritam com a superfície de folga causando a potencialização do desgaste.

Figura 9 - Micrografias da superfície de folga das ferramentas de corte durante o experimento: a) ferramenta com $\mathrm{r}_{\varepsilon}=1 \mathrm{~mm}$; $\mathrm{b}$ ) ferramenta com $r_{\varepsilon}=2 \mathrm{~mm}$; c) ferramenta com $r_{\varepsilon}=3 \mathrm{~mm}$; d)
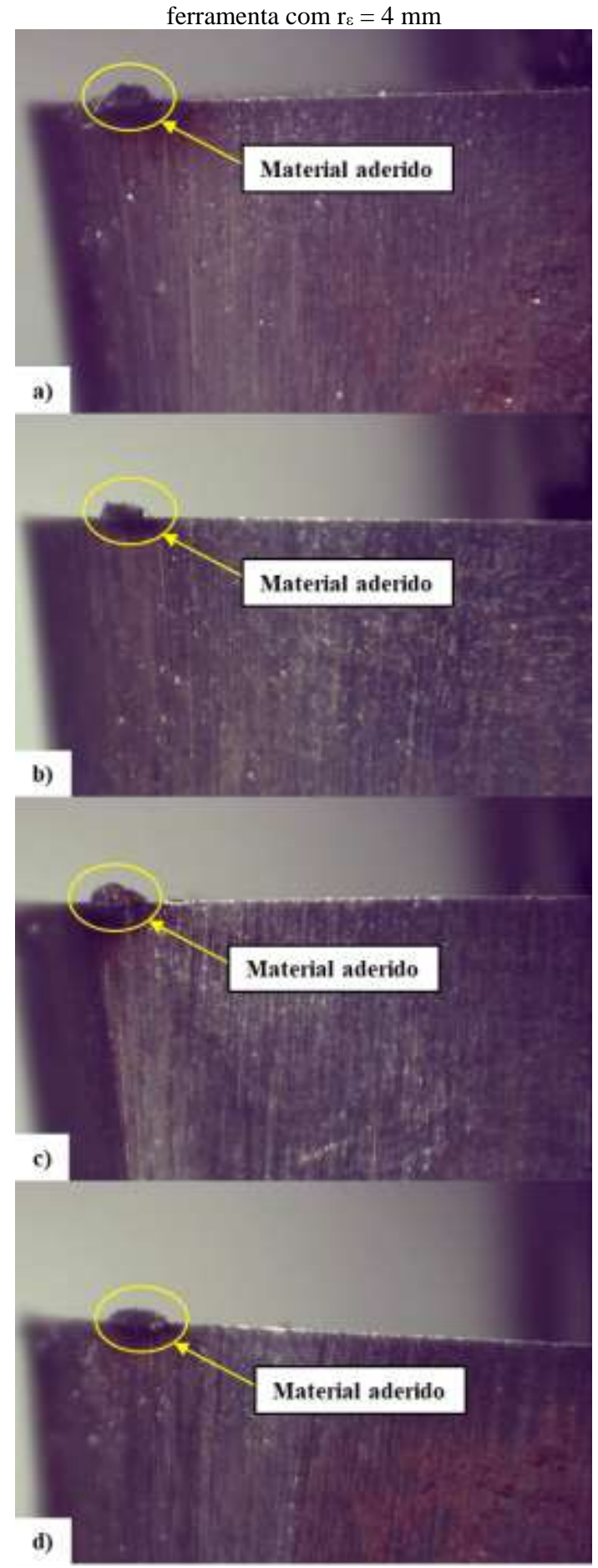

Fonte: Autores (2021). 


\section{2 - Corrente elétrica consumida pela máquina ferramenta}

A corrente elétrica consumida pela máquinaferramenta durante a realização do processo de torneamento foi medida através de sensores de efeito Hall conectados aos cabos de alimentação do torno mecânico utilizado.

A Figura 10 apresenta o sinal de corrente elétrica adquirido durante o percurso percorrido de $50 \mathrm{~mm}$. Analisando o sinal é possível identificar um pico de corrente elétrica referente ao acionamento da rotação do eixo árvore do torno. Em seguida o sinal se estabiliza em valores menores referentes a fase de remoção de material. Após isto, o sinal retorna a zero, obviamente pelo desligamento da máquina após a finalização do ensaio.

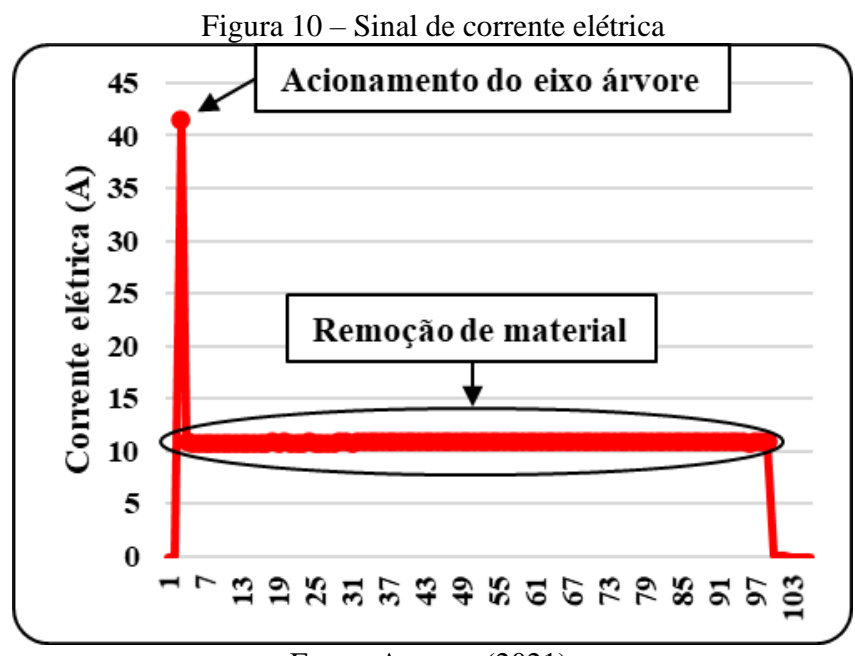

Fonte: Autores (2021).

A Figura 12 mostra as curvas de corrente elétrica para os valores medidos durante o período de remoção de material, os valores que constam em cada ponto do gráfico são referentes à média aritmética dos valores medidos nas três fases do motor onde os sensores foram conectados.

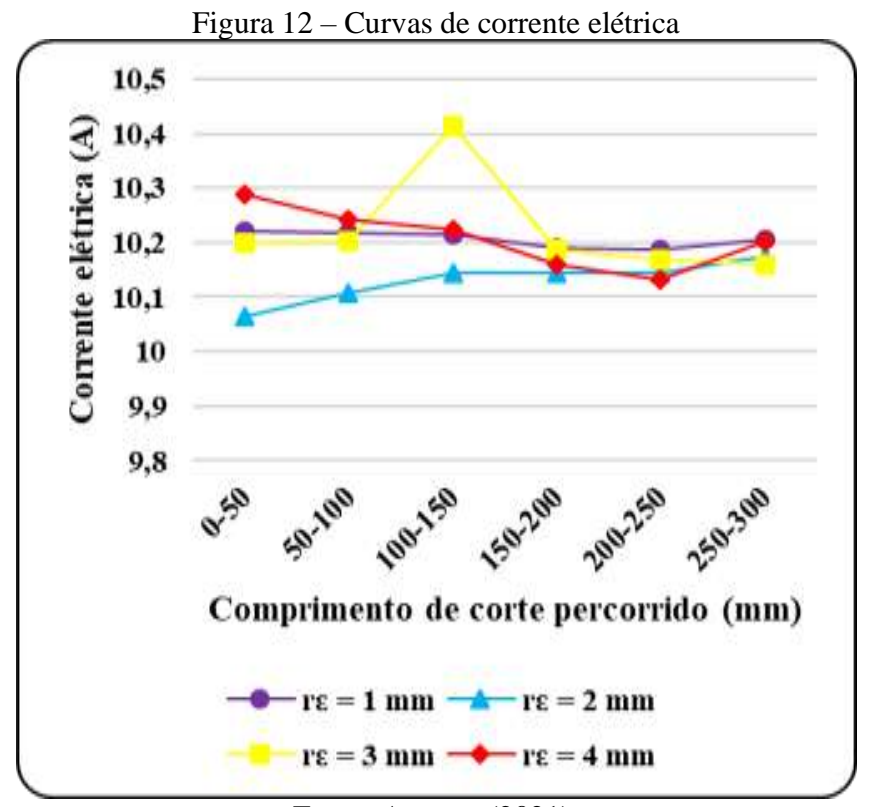

Fonte: Autores (2021).

Analisando as curvas não é possível afirmar que o desgaste progressivo das ferramentas de corte tenha exercido influência nos valores de corrente elétrica, nem no sentido de aumentá-los, nem no sentido de diminuí-los. Um valor que destoa dos demais pode ser observado para a usinagem com a ferramenta com raio de ponta de $3 \mathrm{~mm}$, no percurso percorrido de $100 \mathrm{~mm}$ a $150 \mathrm{~mm}$. Esse comportamento pode estar ligado a diversos fatores, entre eles alguma descontinuidade no material usinado, que exigiu mais energia para a realização do corte ou possivelmente uma sobrecarga momentânea da rede elétrica de alimentação da máquina.

A Figura 13 mostra a média de todos os valores de corrente elétrica medidos durante a remoção de material para cada condição de corte estudada. Analisando os dados, não é possível afirmar que o raio de ponta tenha sido fator de influência na corrente elétrica consumida e consequentemente na potência requerida para o corte de material, uma vez que os valores apresentados no gráfico não apresentam diferença significativa. Um dado importante a ser levantado em relação a isto é que a máquina ferramenta utilizada para a realização dos ensaios utiliza uma caixa de transmissão de potência com várias engrenagens, que movimenta o eixo árvore e os carros de avanço, ao contrário de máquinas $\mathrm{CNC}$, que possuem um servo motor para transmissão de movimento para cada eixo.

Figura 13 - Valores médios de corrente elétrica consumida durante o corte de material

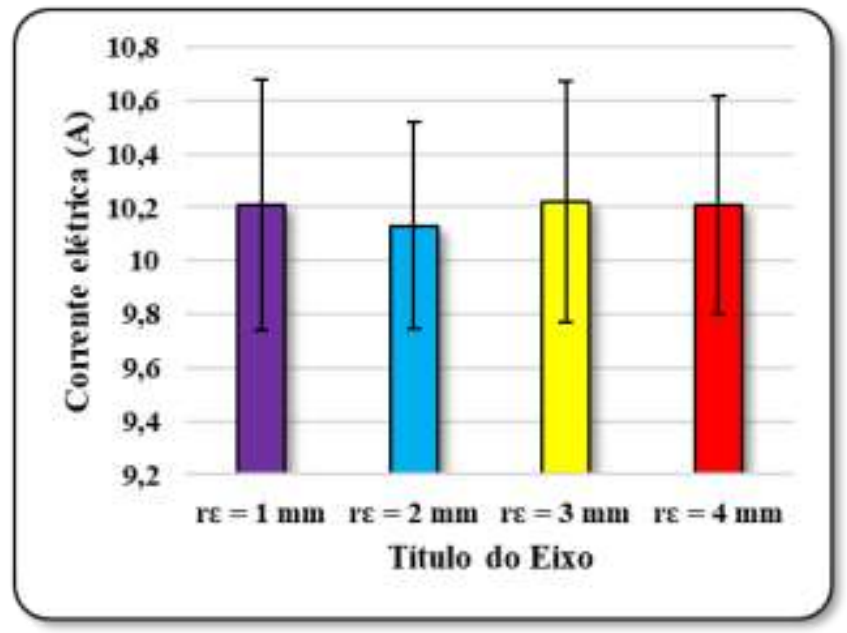

Fonte: Autores (2021).

\section{CONCLUSÃO}

A partir da apresentação e discussão dos resultados foi possível concluir que:

$>$ A evolução do desgaste das ferramentas de corte se deu conforme descrito pela literatura, que divide a vida da ferramenta em três fases;

> As ferramentas com maior raio de ponta ( $3 \mathrm{~mm} \mathrm{e} 4$ $\mathrm{mm})$ tiveram menor desgaste de flanco em relação às ferramentas com menor raio de ponta $(1 \mathrm{~mm}$ e 2 $\mathrm{mm})$, indicando que a utilização de maiores valores de raio de ponta em ferramentas de aço rápido tende a auxiliar no aumento de sua vida útil;

$>$ A adesão de material nas superfícies foi a principal causadora do desgaste, sugerindo a presença de aresta postiça de corte durante todos os ensaios realizados;

> As curvas de corrente elétrica não indicaram relação direta entre o desgaste da ferramenta de corte e um possível aumento ou diminuição dos valores de corrente elétrica medidos; 
Os valores de corrente elétrica medidos não indicaram a influência do raio de ponta nesse parâmetro.

\section{REFERÊNCIAS}

ABNT. NBR NM 87:2000: Aço carbono e ligados para construção mecânica - Designação e composição química. Rio de Janeiro, 2000.

BHUSHAN, Rajesh Kumar. Impact of nose radius and machining parameters on surface roughness, tool wear and tool life during turning of $\mathrm{AA} 7075 / \mathrm{SiC}$ composites for green manufacturing. Mechanics of Advanced Materials and Modern Processes, [s. 1.], v. 6, n. 1, p. 1-18, 2020.

CHOU, Y. Kevin; SONG, Hui. Tool nose radius effects on finish hard turning. Journal of Materials Processing Technology, [s. 1.], v. 148, n. 2, p. 259-268, 2004.

FERRARESI, Dino. Fundamentos da Usinagem dos Metais. $1^{\mathrm{a}}$ ed. São Paulo.

FERRARESI, Dino. Usinagem dos Metais. São Paulo: Associação Brasileira de Metais, 1986.

GÜRGEN, Selim; TALI, Dinçer; KUSHAN, Melih Cemal. An investigation on surface roughness and tool wear in turning operation of inconel 718. Journal of Aerospace Technology and Management, [s. 1.], v. 11, p. 1-10, 2019.

MACHADO, Álisson Rocha et al. Teoria da Usinagem dos Materiais. $3^{\text {a }}$ ed. São Paulo: Blucher, 2015.

MACHADO, Álisson Rocha; SILVA, Márcio Bacci. Usinagem dos metais. $8^{\mathrm{a}}$ ed. Uberlândia.

MEDEIROS, Eurllys Morais de; EICH, Guilherme Alexandre; MACHADO, Luis Carlos. OTIMIZAÇÃO DO PROCESSO DE USINAGEM PARA A CONFECÇÃO DE UM PRODUTO AUTOMOTIVO. XXXIII International Sodebras Congress, Volume 10, $\mathrm{n}^{\circ}$ 116, Salvador, 2015.

PAIVA, Raphael Lima De; BARBOSA, Marcos Guilherme Carvalho Braulio. ANÁLISE DA MEDIÇÃO DE POTÊNCIA ELÉTRICA DA MÁQUINA-FERRAMENTA NO PROCESSO DE FURAÇÃO. XXII Colóquio de Usinagem, Uberaba, p. 5, 2018.

RODRIGUES, Alessandro Roger. Estudo da geometria de arestas de corte aplicadas em usinagem com altas velocidades de corte. 2005. Universidade de São Paulo, [s. 1.], 2005. Disponível em: <http://www.teses.usp.br/teses/disponiveis/18/18135/tde03072005-134755/>

TRENT, Edward; WRIGHT, Paul. Metal Cutting. 4. ed. Oxford: Butterworth Heinemann, 2000.

\section{COPYRIGHT}

Direitos autorais: Os autores são os únicos responsáveis pelo material incluído no artigo. 